\title{
Effects of new learning environments: taking students' perceptions, approaches to learning and assessment into account : studies in problem-based learning
}

Citation for published version (APA):

Gijbels, D. (2005). Effects of new learning environments: taking students' perceptions, approaches to learning and assessment into account : studies in problem-based learning. [Doctoral Thesis, Maastricht University]. Datawyse / Universitaire Pers Maastricht. https://doi.org/10.26481/dis.20050407dg

Document status and date:

Published: 01/01/2005

DOI:

$10.26481 /$ dis.20050407dg

Document Version:

Publisher's PDF, also known as Version of record

Please check the document version of this publication:

- A submitted manuscript is the version of the article upon submission and before peer-review. There can be important differences between the submitted version and the official published version of record.

People interested in the research are advised to contact the author for the final version of the publication, or visit the DOI to the publisher's website.

- The final author version and the galley proof are versions of the publication after peer review.

- The final published version features the final layout of the paper including the volume, issue and page numbers.

Link to publication

\footnotetext{
General rights rights.

- You may freely distribute the URL identifying the publication in the public portal. please follow below link for the End User Agreement:

www.umlib.nl/taverne-license

Take down policy

If you believe that this document breaches copyright please contact us at:

repository@maastrichtuniversity.nl

providing details and we will investigate your claim.
}

Copyright and moral rights for the publications made accessible in the public portal are retained by the authors and/or other copyright owners and it is a condition of accessing publications that users recognise and abide by the legal requirements associated with these

- Users may download and print one copy of any publication from the public portal for the purpose of private study or research.

- You may not further distribute the material or use it for any profit-making activity or commercial gain

If the publication is distributed under the terms of Article $25 \mathrm{fa}$ of the Dutch Copyright Act, indicated by the "Taverne" license above, 


\title{
Effects of new learning environments: Taking students' perceptions, approaches to learning and assessment into account.
}

Studies in problem-based learning.

\author{
PROEFSCHRIFT
}

ter verkrijging van de graad van doctor aan de Universiteit Maastricht, op gezag van de Rector Magnificus,

Prof. mr. G.P.M.F. Mols

volgens het besluit van het College van Decanen, in het openbaar te verdedigen

op donderdag 7 april 2005 om 14.00 uur

door

David Gijbels

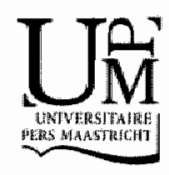


Promotor:

Prof. dr. F. Dochy

Beoordelingscommissie:

Prof. dr. P. Van den Bossche (voorzitter)

Prof. dr. W. Gijselaers

Prof. dir. B. Van Hout-Wolters (Universiteit van Amsterdam)

Prof. dr. S. Janssens (Katholleke Universiteit Leuven)

Dr, G. Span

ISBN 9052784477

(C) Gijbels, Maastricht 2005

Druk: Datawyse/Universitaire Pers Maastricht 


\section{Content}

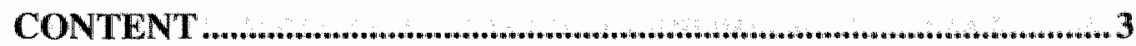

ACKNOWLEDGEMENTS ......................................................... 6

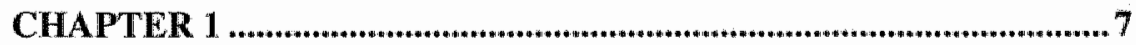

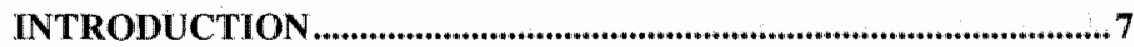

STRUCTURE OF THE DISSERTATION AND RESEARCH QUESTIONS ............. 9

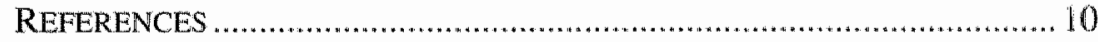

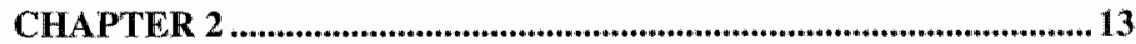

PROBLEM-BASED LEARNING AND CONSTRUCTIVISM: THE STUDENTS' PERSPECTIVE .............................................................13

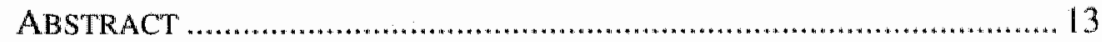

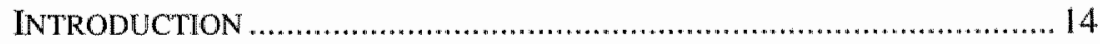

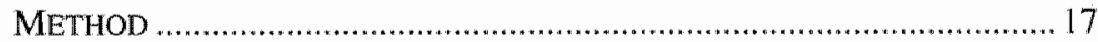

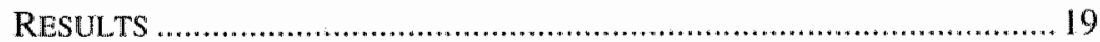

CONCLUSION AND DISCUSSION ................................................. 20

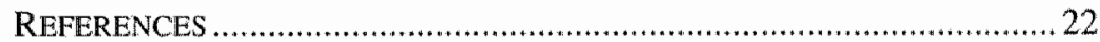

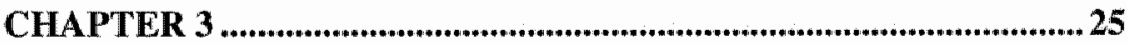

'THE RELATIONSHIP BETWEEN STUDENTS' APPROACHES TO

LEARNING AND THE ASSESSMENT OF LEARNING

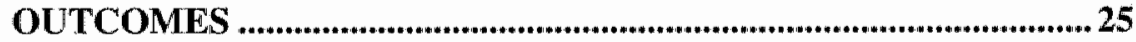

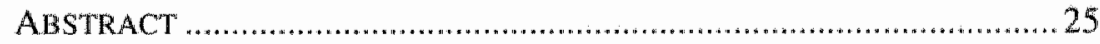

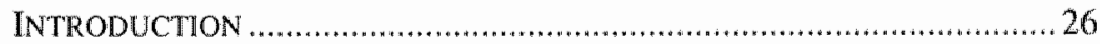

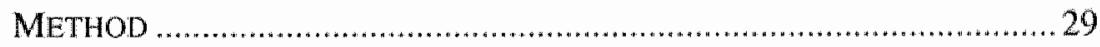

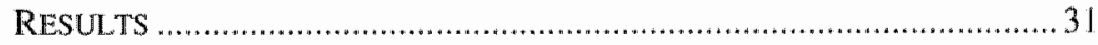

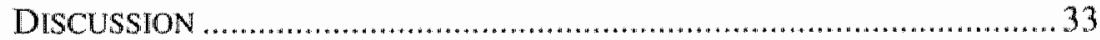

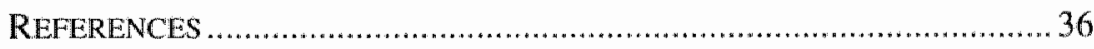

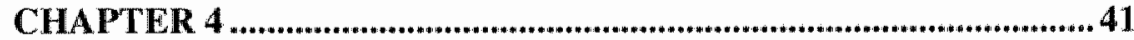

EFFECTS OF PROBLEM-BASED LEARNING: A META-

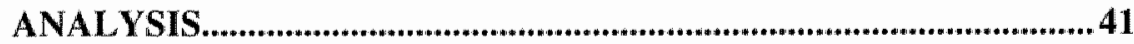

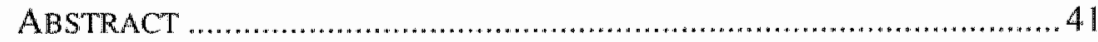

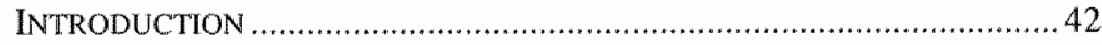

PROBLEM-BASED LEARNING VERSUS CONVENTIONAL LECTURE-BASED

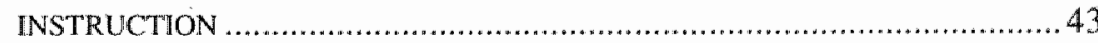

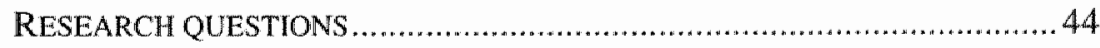




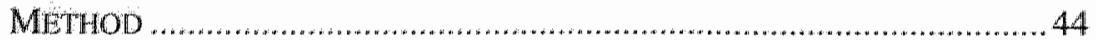

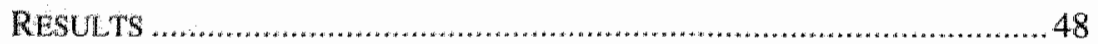

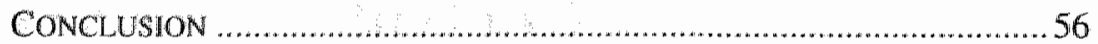

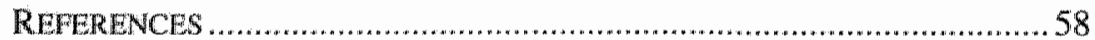

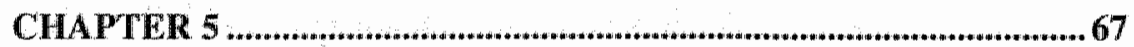

EFFECTS OF PROBLEM-BASED LEARNING: A METAANALYSIS FROM THE ANGLE OF ASSESSMENT .........................67

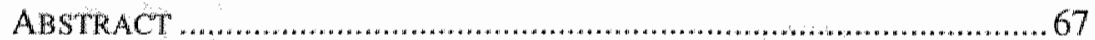

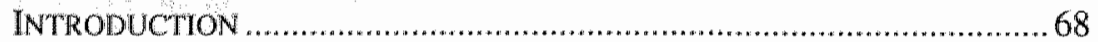

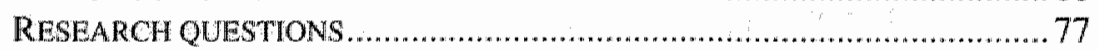

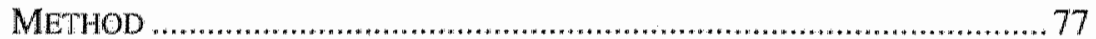

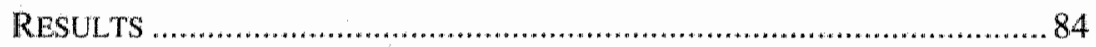

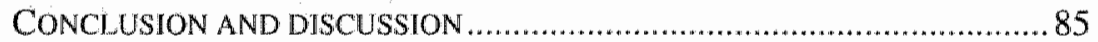

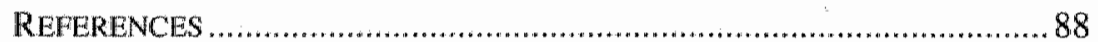

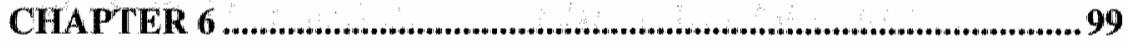

EFFECTS OF PROBLEM-BASED LEARNING: A QUASIEXPERIMENTAL STUDY WITHIN A SINGLE COURSE................99

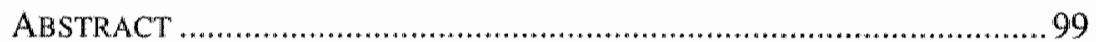

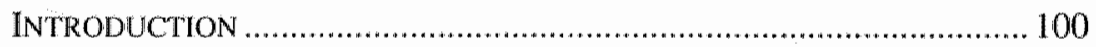

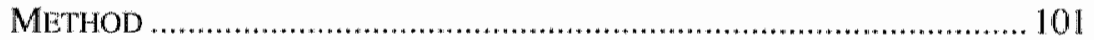

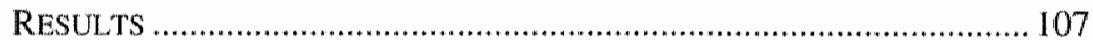

CONCLUSIONS AND DISCUSSION …….............................................. 109

CRITICAL REFLECTION AND SUGGESTIONS FOR FURTHER RESEARCH ... 111

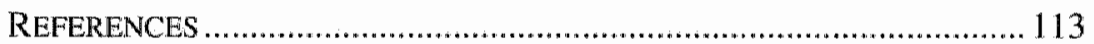

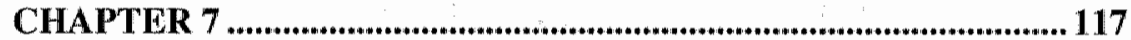

IMPROVING THE EFFECTS OF PROBLEM-BASED LEARNING: INTEGRATING ASSESSMENT-TASKS IN THE LEARNING ENVIRONMENT .........................................................................117

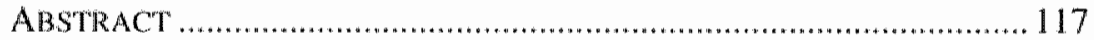

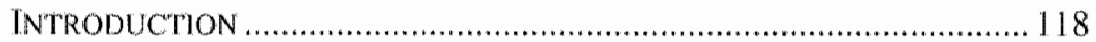

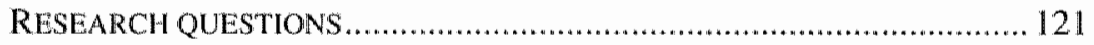

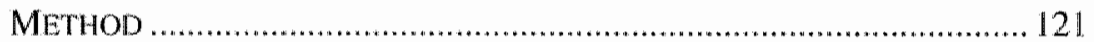

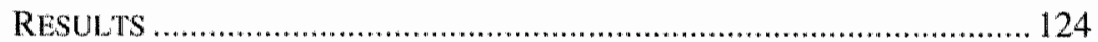

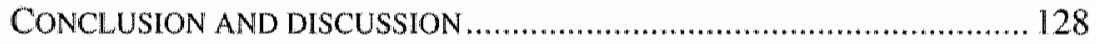

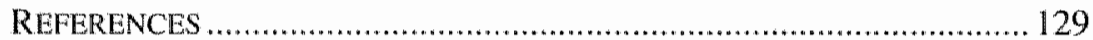

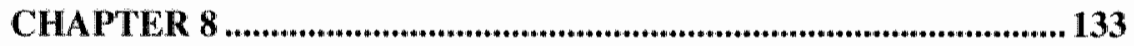

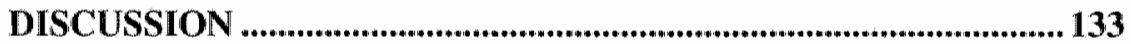

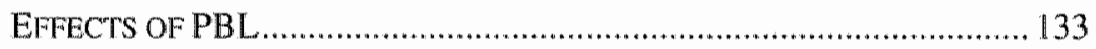

THE ROLE OF STUDENTS" PERCEPTIONS AND APPROACHES TO

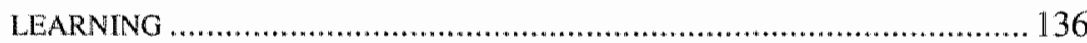


IMPROVING THE EFFECTS OF PBL. THE ROLE OF ASSESSMENT 138

SUGGESTIONS FOR FURTHER RESEARCH .................................... 138

PRACTICAL IMPLICATIONS .......................................................... 139

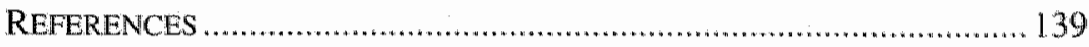

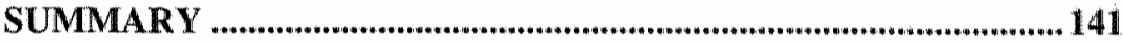

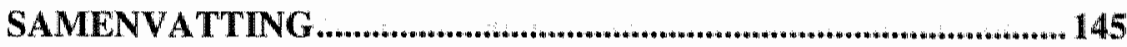

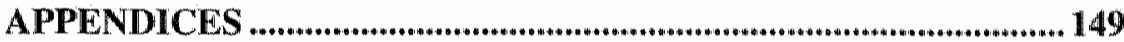

APPENDIX A: STUDIES MEASURING KNOWLEDGE .............................. 149

APPENDIX B: STUDIES MEASURING SKILLS..................................... 152

APPENDIX C: LEGEND FOR THE TABLES OF APPENDIX A AND B ......... 154

APPENDIX D: STUDIES MEASURING THE KNOWLEDGE STRUCTURE...... 155

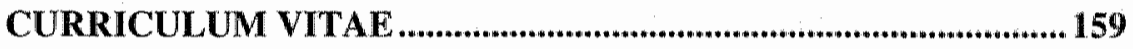

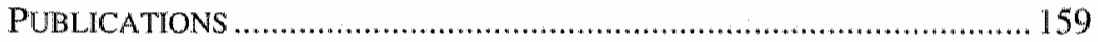




\section{Acknowledgements}

This dissertation is not entirely my work. In the first place I want to express iny warm thanks to my supervisor Filip Dochy for introducing me into the interesting international world of research on learning and instruction. His optimistic approach and his qualities as a researcher and as a connoisseur have made the writing of this dissertation a valuable and pleasant experience for me. I am also especially grateful to my colleagues Gerard Van de Watering, Piet Van den Bossche and Mien Segers who were most directly involved. Others I am grateful for their critical and constructive comments on parts of the manuscript: Eduardo Cascallar, Alicia Schmid, Neville Bennett, Dan Hickey and Rachel Lewis.

It has been a pleasure to work for four years within the faculty of law at the University of Maastricht. I would like to thank all students, faculty colleagues and administrators for their ideas and co-operation. I have been a happy employee at the department of educational innovation and information technology. I had the privilege to work in good company. Some of my colleagues helped me with collecting data; all of them offered me inspiration and friendship. For this I want to thank my colleagues. I will never forget the lunches we had together.

Finally, I would like to thank my parents for their unconditional support and my dearest Ruth and our darling Nel for giving me the energy to carry out scientific work and making me see there is much more in life than work at the university. 


\section{Chapter 1}

\section{Introduction}

More than ever, successful functioning in society demands more than the understanding of the basic knowledge of a students' domain of study. An important challenge for today"s higher education remains the development and implementation of learning and teaching practices that will foster in students the skill to acquire and apply their knowledge efficiently, think critically, analyse, synthesise and make inferences (Segers, Dochy \& Cascallar, 2003). Overall, it is claimed that 'student-centred' or "new" learning environments have the potential to improve these educational outcomes for students in higher education (Lea, Stephenson \& Troy, 2003; Simons, van der Linden \& Duffy, 2000). New learning environments are rooted in constructivist theory and intend to develop an educational setting to meet the challenge for today's higher education, making the students' learning the core issue and defining instruction as enhancing the learning process. The theory of constructivism is frequently referred to when discussing new learning environments. However, there exists multiple definitions of constructivism and the debates regarding operationalisation of this theory still continue. Constructivism can be seen as an umbrella term that groups learning perspectives with the same basic assumption about learning: The understanding that knowledge is actively constructed by the learner (Birenbaum, 2003; Harris \& Alexander, 1998; Tynjälä, 1999).

A well known example from higher education of such a new learning environment is problem-based learning (Birenbaum, 2003; Hendry, Frommer \& Walker, 1999; Russel, Creedy \& Davis, 1994; Savery \& Dufy, 1995; Segers, Dochy \& De Corte, 1999). Although originally developed for medical training in Canada at McMaster university, the orthodox version of problem-based learning (PBL) has been modified and applied globally in many disciplines (Gijselaers, 1995). Many curricula or parts thereof are modelled on the basis of problem-based learning. The desire to implement problem-based learning as an alternative for existing teaching practices inevitably raises the question as to whether problem-based learning is an alternative capable of effectively replacing conventional instruction (Albanese \& Mitchell, 1993). Although contemporary educational practice increasingly consists of a blend of conventional and student-centred methods, there seems to be a need to compare the merits of the two approaches.

The core issue in this dissertation is: "To what extent is PBL an effective learning environment?" The question itself is indicative of a clear description of 
educational interventions that can be labelled 'PBL' (Newman, et al., 2004). In spite of the many variations of $\mathrm{PBL}$ that aim to match $\mathrm{PBL}$ with the specific educational or discipline context, for comparative research, a core model or basic definition is needed to which other educational methods can be compared. The six core characteristics of PBL as distinguished in Barrows" (1996) core model are used as a frame of reference in this dissertation. They can be described as follows. The first characteristic is that learning needs to be student-centred. Secondly, learning has to occur in small student groups. The third characteristic refers to the presence of a tutor as a facilitator or guide. Fourthly, authentic problems are primarily encountered in the learning sequence, before any preparation or study has occurred. Fifthly, the problems encountered are used as a tool to achieve the required knowledge and the problem-solving skills necessary to eventually solve the problem. Finally, new information needs to be acquired through self-directed learning. It should be noted that just as the definition of PBL is ambiguous, the definition of what constitutes conventional instruction is also ambiguous. For the most part, conventional instruction is marked by large group lectures and instructorprovided learning objectives and assignments (Albanese \& Mitchell, 1993).

Finally, the question to what extent PBL is an effective learning environment should raise the question how PBL can be made more effective. The alignment between the learning environments" objectives and the assessment is an important issue in improving students' learning (Biggs, 2003; Cohen, 1987; Gibbs, 1999). Using assessment more strategically has the potential to have educationally sound and positive influences. The traditionally view that the assessment of students' achievement is separate from instruction and only comes at the end of the learning process, is no longer tenable. As assessment, learning and instruction become more and more integrated, there is a strong support for representing assessment as a tool for learning (Dochy \& McDowell, 1997; Sambell, McDowell \& Brown, 1997). However, the integration of assessment, learning and instruction remains a challenge for most teachers and a scarce subject of research.

The main scope in this dissertation is focussing on two cognitive learning outcomes: The acquisition as well as the application of knowledge. The main aim of problem-based learning environments in higher education is to guide students to become experts in a certain field of study, so-called professionals: Graduates who can identify the problems of different disciplines and who are capable of analysing and contributing to the solutions of these problems. The findings of cognitive psychological research, especially results from expert versus novice studies have contributed to the insights in the nature of expertise (Feltovich, Spiro \& Coulson, 1993; Gagné, Yekovich \& Yekovich, 1993; Glaser, 1990). These findings have provided a basis for unravelling the general goal of PBL, the development of successful problem-solving into two dimensions i.e. the acquisition as well as the application of knowledge. However, in order to get more insight into the way students realise these learning outcomes, issues as students' perception of their learning environment and students' approaches to learning are of vital importance. If constructivism is taken seriously, the idea that students construct (whether public or individual) their own knowledge and perceptions of their learning, points us to pay attention to students" perception of the learning environment (den Brok, 
Bergen, Stahl \& Brekelmans, 2004). Students perceptions of the academic learning environment, rather than the academic environment 'an sich' affect their approaches to learning, and this in turn affects their learning outcomes (Brekelmans, van den Eeden, Terwel \& Wubbels, 1997; Entwistle \& Tait, 1990; Fraser, Walberg, Welch \& Hattie, 1987).

Generally, the studies in this dissertation focus on the effectiveness of PBL. The dissertation starts with a study examining students' perception of PBL and a study investigating the relationship between students' approaches to learning in PBL and their learning outcomes. Then the effects of PBL are examined in two meta-analyses and a study within a single course. The finall study in this dissertation looks for the potentials of integrating assessment-tasks in the learning environment to improve the effects of PBL. In the next paragraph the structure of this dissertation and the research questions will be further outlined.

\section{Structure of the dissertation and research questions}

This first chapter gives an introduction and clescribes the structure and research questions of the dissertation.

In the second chapter a study is presented which investigates whether students in PBL perceive the learning environment as more constructivist compared to students in a conventional lecture-based environment. Because constructivism is the underlying theory referred to when superior effects of PBL are postulated, it is assumed that the extent to which students perceive the constructivist principles in the learning environment as being present will be related to the expected effects of the learning environment.

The purpose of the study presented in chapter three is to gain more insight into the relationship between students' approaches to learning and students' quantitative learning outcomes, as a function of the different components of problem solving that are measured within the assessment.

Chapter four describes a meta-analysis guided by two sets of research questions. First, the main effects of PBL on two broad categories of outcomes: Knowledge and the application of knowledge are investigated. Secondly, the potential moderators of the effect of PBL are addressed. A first category of moderators are design aspects of the reviewed research. In the second category of moderators, we examined whether the effect of PBL differs according to various levels of student expertise. Thirdly, we looked more closely at different types of assessment methods. Fourthly, we investigated the influence of the insertion of a retention period.

Chapter five builds on the previous chapter by taking the influence of assessment as the main independent variable. The goal of this chapter is to describe the effects of PBL from the angle of the underlying focal constructs being measured with the assessment. Using a model of cognitive components of problem-solving as a frame of reference, the research question is formulated as follows: What are the 
effects of PBL when the assessment of its main goals focuses on respectively (1) the understanding of concepts, (2) the understanding of the principles that link concepts and (3) the linking of concepts and principles to conditions and procedures for application?

Chapter six addresses the effects on students' knowledge and knowledge application of an in time and theme limited implementation of PBL. Two research questions need to be answered in this chapter. First, to what degree do students studying for a limited period of time in a PBL-course acquire an accessible knowledge base of the subject studied compared to students to whom the subject was presented in a conventional way? Secondly, are students who have been subjected for a limited period of time to a PBL-course better equipped to apply the knowledge of the subject studied than students to whom the subject was presented in the conventional lecture-based way?

The central question in chapter seven is whether integrating teacher made written assessment-tasks in the problem based learning environment can result in improvements in the overall-student performance? It is expected that students who make such assessment-tasks during a course will have higher grades on their final exam compared to students who do not participate in such assessment-tasks. Students" and tutors' perceptions of the learning-assessment environment are taken into consideration in order to get more insight into the effect.

In chapter eight the information from the previous chapters will be summarised and discussed.

Since every chapter is written to be read on its own, repetitions and overlap across chapters are inevitable. In the summaries (English and Dutch) an overview of the most important results is presented.

\section{References}

Albanese, M.A., \& Mitchell, S. (1993). Problem-based learning: A review of literature on its outcomes and implementation issues. Academic Medicine, $68,52-81$.

Barrows, H.S. (1996). Problem-based learning in medicine and beyond. In L. Wilkerson, \& W.H. Gijselaers (Eds.), Bringing problem-based learning to higher education: Theory and practice. New directions for teaching and learning, No. 68. (pp. 3-13). San Francisco: Jossey-Bass Inc. Publishers.

Biggs, J. (2003). Teaching for quality learning at university (Second edition). Buckingham: Open University Press.

Birenbaum, M. (2003). New insights into learning and teaching and their implications for assessment. In M. Segers, F. Dochy \& E. Cascallar (Eds.), Optimising new modes of assessment: In search for qualities and standards (pp. 13-36). Dordrecht: Kluwer Academic Publishers.

Brekelmans, M., van den Eeden, P., Terwel, J., \& Wubbels, T. (1997). Student characteristics and learning environment interactions in mathematics and 
physics education: A resource perspective. Intemational formal of Educational Research, 27 (4), 283-292.

Cohen, S.A. (1987). Instructional alignment: Searching for a magic bullet. Educational Researcher, 16(8), 16-20.

Den Brok, Bergen, T., Stahl, R.J., \& Brekelmans, M. (2004). Students' perceptions of teacher control behaviours. Learning and Instruction, 14 (4), 425-443.

Dochy, F., \& McDowell, L. (1997). Assessment as a tool for learning. Studies in Educational Evaluation, 23 (4), 279-298.

Entwistle, N.J.; \& Tait, H. (1990). Approaches to learning, evaluations of teaching, and preferences for contrasting academic environments. Higher Education, 19 (2), 169-194.

Feltovich, P.J., Spiro, R.J., \& Coulson, R.L. (1993). Learning, teaching, and testing for complex conceptual understanding. In N. Frederksen, R. J. Mislevey \& I.I. Bejar (Eds.), Test theory for a new generation of tests. Hilsdale, NJ: Erlbaum.

Fraser, B.J., Walberg, H.J., Welch, W.W., Hattie, J.A. (1987). Syntheses of educational productivity research. International Journal of Educational Research, 11, 145-252.

Gagné, E. D., Yekovich, C. W., \& Yekovich, F. R. (1993). The cognitive psychology of school learning (2nd ed.). New York: HarperCollins College publishers.

Gibbs, G. (1999). Using assessment strategically to change the way students learn. In S. Brown \& A. Glasner (Eds.), Assessment matters in higher education: Choosing and using diverse approaches (pp.41-53). Buckingham: Open University Press.

Gijselaers, W. (1995). Perspectives on problem-based learning. In W. Gijselaers, D. Tempelaar, P. Keizer, J. Blommaert, E. Bernard \& H.Kasper (Eds.), Educational innovation in economics and business administsration. The case of problem-based learning (pp. 39 - 52). Norwell, Mass.: Kluwer.

Glaser, R. (1990). Toward new models for assessment. Intemational Journal of Educational Research. 14, 475-483.

Harris, K. R., \& Alexander, P. A. (1998). Integrated, constructivist education: Challenge and reality. Educational Psychology Review, 10 (2), 115-127.

Hendry, G. D., Frommer, M., \& Walker, R.A. (1999). Constructivism and Problembased learning. Joumal of Further and Higher Education, 23 (3) 359-371.

Lea, S. J., Stephenson, D., \& Troy, J. (2003). Higher education students' attitudes toward student-centred learning: beyond 'educational bulimia'? Studies in Higher Education, 28 (3), 321-334.

Newman, M., Van den Bossche, P., Gijbels, D., McKendree, J., Roberts,T., Rolfe, I., Smucny, J., \& De Virgilio, G. (2004). Responses to the pilot systematic review of problem-based learning. Medical Education, 38, 921-923.

Russell, A. L., Creedy, D. \& Davis, J. (1994). The use of contract learning in PBL. In: S. E. Chen, S. E. Cowdroy, A. J. Kingsland \& M. J. Ostwald (Eds.), Reflections on problem based learning. (pp. 57-72). Sydney: Australian Problem Based Network. 
Sambell, L., McDowell, L., \& Brown, S. (1997). "But is it fair?": An exploratory study of student perceptions of the consequential validity of assessment. Studies in Educational Evaluation, 23 (4), 349-371.

Savery, J. R., \& Duffy, T. M. (1995). Problem-based learning: An instructional model and its constructivist framework. Educational Technology, 35, 3138.

Segers, M., Dochy, F, \& Cascallar, E. (2003). The era of assessment engineering: Changing perspectives on teaching and learning and the role of new modes of assessment In M. Segers, F. Dochy \& E. Cascallar (Eds.), Optimising new modes of assessment: In search for qualities and standards (pp. 1-12). Dordrecht: Kluwer Academic Publishers.

Segers, M., Dochy, F. \& De Corte, E. (1999). Assessment practices and students" knowledge profiles in a problem-based curriculum. Learning Environments Research, 12 (2), 191-213.

Simons, R.J., van der Linden, J., \& Duffy, T. (2000). New learning: Three ways to learn in a new balance. In R.J. Simons, J. van der Linden \& T. Duffy (Eds.), New leaming (pp. 1-20). Dordrecht: Kluwer Academic Publishers.

Tynjälä, P. (1999). Towards expert knowledge? A comparison between a constructivist and a traditional learning environment in the university. International Journal of Educational Research, 33, 355-442. 


\section{Chapter 2}

\section{Problem-based learning and constructivism: The students' perspective}

\section{Abstract}

Research into students' perceptions of the learning environment reveals its impact on the way students cope with the learning environment. Consequently, students' perceptions affect the results of their learning. This study aims to investigate whether students in a problem-based learning environment perceive it to be more constructivist when compared with the perceptions of students in a conventional lecture-based environment. Using a questionnaire based on seven key factors of constructivist learning environments, the results show that students in the problembased learning environment perceive the environment as more constructivist when compared to the perceptions of students in a conventional lecture-based environment. The difference was statistically significant for each of the seven factors. According the effect size, as measured by the $d$-index, the difference in perception between the two groups was the largest for the factor "conceptual conflicts and dilemmas".

\footnotetext{
${ }^{~ B a s e d ~ o n: ~ G i j b e l s, ~ D ., ~ V a n ~ d e ~ W a t e r i n g, ~} G$., \& Dochy, F. (submitted to Instructional Science). New learning environments and constructivism: The students" perspective.
} 


\section{Introduction}

In recent years, higher education has frequently been blamed because graduates are not sufficiently able to apply their knowledge to solve complex problems in a working context. The development and implementation of instructional practices that will foster students" skills to communicate, think and reason effectively, make judgements about the accuracy of masses of information, solve complex problems and work collaboratively in diverse teams, remains an important challenge for today's higher education (Pellegrino, Chudowsky \& Glaser, 2001). New leaming environments based on constructivist theory claim to develop an educational setting in which to reach this goal, making the students' learning the core issue and defining instruction as enhancing learning (Lea, Stephenson \& Troy, 2003). However, the gap between educational practice and the theory of constructivism seems to be difficult to bridge (De Corte, 2000). One major problem is that it has been difficult to characterise a constructivist learning environment (Windschitl, 2002). Constructivism can be seen as an umbrella term that groups learning perspectives with the same basic assumption about learning: The understanding that knowledge is actively constructed by the learner (Birenbaum, 2003; Harris \& Alexander, 1998; Tynjälä, 1999). In this sense, all learning environments are constructivist, since, even in teaching situations such as drill and practice, students are constructing knowledge and this simply because that is the way the mind operates (von Glaserfeld, 1993). The many discussions between the different theoretical positions of constructivism, all with varying emphasis, have inhibited the narrowing of the bridge between theoryiand practice (Kennedy, 1997). Different perspectives of constructivism emphasise either individual cognitive processes, such as cognitive constructivism which is concerned with the knowledge construction of the individual, or social co-constructions of knowledge, such as social constructivism which stresses the collaborative processes in knowledge building (Windschitl, 2002). Despite many animated discussions, there seems to be no incompatibility amongst the theories and integrative approaches seem to be developing (Resnick, 1994; Vosniadou, 1996; Tynjäłä, 1999). Despite ongoing debates, the constitution of the instructional principles of constructivist theory, which guide matters of the nature and quality of educational materials and the learning environment, remains unclear (Harris \& Alexander, 1998; Tenenbaum, Naidu, Jegede \& Austin, 2001). Both teachers and researchers are in need of more concrete anchors to support their thoughts and actions in applying constructivism to educational practice (Windschitl, 2002). Accordingly, some authors attempted to define the key features of constructivist learning environments and developed questionnaires to evaluate their presence in daily educational practice. Taylor, Fraser and Fisher (1997) developed the new Constructivist Learning Environment Survey (CLES), based on the original CLES (Taylor \& Fraser, 1991), to assess the degree to which students in secondary education perceive a mathematics or science learning environment to be consistent with the key dimensions of constructivism. 
Small-scale qualitative studies, as well as large-scale quantitative studies, were conducted. In the qualitative studies, the researchers visited classrooms as participant-observers, interviewed students and teachers and analysed documents on the curriculum. In both cases, the focus was on the way the students made sense of responding to CLES items and how the data from the CLES were compatible with the observations. The qualitative part resulted in a $30 \mathrm{item}$ questionnaire, divided into five six item scales. The statistical characteristics of this questionnaire were determined in two large-scale quantitative surveys. The final version of their survey consists of 5 scales of 6 items each to be answered on a 5-point Likert scale. The 5 scales Taylor and colleagues distinguish for secondary education are: (1) personal relevance, (2) uncertainty, (3) critical voice, (4) shared control and (5) student negotiation. Taylor et al. $(1997$, p. 300) argue that, because of the satisfactory internal consistency and factorial validity of the 5 scales, the CLES can be used "to monitor the development of constructivist learning environments in school science in Western cultures".

In the field of university teaching. Tenenbaum and colleagues (2001) recently empirically defined and examined key features of constructivist learning environments and their incorporation into two different learning environments (oncampus and distance learning). In the first phase of their study, they carried out a survey using an international electronic mailing list to explore the concept of constructivism, the processes underlying constructivist learning, and its facilitation. In the second phase, they further elaborated on the key features of constructivism in the learning environment and developed a questionnaire using the results of phase 1. A subsidiary aim of this second, quantitative phase was the development of a questionnaire that could be used by other researchers in different educational settings to investigate the presence and/or absence of constructivist practices. The results of the study in both phases were very similar and resulted in a survey containing thirty 5-point Likert scale questions. Seven key factors of constructivist learning environments underlie this questionnaire: (1) arguments, discussions, debates; (2) conceptual conflicts and dilemmas; (3) sharing ideas with others; (4) materials and measures targeted toward solutions; (5) reflections and concept investigation; (6) meeting student needs; and (7) making meaning, real-life examples.

Comparison of students' perceptions of the seven factors in different units within the same educational setting revealed that the extent to which the seven factors are experienced differ between various units. Furthermore, comparison between designers' perceptions and students' perceptions indicated that the sevent factors are not very strongly present in the learning environment from the perception of the students, despite the belief of the designers that they had created the learning environments in such a way. The difference was clearest for the factors 'sharing ideas with others' and 'making meaning, real life examples'.

Generally, the theory of constructivism is frequently referred to when discussing new learning environments. New learning environments, such as project-based education and problem-based learning are claimed to have the potential to improve the educational outcomes for students in higher education (Lea 
et al., 2003; Simons, van der Linden \& Duffy, 2000). Problem-based learning is probably the best known example of a new leaming environment claiming to be highly consistent with constructivist features (Birenbaum, 2003; Hendry, Frommer \& Walker, 1999; Russel, Creedy \& Davis, 1994; Savery \& Dufy, 1995; Segers, Dochy \& De Corte, 1999). Although new in some aspects, problem-based learning (PBL) is generally based on ideas that originated earlier and have been nurtured by different researchers (Ausubel, Novak \& Hanesian, 1978; Bruner, 1959, 1961; Dewey, 1910, 1944; Piaget, 1954; Rogers, 1969). PBL, as it is known today, originated in the 1950s and 1960s. Nowadays, PBL is developed and implemented in a wide range of domains. In spite of the many variations of PBL that have evolved, Barrows (1996) describes a core model of PBL in which six fundamental characteristics can be distinguished. The first characteristic is that learning needs to be student-centred. Secondly, learning has to occur in small student groups, under the guidance of a tutor. The third characteristic refers to the tutor as a facilitator or guide. Fourthly, authentic problems are encountered in the learning sequence, before any preparation or study has occurred. Fifthly, the problems encountered are used as a tool to achieve the required knowledge and the problem-solving skills necessary to eventually solve the problem. Finally, new information is acquired through self-directed learning.

Although all new learning environments are designed to educate students to analyse and solve problems in an efficient way, empirical studies regarding the effects of such learning environments do not always demonstrate the expected learning outcomes (Segers, 1996). Understanding and improving educational effects demands a 'multi-directional attack' (Goodyear \& Hativa, 2002). Research shows that the way the learning environment is perceived by the students, rather than the factual curriculum, affects to a large extent how students cope with the learning environment and, consequently, their learning results (Brekelmans, van den Eeden, Terwel \& Wubbels, 1997; Entwistle \& Tait, 1990; Fraser, Walberg, Welch \& Hattie, 1987; Segers \& Dochy, 2001). It follows that educational interventions will be ineffective unless they modify students' perceptions in the intended way. A recent study on students' perceptions of PBL (Dochy, Segers, Van den Bossche \& Struyven, in press) indicated that students perceive the characteristics of the problem-based learning environment, translated into statements, as being present and of high consequence for their learning. If one ponders the implementation of PBL, a major question is whether students from PBL achieve goals in a more effective way than students who receive more conventional instruction. Conventional instruction methods are those that are marked by large group lectures and instructor-provided learning objectives and assignments (Albanese \& Mitchell, 1993). Because constructivism is the underlying theory referred to when superior effects of problem-based learning environments are postulated, we assume that the extent to which students perceive the constructivist principles in the learning environment as being present will be related to the expected effects of the learning environment. The main aim of the present study is therefore to verify whether students in PBL perceive the learning environment to be more constructivist when compared to the perceptions of students in a conventional lecture-based environment. A question of particular interest is for which factors the differences 
between the problem-based learning environment and the conventional lecturebased environment are the largest.

\section{Method}

\section{Participants}

The participants in this study were 229 law students studying in a problembased curriculum and 188 law students in a lecture-based curriculum. Both groups were enrolled in a second year course on the topic of private law.

\section{Instrument}

The students completed the questionnaire developed by Tenenbaum and colleagues (2001) to obtain a view of students' perceptions of the presence of constructivist practices and principles in their learning environments. The original questionnaire was translated into Dutch. Four expert educational scientists were given the questionnaire in order to decide if the translation was accurate and clearly enough phrased. To check the latter, the questionnaire was also presented to a small group of students. This resulted in a final translation of the original questionnaire. An example for each factor is presented in Table 1. The first factor, "arguments, discussions, debates', stresses learning as an active and cumulative construction of knowledge. The extent to which students are confronted with conceptual conflicts indicating that knowledge is not certain is captured by the second factor, 'conceptual conflicts and dilemmas'. The third factor, 'sharing ideas with others', deals with learning as a co-operative process. The goal-oriented aspect of learning is covered by the fourth factor, 'materials and measures targeted toward solutions'. The fifth factor, "motivation toward reflections and concept investigation", asks about the extent to which meta-cognitive aspects of learning are stimulated. The student-centred character of the learning process is stressed in the sixth factor, "meeting student needs'. Finally, the seventh factor, 'making meaning, real-1ife examples', deals with the contextual aspect of learning.

The Cronbach"s alpha coefficient of 0.91 indicated a high overall reliability of the translated questionnaire. The alpha coefficients of the subscales are also all judged to be acceptable for assessing differences between groups (Mehrens \& Lehmann, 1991): The arguments, discussions, debates scale: 0.79; the conceptual conflicts and dilemmas scale: 0.66 ; the sharing ideas with others scale: 0.76 ; the materials and measures targeted toward solutions scale: 0.60 ; motivation toward reflections and concept investigation scale: 0.79 ; the meeting student needs scale: 0.74 ; and the making meaning, real-life examples scale: 0.62 . 


\section{Procedure}

In both groups, the questionnaires were administered to all students present during one of the meetings near the end of the course. Participation was voluntary and confidential. Students were told that their responses would remain anonymous.

Table 1: Main characteristics and example for each factor of the questionnaire used in the study

\begin{tabular}{|c|c|c|}
\hline Factor & Main characteristics & Scale example \\
\hline Arguments, discussions, debates & $\begin{array}{l}\text { Learning as an active and } \\
\text { cumilative construction of } \\
\text { knowledge }\end{array}$ & $\begin{array}{l}\text { The unit allowed for consiant } \\
\text { exchange of ideas between } \\
\text { student and teacher }\end{array}$ \\
\hline $\begin{array}{l}\text { Conceptual conflicts and } \\
\text { dilemmans }\end{array}$ & $\begin{array}{l}\text { Confrontation with conceptual } \\
\text { conflicts: knowledge is not } \\
\text { certain }\end{array}$ & $\begin{array}{l}\text { The unit caused confusion } \\
\text { among conceptual idleass }\end{array}$ \\
\hline Sharing ideas with others & Learning is co-operative & $\begin{array}{l}\text { The anit allowed social } \\
\text { interaction }\end{array}$ \\
\hline $\begin{array}{l}\text { Materials and resources targeted } \\
\text { towards solutions }\end{array}$ & Learring is goal-oriented & $\begin{array}{l}\text { The unit included relevant } \\
\text { examples }\end{array}$ \\
\hline $\begin{array}{l}\text { Motivation toward reflections } \\
\text { and concept investigation }\end{array}$ & $\begin{array}{l}\text { Motivating the meta-cognitive } \\
\text { aspects of learning }\end{array}$ & $\begin{array}{l}\text { The unit encouraged me to } \\
\text { examine several perspectives } \\
\text { of an issue }\end{array}$ \\
\hline Meeting student's needs & $\begin{array}{l}\text { The student-centredness of the } \\
\text { learning environment }\end{array}$ & $\begin{array}{l}\text { The unit took into } \\
\text { consideration my needs and } \\
\text { concerns }\end{array}$ \\
\hline $\begin{array}{l}\text { Making meaning, real-life } \\
\text { examples }\end{array}$ & $\begin{array}{l}\text { The contextual aspect of } \\
\text { learning }\end{array}$ & The unit was rich in examples \\
\hline
\end{tabular}

\section{Learning environments}

Students in the PBL curriculum worked over 8 weeks on a topic in the area of private law. During these 8 weeks the students worked twice a week for two hours in small groups (maximum 19 students) on different tasks, guided by a tutor. As well as these tutorial groups, they were enrolled in somewhat bigger practical classes (38 students) for 2 hours a week and another 4 hours a week ( 2 limes two hours) in large class lectures. Assessment for this course took place by means of a written exam, immediately after the course.

Students in the conventional lecture-based curriculum worked over 12 weeks of the course on a topic in the area of private law. During these 12 weeks, the students attended lectures of 2 hours each, twice a week. Assessment for this course took place by means of a written exam, in the examination period at the end of the year. 


\section{Results}

The responses of the students in the PBL group and the conventional lecture-based group on the seven factors in the questionnaire were plotted to test normal distribution of the variables in each of the two groups. The students' responses on the seven factors were then analysed by means of descriptive statistics followed by independent sample $t$-tests and calculation of effect sizes ( $d$-index) to examine the possible differences between the two in the respective factors. Guidelines for the interpretation of the $d$-index generally take $d=0.2$ as a small effect, $d=0.5$ as a moderate effect and $d=0.8$ as a large effect (Cohen, 1988; Kirk, 1996).

Table 2: Means (standard deviations in parentheses) for the seven key components of constructivist learning environments in the two conditions. Results of the $t$-tests $(d=\mathrm{effect}$ size)

\begin{tabular}{|c|c|c|c|c|c|c|c|}
\hline \multirow[b]{2}{*}{ Dimensions } & \multicolumn{2}{|c|}{ Traditional } & \multicolumn{2}{|l|}{ PBL } & \multirow[t]{2}{*}{$d^{k t}$} & \multirow[t]{2}{*}{$f^{3 / 3}$} & \multirow[t]{2}{*}{$p$} \\
\hline & $\bar{M}$ & SD & $M$ & $\mathrm{SD}$ & & & \\
\hline arguments, discussions, debates. & 3.15 & $(.62)$ & 3.40 & $(.71)$ & .30 & 3.74 & $<01$ \\
\hline conceptual conflicts and dilemmas & 2.68 & $(.73)$ & 3.37 & $(.69)$ & .81 & 9.77 & $<.01$ \\
\hline sharing ideas with others & 3.00 & $(.70)$ & 3.61 & (.61) & .75 & 9.39 & $<.01$ \\
\hline $\begin{array}{l}\text { materials and measures targeted } \\
\text { toward solutions } \\
\text { motivation toward reflections and }\end{array}$ & 3.43 & (.67) & 3.57 & (.64) & .17 & 2.14 & $<.05$ \\
\hline concept investigation & 3.04 & $(.61)$ & 3.18 & (.67) & .18 & 2.32 & $<.05$ \\
\hline meeting student needs & 2.67 & $(.65)$ & 2.99 & $(66)$ & .40 & 5.02 & $<.01$ \\
\hline making meaning, real-life examples & 3.42 & (.61) & 3.58 & (.59) & .21 & 2.67 & $<0 \mathrm{l}$ \\
\hline
\end{tabular}

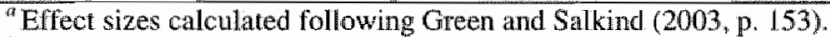

${ }^{b} t$-value for $\mathrm{df}=415$ in case of equal variances; otherwise, the degrees of freedom were adjusted.

From the results in Table 2, it is clear that students in PBL perceive their learning environment to be more constructivist, compared to students in a conventional lecture-based environment. The difference between the PBL group and the lecture-based group is statistically significant $(p<0.05)$ in the expected direction for each of the seven factors. For five of the seven factors the difference is significant at the $p<0.01$ level.

Although students perceive the factors 'reflections and concept investigation" and "meeting students needs" as being more present in PBL, the mean scores for these two dimensions (respectively 3.18 and 2.99) are low. On the other hand the factors 'materials and measures targeted toward solutions' and 'making meaning, real-life examples' are perceived by the students in the conventional lecture-based environment as relatively highly present (mean scores respectively 3.43 and 3.42 ).

All mean differences between the PBL group and the conventional lecturebased group are accompanied by a small to large effect size. The effect size is about $d=0.2$ for the factors 'materials and measures targeted toward solutions', 
"motivation toward reflections and concept investigalion" and 'making meaning, real-life examples". Somewhat larger effect sizes (about $d=0.4$ ) are found for the factors "arguments, discussions, debates" and "meeting student needs". According the large effect sizes (about $d=0.7$ ), the difference in perception between the two groups is most salient for the factors "motivation toward conceptual conflicts and dilemmas" and "sharing ideas with others".

\section{Conclusion and discussion}

Research into students' perceptions of the learning environment reveals its impact on the way students cope with the learning environment and, consequently, their leaning results (Brekelmans et al., 1997; Entwistle \& Tait, 1990; Fraser et al., 1987; Segers \& Dochy, 2001). This chapter investigated whether students in PBL. perceive their learning environment as more constructivist compared to the perceptions of students in a conventional lecture-based environment. Learning environments based on constructivism have the potential to improve the educational outcomes for students in higher education (Lea et al., 2003) and PBL is claimed to be consistent with constructivist features (Brrenbaum, 2003; Hendry et al., 1999; Russel et al., 1994; Savery \& Dufy, 1995; Segers et al., 1999). Of particular interest was the question of for which factors the differences between students" perceptions of the problem-based and the conventional lecture-based environment were the largest.

Using the questionnaire of Tenenbaum et al. (2001) to probe into students" perceptions of the learning environments, it became clear that students in PBL. perceive the learning environment to be more constructivist when compared to students in a conventional lecture-based environment. According to the effect size as measured by the $d$-index, the difference in perception between the two groups was most salient for the factor "conceptual conflicts and dilemmas". Tenenbaum and colleagues (2001) argue that this factor, stressing the idea that knowledge cannot be found "out there" and consequently is not certain, represents the constructivist approach more than others. A second factor, called "sharing ideas with others" also clearly distinguished between the two learning environments. A recent study by Chennoblisky, Dacosta and Hmelo-Silver (2004) indicated that effective co-operative learning communities function better and are associated with more meaningful knowledge construction. These two factors determine the strength of PBL in incorporating constructivist principles. "Tutors should be aware of the importance of facilitating these two factors to create a well functioning, cooperative tutorial group that promotes meaningful knowledge construction.

Although the students' perceptions were statistically significant for all seven factors in the questionmaire and effect sizes vary from sufficient to large, the difference between the two learning environments is not 'extremely' large. For the conventional lecture-based course this means that, in the perception of the students, constructivist principles are also partly incorporated. For PBL this means that, if PBL claims to be highly consistent with constructivist features, at least in the 
perception of the students, a lot of opportunities still remain to be taken. In particular, the factor "meeting students' needs' was only moderately present in PBL. This indicates that students in PBL only had a relatively small say in the learning process. On the other hand, the conventional lecture-based environment succeeds in paying relatively large amounts of attention to the factors 'materials and measures targeted toward solutions' and 'making meaning, real-life examples', indicating that working with real-life contexts and authentic problems are not the restricted hallmark of new learning environments.

Some contents lend themselves more easily to a constructivist approach than others. Therefore, the question of whether the content of the courses was sufficiently comparable should be discussed. Although a lot of attention was paid to selecting comparable courses, no courses are completely the same. Nevertheless, the significant differences between units reported in the study by Tenenbaum et al. (2001) involved differences in disciplines such as arts, business, education, commerce and engineering, while in our study both courses covered the topic of private law at the level of a second year law course at the university.

It should be noted that students" perceptions are not only based on the actual learning environment, but are also based on former learning experiences and recent experiences (Segers \& Dochy, 2001). In both the problem-based and the conventional lecture-based environment, the courses involved in this study took place during the last part of the second year. As a consequence, the learning experiences of the students in the conventional lecture-based group are based on other lectures in the first and second year of the curriculum, while the learning experiences of students in the PBL group are based on other courses in the PBL curriculum. It is possible that students in the PBL group judged the course under study as less (or more) constructivist compared to previous courses in the PBL curriculum. This also accounts for the students in the conventional lecture-based group: There is a possibility that the course under study was more (or less) congruent with previous courses in the lecture-based curriculum. Students' perceptions of a PBL course after experiences in a conventional lecture-based curriculum and students' perceptions of a lecture-based course after experience in a PBL curriculum would probably show a bigger gap between the two learning environments. This also resulted from a recent study by Dochy et al. (in press).

As students' perceptions of the learning environment are seen as a powerful factor in the way students cope with the learning environment, it follows that educational interventions will be less effective if they don't succeed in modifying students' perceptions in the intended way. Research into students' perceptions provides us with more information on the way new learning environments are perceived in the intended - constructivist - way. The problem-based learning environment under study in this chapter is perceived by the students as more constructivist than the conventional lecture-based environment under study. However, it seems that students' perceptions of constructivist principles in the learning environment are triggered by a greater variety in learning environments. Therefore, a global implementation of problem-based curricula, although perceived as more constructivist by the students, is not recommendable. Rather, we believe 
that future research should focus on the engineering of an optimal mix of learning environments and take into account students' perceptions in the blend of lectures, problem- and case-based learning groups, practicals, task-oriented learning, workplace learning, online learning opportunities, etc.

\section{References}

Albanese, M.A., \& Mitchell, S. (1993). Problem-based learning: A review of literature on its outcomes and implementation issues. Academic Medicine, $68,52-81$.

Ausubel, D., Novak, J., \& Hanesian, H. (1978). Educational Psychology: A cognitive view (2nd ed.). New York: Holt, Rinehart \& Winston.

Barrows, H.S. (1996). Problem-based learning in medicine and beyond. In L. Wilkerson, \& W.H. Gijselaers (Eds.). Bringing problem-based learning to higher education: Theory and practice. New directions for teaching and learning, $n^{\circ}$ 68. (pp. 3-13). San Francisco: Jossey-Bass Inc. Publishers.

Biggs, J. (2003). Teaching for quality learning at university (second edition). Buckingham: Open University Press

Birenbaum, M. (2003). New insights into learning and teaching and their implications for assessment. In M. Segers, F. Dochy \& E. Cascallar (Eds.), Optimising new modes of assessment: In search for qualities and standards (pp.13-36). Dordrecht: Kluwer Academic Publishers.

Brekelmans, M., van den Eeden, P., Terwel, J., \& Wubbels, T. (1997). Student characteristics and learning environment interactions in mathematics and physics education: A resource perspective. International Journal of Educational Research, 27 (4), 283-292.

Bruner, J.S. (1959). Learning and thinking. Harvard Educational Review, 29, 184192.

Bruner, J.S. (1961). The act of discovery. Harvard Educational Review, 31, 21-32.

Chernobilisky, E., Dacosta, M.C., \& Hmelo-Silver, C.E. (2004). Learning to talk the educational psychology talk through a problem-based course. Instructional Science, 32, 319-356.

Cohen, J. (1988). Statistical power analysis for the behavorial sciences (second edition). Hillsclale, NJ: Erlbaum.

De Corte, E. (2000). Marrying theory building and the improvement of school practice: a permanent challenge for instructional psychology. Learning and Instruction, 10, 249-266.

Dewey, J. (1910). How we think. Boston: Health \& Co.

Dewey, J. (1944). Democracy and education. New York: Macmillan Publishing Co. Dochy, F., Segers, M., Van den Bossche, P., \& Struyven, K. (in press). Students' perceptions of a problem-based learning environment. Learning Enviromments Research. 
Entwistle, N.J., \& Tait, H. (1990). Approaches to learning, evaluations of teaching, and preferences for contrasting academic environments. Higher Education, $19(2), 169-194$.

Fraser, B.J., Walberg, H.J., Welch, W.W., Hattie, J.A. (1987). Syntheses of educational productivity research. International Joumal of Educational Research, 11, 145-252.

Green, S. B., \& Salkind, N. J. (2003). Using SPSS for windows and macintosh. Analyzing and understanding data (third edition). New Jersey: Pearson Education.

Goodyear, P., \& Hativa, N. (2002). Introduction: Research on teacher thinking, beliefs and knowledge in higher education. In N. Hativa \& P. Goodyear (Eds.), Teacher thinking, beliefs and knowledge in higher education (pp. 113). Dordrecht: Kluwer academic publishers.

Harris, K. R., \& Alexander, P.A. (1998). Integrated, constructivist education: Challenge and reality. Educational Psychology Review, 10 (2), 115-127.

Hendry, G.D., Frommer, M., \& Walker, R.A. (1999). Constructivism and problembased learning. Journal of Further and Higher Education, 23 (3) 359-371.

Kennedy, M.M. (1997). The connection between research and practice. Educational Researcher, $26(7), 4-12$.

Kirk, R.E. (1996). Practical significance: A concept whose time has come. Educational and Psychological Measurement, 56, 746-759.

Lea, S.J., Stephenson, D., \& Troy, J. (2003). Higher education students' attitudes toward student-centred learning: Beyond 'educational bulimia'? Studies in Higher Education, 28 (3), 321-334.

Mandl, H., Gruber, H., \& Renkl, A. (1996). Communities of practice toward expertise: Social foundation of university instruction. In P.B. Baltes \& U.M. Staudinger, Interactive minds. Life-span perspectives on the social foundation of cognition (pp. 394-412). Cambridge: Cambridge University Press.

Mehrens, W.A., \& Lehmann, I.J. (1991). Measurement and evaluation in education and psychology ( $4^{\text {th }}$ edition). Fort Worth: Holt, Rinehart \& Winston.

Pellegrino, J.W., Chudowsky, N., \& Glaser, R. (2001). Knowing what students know: The science and design of educational assessment. Washington, DC : National Academy Press.

Piaget, J. (1954). The construction of reality in the child. New York: Basic Books.

Resnick, L. B. (1994). Situated rationalism: Biological and social preparation for learning. In L.A. Hirschfeld \& S.A. Gelman (Eds.), Mapping the mind (pp. 474-494). New York: Cambridge University Press.

Rogers, C.R. (1969). Freedom to learn. Colombus, Ohio: Charles E. Merill Publishing Company.

Russell, A.L., Creedy, D. \& Davis, J. (1994). The use of contract learning in PBL, in: S. E. Chen, S.E. Cowdroy, A.J. Kingsland \& M.J. Ostwald (Eds.), Reflections on problem based learning. (pp. 57-72). Sydney: Australian Problem Based Network. 
Savery, J.R , \& Duffy, T.M. (1995). Problem-based learning: An instructional model and its constructivist framework. Educational Technology, 35, 3138.

Segers, M. (1996). Assessment in a problem-based economics curriculum. In M. Birenbatm \& $\mathrm{F}$. Dochy (Eds.), Alternatives in assessment of achievements, learning processes and prior leaming (pp. 201-226). Boston: Kluwer Academic Press.

Segers, M., \& Dochy, F. (2001). New assessment forms in problem-based learning: The value-added of the students" perspective. Studies in Higher Education, $26(3), 327-343$.

Segers, M., Dochy, F, \& De Corte, E. (1999). Assessment practices and students' knowledge profiles in a problem-based curriculum. Learning Environments Research, /2(2), 191-213.

Simons, R.J., van der Linden, J., \& Duffy, T. (2000). New learning: Three ways to learn in a new balance. In R.J. Simons, J, van der Linden \& T. Duffy (Eds.), New learning (pp. 1-20). Dordrecht: Kluwer Academic Publishers.

Taylor, P.C., Fraser, B.J. (1991, April). Development of an instrument for assessing constructivist learning environments. Paper presented at the annual meeting of the American Educational Research Association (AERA), New Orleans, LA.

Taylor, P.C., Fraser, B.J., \& Fisher, D.L. (1997). Monitoring constructivist classroom learning environments. International Journal of Educational Research, 27, 293-302.

Tenenbaum, G., Naidu, S., Jegede, O, \& Austin, J. (2001). Constructivist pedagogy in conventional on-campus and distance learning practice: An exploratory investigation. Learning and Instruction, 11,87-111.

Tynjầlä, P. (1999). Towards expert knowledge? A comparison between a constructivist and a traditional learning environment in the University. International Journal of Educational Research, 33, 355-442.

Vosniadou, S. (1996). Towards a revised cognitive psychology for new advances in learning and instruction. Learning and Instruction, 6, 95-109.

Von Glaserfeld, E. (1993). Questions and answers about radical constructivism. In Tobin (Ed.), The practice of constructivism in science education (pp. 2338). Hildale, NJ: Lawrence Erlbaum.

Windschitl, M. (2002). Framing constructivism in practice as the negotiation of dilemmas: An analysis of the conceptual, pedagogical, cultural, and political challenges facing teachers. Review of Educational Research, 72 (2), 131-175. 


\section{Chapter 3}

\section{The relationship between students' approaches to learning and the assessment of learning outcomes ${ }^{2}$}

\section{Abstract}

The purpose of this chapter is to gain more insight into the relationship between students' approaches to learning and students' quantitative learning outcomes, as a function of the different components of problem solving that are measured within the assessment. Data were obtained from two sources: The revised two factor study process questionnaire (R-SPQ-2F) and students' scores in their final multiplechoice exam. Using a model of cognitive components of problem solving translated into specifications for assessment, the multiple-choice questions were divided into three categories. Three aspects of the knowledge structure that can be targeted by assessment of problem solving were used as the distinguishing categories. These were: Understanding of concepts; understanding of the principles that link concepts; and linking of concepts and principles to conditions and procedures for application. The 133 second year law school students in our sample had slightly higher scores for the deep approach than for the surface approach to learning. Plotting students' approaches to learning indicated that many students had low scores for both deep and surface approaches to learning. Correlational analysis showed no relationship between students' approaches to learning and the components of problem solving being measured within the multiple choice assessment. Several explanations are discussed.

\footnotetext{
${ }^{2}$ Based on: Gijbels, D., Van de Watering, G., Dochy, F., \& Van den Bossche, P. (2005). The relationship between students' approaches to learning and the assessment of learning outcomes. Accepred for publication in European Journal of Psychology of Edncation.
} 


\section{Introduction}

Since its original publication, nearly 30 years ago, the paper by Marton and Saljö (1976) has served as an impetus for the study of students' approaches to learning in order to search for the fundamental differences students bave in their approaches to engaging in learning tasks (Biggs, 1987). The study by Marton and Saljö (1976) introduced two concepts which have been widely used in educational research: 'Deep' and 'surface' approaches to learning. The concept of the deep approach is associated with students' intentions to understand and construct the meaning of the content to be learned, whereas the concept of the surface approach refers to students' intentions to learm by memorizing and reproducing the factual contents of the study materials.

The original Gothenburg group looked at students" ways of approaching learning in a more qualitative way (Marton, 1981). Others, like the research group of Entwistle in the United Kingdom (Entwistle \& Ramsden, 1983) or Biggs and his colleagues in Australia (1987), developed questionnaires and investigated the approaches in a more quantitative way. Although there are substantial differences between the aims, methods, and results of the different studies, they all have in common the dichotomy between a deep approach and a surface approach in students' learning (Prosser \& Trigwell, 1999). Besides these two core concepts of approaches to learning, a kind of mixed approach to learning, called the strategic (or achieving) approach, is often identified (Biggs, 1993; Entwistle, 1991). The strategic approach can take place through either deep or surface processing, in line with the demands of the context (Mäkinen, 2003).

An interesting question during this time has been the relationship between students" approaches to learning and students' learning outcomes. Although the results seem to be inconsistent, the use of a deep learning approach is, in general, associated with higher quality learning outcomes and a surface approach with lower quality learning outcomes (Crawford, Gordon, Nicholas \& Prosser, 1998; Hazel, Prosser \& Trigwell, 1996; Snelgroove \& Slater, 2003; Trigwell \& Prosser, 1991; Van Rossum \& Schenk, 1984; Zeegers, 2001).

Van Rossem and Schenk (1984) used the Structure of the Observed Learning Outcome (SOLO) taxonomy to describe the quality of the learning outcomes of 69 first year psychology students. The SOLO taxonomy consists of five structural categories of learning outcomes, going from the lowest level: "Prestructural' (an irrelevant response), to the most complete level, called 'extended abstract" (Biggs \& Collis, 1982). Their results show a clear positive relationship between the observation of a deep study approach and high quality learning outcomes. The difference in quantitative learning outcomes (using average exam scores) between students using the surface or the deep approach was only significant for questions measuring insight, not for questions measuring the reproduction of knowledge.

Trigwell and Prosser (1991) studied the relationship between the observed approaches to learning and the learning outcomes of 122 first year nursing students. 
Using the SOLO taxonomy, they found a positive correlation between a deep approach to learning and high qualitative levels in learning outcomes, but no such correlation to quantitative differences in outcome. There were no relationships found between surface approaches to learning and qualitative or quantitative outcome measures. In a later study in the field of biology, Hazel, Prosser \& Trigwell (1996) also made use of the SOLO taxonomy to analyse the learning outcomes, complimented with concept maps and phenomenographic methods. The 272 students involved in this study ended up in two clusters. In the first cluster, there was a relationship between low outcome measures, low scores on deep approaches and high scores on surface approaches. On the other hand, the second cluster reported high outcome scores related to low surface approach scores and high deep approach scores.

In the field of mathematics, Crawford and colleagues (1998) found strong correlations between 300 first year students' observed approaches to learning and their final percentage mark in their first year mathematics course. Relatively high scores on the surface approach subscale were related to low marks in the final exam, while relatively high scores on the deep approach to learning subscale were related to higher final exam scores.

In a longitudinal study with 200 first year science students, Zeegers (2001) used Bïggs' (1987) Study Process Questionnaire (SPQ) and annual GPA scores to evaluate the predictive value of the SPQ scales on students" learning outcomes. The results showed a consistent positive correlation between the deep approach to learning and assessment outcomes.

Snelgrove \& Slater (2003) also used the SPQ (Biggs, 1987) with 300 nursing students and found the deep factor to be positively and significantly correlated with average grade performance.

Recently, Watkins (2001) conducted a cross-cultural meta-analysis in which the relationship between students' approaches to learning and their academic performance was one of the central questions. It was hypothesised that surface approaches to learning would be significantly negatively correlated with students' grades, whilst the deep approach would be positively related with academic achievement. The results of his study were rather disappointing, although in the expected direction, with correlations of -0.11 for surface and 0.16 for deep approaches.

In the literature, assessment is generally blamed for these disappointing results. Although a deep approach to learning is expected to lead to higher achievement (both in terms of higher quality outcomes and grades), the assessment system does not always reward the deep approach (Biggs, 1987; Marton \& Saljo, 1976; Scouller, 1998; Scouller \& Prosser, 1994). Entwistle, McCune and Hounsell (2003, p. 90) suggest that research findings vary "due to differences in the extent to which understanding is explicitly rewarded in the assessment procedure". A recent study by Minbashian, Huon and Bird (2004) tried to investigate this moderating effect of the type of exam questions in a study involving 49 third year psychology students using Entwistle and Tait's (1994) Revised Approaches to Studying Inventory and short essay questions. However, the hypothesis that a deep approach 
would be more effective for questions of higher cognitive order than for questions of lower cognitive order could not be confirmed: The observed relationship was not significant and was in the opposite direction.

\section{The present study}

The relationship between students' approaches to learning and the assessed (quantitative) learning outcomes is of interest to the present study. Today's stated learning outcomes in higher education are to a large extent, congruent with trends in the marketplace. "With more and more routine jobs being turned over to robots and other automated devices, the jobs left for humans tend to be less routine requiring more problem-solving skill for adequate job performance" (Gagné, Yekovich \& Yekovich, 1993, p. 210). In essence, a primary goal in higher education seems to be to enable students to solve complex problems in an efficient way (Engel, 1997; Gagné et al., 1993; Poikela \& Poikela, 1997; Segers, 1997).

The literature on problem-solving is characterized by a wide variety of theoretical frameworks (e.g. De Corte, 1996; Glaser, Raghavan and Baxter, 1992; O'Neil \& Schacter, 1997; Schoenfeld, 1985; Smith, 1991). Despite their differences in details and terminology, all models agree that an organized and structured domain-specific knowledge base and meta-cognitive functions that operate on that knowledge are essential components of successful problem-solving. There is also a fairly broad consensus that motivation and beliefs account for differences in problem-solving.

As a consequence, the purpose of the present study is to explore further the relationship between students' approaches to learning and their quantitative learning outcomes, from the perspective of the different components of problem solving that are measured with the assessment.

\section{Research context}

The study was conducted in a European law school using problem-based learning (PBL). Educating for successful problem-solvers is one of the main goals of PBL (see also chapter 1). Although originally developed for medical training in Canada, the orthodox version of PBL has been modified and applied globally in many disciplines (Gijselaers, 1995). The present study took place in a course on public law. Students had to work in small tutorial groups (12-18 students) and met twice a week under the supervision of a teacher (tutor). During each session, students were confronted with a range of tasks which they had to analyse and solve by formulating 'learning goals' for self-study. In the next session, students reported their findings and started to analyse new problems. As well as this, students were enrolled on a weekly basis in somewhat larger 'practical groups' (24-36 students) and had one lecture a week. During the course, students had the opportunity to complete 3 assessment tasks on a voluntary basis. These could result in a bonus, which was added to the score of the final exam. 


\section{Method}

\section{Participants}

The sample consisted of 133 second-year law students (65\% females and $35 \%$ males, mean age: 20.6$)$ who were enrolled for the first time on a second year course in public law, using PBL. The students were divided into 17 small groups that were tutored by 7 teachers.

\section{Instruments}

Data were obtained from two sources: a questionnaire and students" final exam results for the course.

The questionnaire was a Dutch translation of Biggs, Kember and Leung's (2001) Revised two Factor Study Process Questionnaire (R-SPQ-2F). The R-SPQ$2 \mathrm{~F}$ is a more refined version of Biggs' (1987) original Study Process Questionnaire (SPQ). In the theoretical framework of the SPQ, three approaches to learning (surface, deep and achieving) are proposed, each with a motive and strategy subscale. Kember \& Leung (1998) conducted a study with over 7000 Hong Kong students which investigated the construct and internal reliability of the SPQ. The results indicated that a model. with two factors had the best fit. Other studies, including cross-cultural research, have also shown a two factor solution with deep and surfaces approaches, rather than the initial three factor solution, accounted for most of the variance (Snelgrove \& Slater, 2003; Watkins \& Regmi, 1996; Zhang, 2000). Biggs and colleagues (2001) accordingly refined the SPQ. The revised two factor SPQ consists of 20 items which are scored on a 5 point Likert scale and categorizes students into two different types of approaches to learning: 'Surface learning approaches' and 'deep learning approaches', each containing two subscales, 'motive' and 'strategy'. The study of Biggs and colleagues (2001) indicated that the 2F-SPQ-R had reasonable Cronbach's alpha values for scale reliability and desirable goodness of fit with the intended two factor model. Leung and Chan (2001) investigated the psychometric properties and applicability of the 2F-SPQ-R in the Hong Kong Chinese context. Their results also indicated reasonably good reliability coefficients and goodness of fit for the two factor model. Our Dutch translation of the questionnaire resulted in acceptable Cronbach's alpha values for the 2 factor model: Surface learning approaches (Cronbach's alpha $=$ 0.75 ) and deep learning approaches (Chronbach"s alpha $=0.73$ ). The subscales deep motive (Chronbach's alpha $=0.60$ ), deep strategy (Chronbach's alpha $=0.54$ ), surface motive (Chronbach's alpha $=0.65$ ) and surface strategy (Chronbach"s alpha $=0.48$ ) had lower reliability coefficients and are not used for further analysis. Confirmatory factor analysis (CFA) was used to verify whether the two factor structure could be validated. The results indicated that the data set fits the two factor model fairly well (chi-square/df $=1.64$, RMSEA $=0.07$ ). Sufficient fit values are 
smaller than 2.0 for the first (Dolmans, Wolfhagen, Scherpbier \& van der Vleuten, 2003; Tenenbaum, Naidu, Jegede \& Austin , 2001), and smaller than 0.08 for the Root Mean Square Error of Approximation (Browne \& Cudeck, 1993; Guay, Marsh \& Boivin, 2003).

The final exam consisted of 40 multiple-choice questions (Cronbachs' alpha $=0.70$ ). In order to distinguish between the different components of problem solving for each question in the final exam, we used Sugrue's $(1993,1995)$ model of cognitive components of problem solving. Sugrue translated her model into specifications for the assessment of the main cognitive components of problemsolving, and is therefore useful for our purpose. The assumption made by Sugrue is that successful problem-solving in a given domain results from the interaction of knowledge structure, meta-cognitive functions and motivation. For each of the three categories of cognitive components, Sugrue describes a limited set of variables that should be targeted by assessment.

In relation to the final exam used in our study, the knowledge structure is of special interest. Three levels which the assessment can appeal to are distinguished in the knowledge structure. These three levels are presented in Figure 1, which gives an overview of possibilities for the assessment within a 'selection' format, of which multiple-choice questions are obviously the most well-known example (Sugrue, 1995). At the first level, assessment of the understanding of concepts, which can be defined as "a category of objects, events, people, symbols or ideas that share common defining attributes or properties and are identified by the same name" (Sugrue, 1993, p.9) is the core issue. In this case, students are confronted with several examples of the concept and asked to select those which are instances of the concept of interest. At the second level, understanding of the principles that link concepts, or in other words the organization of the knowledge structure, is the subject of assessment. Sugrue (1993, p. 9) defines a principle as "a rule, law, formula, or if-then statement that characterizes the relationship (often causaly between two or more concepts. Principles can be used to interpret problems, to guide actions, to troubleshoot systems, to explain why something happened, or to predict the effect a change in some concept(s) will have on other concepts". In this case, students could be asked to select the most appropriate prediction or solution from a list of given descriptions of an event. The third and final level targets the linking of concepts and principles to conditions and procedures for application by assessment. A 'procedure' is defined as "a set of steps that can be carried out either to classify an instance of a concept or to change the state of a concept to effect a change in another" (Sugrue, 1993, p. 22) and 'conditions' as "aspects of the environment that indicate the existence of an instance of a concept, and/or that a principle is operating or can be applied and/or that a particular procedure is appropriate" (Sugrue, 1993, p. 22). At this level, the organized knowledge is applied under appropriate circumstances. A student can be asked to select the most appropriate procedure for a given task in order to reach a particular goal.

A major benefit of Sugrue"s model is that it can easily be used to classify questions. The model allows the use of different assessment reviewers for one assessment, even if the reviewers have little subject knowledge. 
Two reviewers categorized the questions in the final exam separately. After that, items that were differently classified were discussed until a clear consensus was reached. Finally, 17 questions were classified as being at the concepts? level, 11 questions at the "principles' level and 12 questions at the application' level.

Levels in the knowledge structure

\begin{tabular}{ll}
\hline Concepts & $\begin{array}{l}\text { Select examples of concepts } \\
\text { Distinguish between examples that are and are not instances of the } \\
\text { concept of interest }\end{array}$ \\
\hline Principles & $\begin{array}{l}\text { Select best/similar/dissimilar problems } \\
\text { Select best prediction } \\
\text { Select best explanation for event }\end{array}$ \\
\hline Application & $\begin{array}{l}\text { Select correct procedure for identifying instances } \\
\text { Select most appropriate procedure to change the state of aconcept } \\
\text { by manipulating another }\end{array}$
\end{tabular}

Figure 1. Construct-by-format matrix for measuring constructs related to the knowledge structure with selection-formatted questions (after Sugrue, 1995).

\section{Procedure}

Students were asked to complete the 2F-SPQ-R questionnaire during one of the tutorial sessions near the end of a second year law course. The final exam was administered one week after the end of the course.

\section{Results}

Results were plotted and analysed by means of descriptive statistics for the measures used in the present study and by correlation analysis to probe into the relationships between students' approaches to learning and the different components of problem solving measured within the final exam.

Table 1. Descriptive statistics for the main measures used

\begin{tabular}{lll}
\hline Variable & $\mathrm{M}$ & $S D$ \\
\hline Deep approach & 2.99 & 0.51 \\
Surface approach & 2.21 & 0.59 \\
Concepts mark & $12.60(74.12 \%)$ & 2.27 \\
Principles mark & $7.24(65.82 \%)$ & 2.01 \\
Application mark & $7.52(62.67 \%)$ & 1.82 \\
Total mc-exam mark & $27.36(68.40 \%)$ & 4.91 \\
\hline
\end{tabular}

Table 1 presents descriptive statistics for the measures used in the present study. Students' scores for deep approaches were higher than their scores for 
surface approaches in our sample. Students had highest average scores for the questions measuring concepts ( $74.12 \%$ of the questions correct). The second highest scores were obtained for questions measuring principles $(65.82 \%$ of the questions correct). The questions measuring application had the lowest scores ( $62.67 \%$ of the questions correct).

From the plot in Figure 2, it becomes clear that most students fitted into two groups: A group of students with high scores for deep approach and low scores for surface approach and a group with low scores for both the deep and surface approach. Very few students employed high levels of both deep and surface approaches to learning. The group of students that had high scores for the surface approach and low scores for the deep approach to learning is also small.

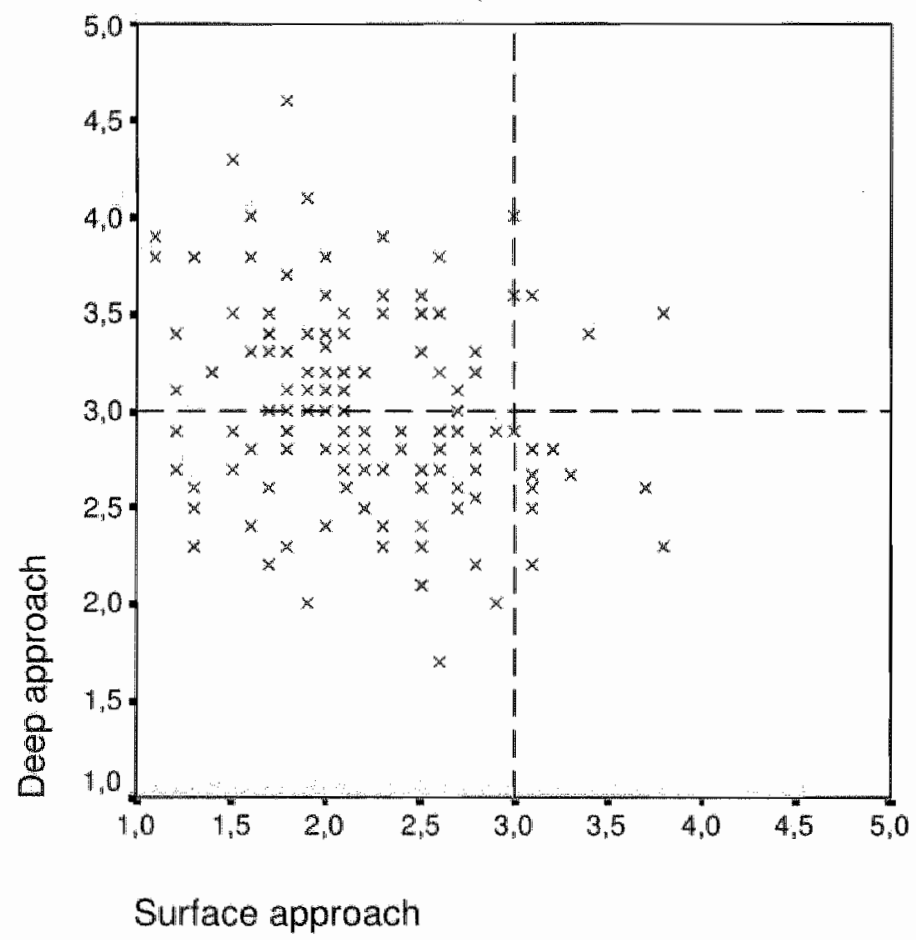

Figure 2: Plot of study appronches

Further analysis indicated that for the surface approach to learning, the mean score of women $(\mathrm{M}=2.07, S D=0.59)$ differs significantly from men's score $(\mathrm{M}=2.43, S D=0.53, \mathrm{~F}(1,129)=12.03, p<0.01)$. Also, the deep approach to learning is significantly related to students" ages: the older the students, the more deep approaches to learning are used $(r=0.22, p=0.01)$.

The correlations of the main variables used in this study are presented in Table 2. The use of the deep approach is positively correlated with higher marks for questions asking for understanding of principles that link concepts, but negatively with questions measuring understanding of these concepts and also negatively with 
questions measuring the linking of concepts and principles to conditions and procedures for application. The use of surface approaches is negatively courelated with questions asking for the understanding of concepts and with questions measuring understanding principles that link concepts. Questions measuring 'application' are positively correlated with surface approaches to learning. Nevertheless, none of these correlations are significant. Both deep and surface approaches to learning are negatively (but not statistically significantly) correlated with the total exam grade. The interrelationships between the three categories of measured components of problem solving and the total exam grade are all high and statistically significant.

Table 2. Correlations among the measures used in the present study

\begin{tabular}{|c|c|c|c|c|c|c|}
\hline Variable & 1 & 2 & 3 & 4 & 5 & 6 \\
\hline 1. Deep approach & 1.00 & & & & & \\
\hline 2. Surface approach & $-.232^{* 4}$ & 1.00 & & & & \\
\hline 3. Concepts mark & -.031 & -.161 & 1.00 & & & \\
\hline 4. Principles mark & .040 & -.119 & $.585^{8.5}$ & 1.00 & & \\
\hline 5. Application mark & -.088 & .020 & $.366^{6 x}$ & $446^{* 4}$ & 1.00 & \\
\hline 6. Total mc-exam & -.031 & -.116 & $.837^{*}$ & $.845^{* .4}$ & $.722^{* \alpha}$ & 1.00 \\
\hline
\end{tabular}

Correlation is significant at the 0.01 level

To conclude, neither students" final exam grades, nor their sub-results on questions in the exam asking for different components of problem solving, are significantly related to the extent to which they use either deep or surface approaches to learning.

\section{Discussion}

In this chapter we wanted to gain more insight into the relationships between students' approaches to learning and the different components of problem solving that were being measured using a multiple choice assessment. The students in our sample showed slightly higher scores for a deep approach than for a surface approach to learning. However, plotting students' approaches to learning indicated that a lot of students had low scores for both deep and surface approaches. Further analysis indicated that male students adopted a significantly higher level of surface approaches and that older students adopted significantly deeper approaches to learning. The first contradicts prior research by Richardson (1993), which showed no consistent evidence of significant differences between men's and women's approaches to learning. The latter is in line with Richardson's later (1995) research which indicated that older students are more meaning oriented when studying. The results of our correlational analysis indicated no relationships between students" approaches to learning and the components of problem solving being measured within the multiple choice assessment. From our data, it is impossible to associate the expected employment of deep learning approaches with higher assessment 
outcomes. The view that within the same question format (i.e. multiple choice questions), students with different approaches to learning would score differently on questions measuring different components of problem solving is also not supported.

Our results are in line with those of Minbashian et al. (2004): Namely, there is no evidence that a deep approach to learning would be more effective for questions assessing more complex components of problem solving. One of the explanations they give is that the wording of the questions (from what we deduced by means of Sugrue's $(1993,1995)$ model the components of problem solving being measured) is by itself not sufficient to influence the nature of students' responses. The method of assessment probably has more influence on the way students study for, and respond to, exam questions (Minbashian et al., 2004). Related to this, students' perceptions of the method of assessment (i.e. multiple-choice questions) could be seen as a mediating factor. Scouller (1998) found that success in multiplechoice examinations was related to the perception of the questions as assessing lower levels of cognitive processes and the non-employment of deep strategies. Although we did not take students' perceptions of the assessment into account, it is possible that students do not differentiate between the different questions within the same assessment method.

Another possible explanation for the lack of clear results could be the effectiveness of the classification model. We used Sugrue's (1993, 1995) model of the cognitive components of problem solving to categorise the different questions in the multiple-choice exam, according to the three components of problem solving that were to be measured. Although the model seems clear and exhaustive for multiple-choice questions, the two assessment reviewers reported difficulties in categorizing some questions. In their opinion, questions asking for 'the reproduction of facts', although important for assessment according to most of the law teachers, at first sight had no place in the model. Since the difference between 'a concept' and 'a fact' appeared difficult to explain, after discussing these questions the reviewers agreed to classify them in the category of 'understanding concepts". Sugrue (1995) remarks that her model lends itself extremely well to domains such as science, mathematics, economics and geography, but that it might not be easy to use in other domains such as history. The reviewers' difficulties in classifying some questions indicate that law could also be added as a domain for which the model is complicated.

Another problem is that one can classify questions in terms of components of problem solving being measured but one can not be sure in a multiple-choice exam that, when a student gives the wrong answer, he fails to achieve the components of problem solving being measured by the question. When a student doesn't understand two related concepts in a familiar problem, the student will fail to select similar problems, not because (s)he doesn't understand the relationship between the two concepts, but simply because (s)he doesn't have basic understanding of the concepts. This would mean that it is very difficult to investigate the relationship between students' approaches to learning and components of problem solving being measured within a multiple-choice setting. Furthermore, it suggests that the students' answers should be the unit of analysis, rather than the questions. However, this problem could be solved in the assessment 
construction process by including a multiple-choice question for each of the three components of problem solving for each subject tested in the assessment.

As well as the method of assessment, the content and method of teaching also influence the way in which students study for and respond to exam questions (Minbashian et all, 2004). The present study was carried out within the context of a second year law course. A recent study by Mäkinen \& Olkinuora (2003) in Finland found that, in contrast to the situation in the faculty of medicine, first year law school students' study credits were negatively correlated with a deep learning orientation, whereas the grades of second year law school students were positively correlated with a deep learning orientation. Not only the content of teaching, but also the teaching method in our study, problem-based learning, must be taken into consideration. According to Biggs (2003), problem-based learning is an instructional approach that has the potential to facilitate deep approaches to learning. Although on average students had slightly higher scores for a 'deep approach" than for a "surface approach", there is no tendency towards a use of deep approaches to learning, despite the problem-based learning environment. Seemingly, the current conditions of teaching and assessment did not make all students decide that a deep approach would give the best results, as indeed it didn't. Interesting questions for future research in this respect would be what kind of influences the tutor or the tutorial group has on students' approaches to learning in problem-based learning environments. Trigwell, Prosser and Waterhouse (1999) conducted an empirical study which showed that approaches to teaching are associated with approaches to learning: Teacher-centred approaches to teaching are related to a surface approach to learning. Conversely, student-centred approaches to teaching were related to deeper approaches to learning. In legal education, the difference between 'traditional PBL tutors' and tutors adopting the 'Socratic method' is well known and could be a possible moderator of students' approaches to learning (Liddle, 1999, 2000).

The tutorial group also influences students' approaches to learning and the outcomes. A recent study by Lindblom-Ylänne, Pihlajamäki \& Kotkas (2003) showed that if students in a PBL group participate more evenly and actively in the discussions. they achieve higher grades as a group.

Finally, like gender and age, some other elements in the learningenvironment (such as the possibility students had to make three assessment tasks during the course) will have had an influence on students" approaches to learning and possibly also indirect on their final exam. More general factors such as prior academic achievement or GPA (Snelgrove \& Slater, 2003; Young, 1993, Zeegers, 2001), self-confidence (Watkins \& Biggs, 1996) and academic self-efficacy (Pintrich \& De Groot, 1990) are potential moderators in the relation between students" approaches to learning and students" quantitative learning outcomes which should be subject of future research. 
References

Biggs, J. (1987). Student approaches to learning and studying. Melbourne: Australian Council for Educational Research.

Biggs, J. (1993). What do inventories of students learning processes really measure? A theoretical review and clarification. British Joumal of Educational Psychology, 63, 3-19.

Biggs, J. (2003). Teaching for quality learning at university (second edition). Buckingham: Open University Press.

Biggs, J., \& Collis, K. (1982). Evaluating the quality of learning: The SOLO taronomy. New York: Academic Press.

Biggs, J., Kember, D., \& Leung D.Y.P. (2001). The revised two-factor study process questionnaire: R-SPQ-2F. British Journal of Educational Psychology, 71, 133-149.

Browne, M.W., \& Cudeck, R. (1993). Alternative ways of assessing model fit. In K. Bollen \& R. Stine (Eds.), Testing structural equation models (pp. 136-162). Newbury Park, CA: Sage.

Crawford, K., Gordon, S., Nicholas, J., \& Prosser, M. (1998). Qualitatively different experiences of learning mathematics at university. Learning and Instruction, 8, 455-468.

De Corte, E. (1996). Instructional psychology: Overview. In E. De Corte \& F.E. Weinert (Eds.), International encyclopedia of developmental and instructional psychology (pp. 33-43). Oxford: Elsevier Science Ltd.

Dolmans, D., Wolfhagen, H., Scherpbier, A., \& van der Vleuten, C. (2003). Development of an instrument to evaluate the effectiveness of teachers in guiding small groups. Higher Education, 46 (4), 431-446.

Engel, C.E. (1997). Not just a method but a way of learning. In D. Boud \& G. Feletti (Eds.), The challenge of problem-based learning (2nd ed., pp.1727). London: Kogan Page.

Entwislte, N. (1991). Approaches to learning and perceptions of the learning environment. Higher Education, 22, 201-204.

Entwistle, N., \& Ramsden, P. (1983). Understanding student learning. London: Croom Helm.

Entwistle, N., McCune, V., \& Hounsell, J. (2003). Investigating ways of enhancing university teaching-learning environments: Measuring students* approaches to studying and perceptions of teaching. In E. De Corte, L. Verschaffel, N. Entwisle \& J. van Merriënboer (Eds.), Powerful learning environments: Unravelling basic components and dimensions. Amsterdam: Pergamon, Elsevier Science.

Entwistle, N., \& Tait, H. (1994). The revised approaches to studying inventory. University of Edinburgh: Centre for Research into Learning and Instruction.

Gagné, E.D., Yekovich, C.W., \& Yekovich, F.R. (1993). The cognitive psychology of school learning (second edition). New York: HarperCollins College publishers. 
Gijselaers, W. (1995). Perspectives on problem-based learning: In W. Gijselaers, D. Tempelaar, P. Keizer, J. Blommaert, E. Bernard \& H.Kasper (Red.), Educational innovation in economics and busimess administration: The case of problen-based learning (pp 39 - 52). Norwell, Mass.: Kluwer.

Glaser, R., Raghavan, K., Baxter, G.P. (1992). Cognitive theory as the basis for design of innovative assessment: Design characteristics of science assessments (CSE Tech. Rep. No. 349). Los Angeles: University of California, National Center for Research on Evaluation, Standards, and Student Testing.

Guay, F., Marsh, H.W., \& Boivin, M. (2003). Academic self-concept and academic achievement: Developmentall perspectives on their causal ordering. Joumal of Educational Psychology, 95 (1), 124-136.

Hazel, E., Prosser, M., \& Trigwell, K. (1996). Student learning of biology concepts in different university contexts. Research and Development in Higher Education, 19, 323-326.

Kember, D., \& Leung, D.Y.P. (1998). The dimensionality of approaches to learning: An investigation with confirmatory factor analysis on the structure of the SPQ and LPQ. British Journal of Educational Psychology, $68,395-407$.

Leung, M., \& Chan, K. (2001, december). Construct validity and psychometric properties of the revised two-factor study process questionnaire (R-SPQ$2 F)$ in the Hong Kong context. Paper presented at the AARE conference, Perth, Australia.

Liddle, M. (1999). Problem based learning in Law: Student attitudes. In J. Marsh (Ed.) Implementing problem based learning project: Proceedings of the first Asia Pacific conference on problem-based learning (pp.235-240). Hong Kong: The university grants committee of Hong Kong, teaching development project.

Liddle, M. (2000). Student attitudes toward Problem-based learning in law. Journal on Excellence in College Teaching, II(2), 163-190.

Lindblom-Ylänne, S., Pihlajamäki, H., \& Kotkas, T. (2003). What makes a student group successful? Student-student and student-teacher interaction in a problem-based learning environment. Learning Environments Research, 6 (1), 59-76.

Mäkinen, J. (2003). University students" general study orientations. Theoretical background, measurements, and practical implications [dissertation]. Turku: Turun Yliopisto.

Mäkinen, J., \& Olkinuora, E. (2003, August). Personal experience of studying and study success: A three-years follow-up study of university students. Paper presented at the $10^{\text {th }}$ biannual conference of the European Association for Research on Learning and Instruction (EARLL), Padova, Italy.

Marton, F. (1981). Phenomenographic: Describing conceptions of learning. International Journal of Educational Research, 19, 277-300.

Marton, F., \& Säljö, R. (1976). On qualitative differences in learning - I: Outcome and process. British Journal of Educational Psychology, 46, 4-11. 
Minbashian, A., Huon, G.F., \& Bird, K.D. (2004). Approaches to studying and academic performance in short-essay exams. Higher Education, 47 (2), $161-176$.

O'Neil, H.F., \& Schacter, J. (1997). Test specifications for problem-solving assessment (CSE Tech. Rep. No. 463). Los Angeles: University of California, National Center for Research on Evaluation, Standards, and Student Testing.

Pintrich, P.R., \& De Groot, E.V. (1990). Motivation and self regulated learning components of classroom academic performance. Joumal of Educational Psychology, 82 (1), 33-40.

Poikela, E., \& Poikela, S. (1997). Conceptions of learning and knowledge - impacts on the implementation of problem-based learning. Zeitschrift fur Hochschuldidactic, $21(1), 8-21$.

Prosser, M., \& Trigwell, K. (Eds.) (1999). Understanding learning and teaching. The experience in higher education. Buckingham: The society for research into higher education.

Richardson, J.T.E. (1993). Gender differences in response to the approaches to studying inventory. Studies in Higher Education, 18 (1), 3-13.

Richardson, J.T.E. (1995) Mature students in higher education: II. An investigation of approaches to studying and academic performance. Studies in Higher Education, 20, 1, 5-17.

Schoenfeld, A.H. (1985). Mathematical problem solving. San Diego, CA: Academic Press.

Scouller, K. \& Prosser, M. (1994). Students' experiences in studying for multiple choice question examinations. Studies in Higher Education, 19, 267-279.

Scouller, K. (1998). The influence of assessment method on students" learning approaches: Multiple choice question examination versus assignment essay. Higher Education, 35, 453-472.

Segers, M. (1997). An alternative for assessing problem-solving skills: The overall test. Studies in Educational Evaluation, 23 (4), 373-398.

Smith, M.U. (199l). Toward a unified theory of problem-solving: Views from the content domains. Hilsdale, NJ: Lawrence Erlbaum.

Snelgrove, S., \& Slater, J. (2003). Approaches to learning: Psychometric testing of a study process questionnaire. Journal of Advanced Nursing, 43 (5), 496505 .

Sugrue, B. (1993). Specifications for the design of problem-solving assessments in science. Project 2.1 designs for assessing individual and group problemsolving. Los Angeles: National Centre for Research on Evaluation, Standards, and Student Testing.

Sugrue, B. (1995). A theory-based framework for assessing domain-specific problem solving ability. Educational Measurement: Issues and Practice (14) 3, 29-36.

Tenenbaum, G., Naidu, S., Jegede, O., \& Austin, J. (2001). Constructivist pedagogy in conventional on-campus and distance learning practice: An exploratory investigation. Learning and Instruction, 11, 87-111. 
Trigwell, K., \& Prosser, M. (1991). Relating approaches to study and the quality of learning outcomes at the course level. British Joumal of Educational Psychology, 61, 265-275.

Trigwell, K., Prosser, M., \& Waterhouse, F. (1999). Relations between teachers" approaches to teaching and students' approach to learning. Higher Education, 37, 57-70.

Van Rossum, E.J., \& Schenk, S.M. (1984). The relationship between learning conception, study strategy and outcome. British Joumal of Educational Psychology, 54, 73-83.

Watkins, D., \& Regmi, M. (1996). Toward the cross-cultural validation of a Western model of student approaches to learning. Joumal of CrossCultural Psychology, 27, 547-560.

Watkins, D. (2001). Correlates of approaches to learning: A cross-cultural metaanalysis. In R.J. Sternberg \& L. Zhang (Eds.), Perspectives on thinking, leaming, and cognitive styles (pp. 165-196). London: Lawrence Erlbaum Associates.

Watkins, D., \& Biggs, J. (Eds.) (1996). The Chinese learner: Cultural, psychological and contextual influences. Hong Kong: University of Hong Kong, Comparative Education Research Centre.

Young, J.W. (1993). Grade adjustment methods. Review of Educational Research, $63(2), 151-165$.

Zeegers, P. (2001). Student learning in science: A longitudinal study. British Journal of Educational Psychology, 71, 115-132.

Zhang, L.F. (2000). University students' learning approaches in three cultures: An investigation of Biggs 3P model. Journal of Psychology, 134, 37-56. 


\section{Chapter 4}

\section{Effects of problem-based learning: A meta-analysis ${ }^{3}$}

\section{Abstract}

This meta-analysis has two aims: (a) To address the main effects of problem based learning on two categories of outcomes; knowledge and skills (i.e. application of knowledge) and (b) to address potential moderators of the effect of problem based learning (PBL). The meta-analysis reveals that there is a robust positive effect from PBL on the skills of students. This is shown by either the vote count as well as by the combined effect size. Also no single study reported negative effects. A tendency to negative results is discerned when considering the effect of PBL on the knowledge of students. The combined effect size is significantly negative. However, this result is strongly influenced by two studies and the vote count does not reach a significant level. It is concluded that the combined effect size for the effect on knowledge is non-robust. As possible moderators of PBL effects, methodological factors, expertise-level of students, retention period and type of assessment method were investigated. This moderator analysis shows that the effect of PBL on knowledge is diminishing if the quality of the research method is categorised as higher and that the negative effect of PBL on knowledge in a curriculum-wide implementation of PBL decreases within ti single course. Both for knowledge- and skills-related outcomes the expertise-level of the student is associated with the variation in effect sizes. However, only the results for skills give a consistent positive picture. For knowledge-related outcomes the results suggest that the differences encountered in the first and the second year disappear later on. Related to the retention period, students in PBL gained slightly less knowledge, but remember more of the acquired knowledge. Finally, it is suggested that the extent to which the method of assessment is capable of evaluating the skills of the students is related to the ascertained effect of PBL.

\footnotetext{
${ }^{3}$ Based on: Dochy, F., Segers, M., Van den Bossche, P. \& Gijbels, D. (2003). Heffects of problem" bused learning: A Meta-analysis. Learning and Instruction, 5 (13), 533-568.
} 


\section{Introduction}

The complexity of today's society is characterised by an infinite, dynamic and changing mass of information, the massive use of the internet, multimedia and educationall technology, a rapid changing labor market demanding a more flexible labor force that is directed towards a growing proportion of knowledge-intensive work in teams and lifelong learning (Nonaka \& Takeuchi, 1995; Quinn,1992; Tynjälä, 1999). As a consequence, today's information community expects graduates not only to have a specific knowledge base but also to be able to apply this knowledge to solve complex problems in an efficient way (Engel, 1991; Poikela \& Poikela, 1997; Segers, 1996). Educational research has shown that successful problem solvers possess an organised and flexible knowledge base and master the skills to apply this knowledge for problem solving (Chi, Glaser \& Rees, 1982).

Educational practices have been criticised for not developing these prerequisites of professional expertise (Mandl, Gruber \& Renkl, 1996). An important challenge for today's higher education is the development and implementation of instructional practices that will foster in students the skill to apply knowledge efficiently, For this purpose references are made to the design of 'powerful learning environments' (De Corte, 1990a, 1990b; Honebein, Duffy \& Fishman, 1993; Tynjälä, 1999). Such powerful learning environments should support the constructive cumulative, goal-oriented acquisition processes in all students, they should allow for the flexible adaptation of the instructional support, especially the balance between self-discovery and direct instruction (De Corte, 1995). Further, such environments should use as much as possible representative authentic, real life contexts that have personal meaning for the learners, that offer opportunities for distributed and co-operative learning through social interaction. Finally, powerful learning environments should provide possibilities to acquire general learning and thinking skills (including heuristic methods, metacognitive knowledge and strategies (Boekaerts, 1999a, 1999b)) embedded in different subject-matter (De Corte, 1995) and assessment should be congruent with the learning.

Based on recent insights in cognitive psychology and instructional science (Poikela \& Poikela, 1997), many educational innovations are implemented in the hope of achieving the aforementioned goals more effectively (Segers, 1996) educational achievements that might become regular issues in the future for decades. Already within several international evaluation projects, such as TIMSS or the 2003 OECD PISA international survey, it is seen that complex problem solving will be directly assessed (Salganik, Rychen, Moser, \& Konstant, 1999). Also within the DeSeCo project of the OECD, different types of competencies are developed (that might e.g. require new educational learning environments) (Owen, Stephens, Moskowitz \& Guillermo, 2000). One of these innovations is problem-based learning (PBL) (Barrows, 1984). If one ponders the implementation of PBL, a major question is: Do students from PBL reach the goals (knowledge and skills, i.e., 
knowledge application) in a more effective way than students who receive conventional instruction?

Albanese and Mitchell (1993, p.56) pose this question as follows: "Stated bluntly, if problem-based learning is simply another route to achieving the same product, why bother with the expense and effort of undertaking a painful curriculum revision?" In order to find an answer to this question, a meta-analysis was conducted.

\section{Problem-based learning versus conventional lecture-based instruction}

Although new in some aspects, problem-based learning (PBL) is generally based on ideas that originated earlier and have been nurtured by different researchers (Ausubel, Novak \& Hanesian, 1978; Bruner, 1959, 1961; Dewey, 1910, 1944; Piaget, 1954; Rogers, 1969). PBL, as it is known today, originated in the 1950 s and 1960s. It grew from dissatisfaction with the common medical education practices in Canada (Barrows, 1996; Neufield \& Barrows, 1974). Nowadays PBL is developed and implemented in a wide range of domains. In spite of the many variations of $\mathrm{PBL}$ that have evolved, a basic definition is needed to which other educational methods can be compared. Six core characteristics of PBL are distinguished in the core model described by Barrows (1996). The first characteristic is that learning needs to be student-centred. Secondly, learning has to occur in small student groups under the guidance of a tutor. The third characteristic refers to the tutor as a facilitator or guide. Fourthly, authentic problems are primarily encountered in the learning sequence, before any preparation or study has occurred. Fifthly, the problems encountered are used as a tool to achieve the required knowledge and the problem-solving skills necessary to eventually solve the problem. Finally, new information needs to be acquired through self-directed learning. It is generally recognised that a seventh characteristic should be added: Essential for PBL is that students learn by analysing and solving representative problems. Consequently, a valid assessment system evaluates students' competencies with an instrument based on real life, i.e. authentic problems (Baxter \& Shavelson, 1994; Birenbaum, 1996; Shavelson, Gao \& Baxter, 1996). The assessment of the application of knowledge when solving problems is the heart of the matter. Therefore, test items require examinees to apply their knowledge to commonly occurring and important problem-solving situations (Segers, Dochy \& De Corte, 1999).

It should be noted that just as the definition of PBL is ambiguous, the definition of what constitutes a conventional lecture-based program is also ambiguous. For the most part, conventional instruction is marked by large group lectures and instructor-provided learning objectives and assignments (Albanese \& Mitchell, 1993). 


\section{Research questions}

Two sets of research questions guided this meta-analysis. First, we addressed the main effects of PBL on two broad categories of outcomes: knowledge and skills (i.e, application of knowledge). Secondly, potential moderators of the effect of PBL are addressed. A first category of moderators are design aspects of the reviewed research. In the second category of moderators, we examined whether the effect of PBL differs according to various levels of student expertise. Thirdly, we looked more closely at different types of assessment methods. Fourthly, we investigated the influence of the insertion of a retention period.

\section{Method}

\section{Criteria for inclusion}

Before searching the literature for work pertaining to the effects of PBL, we determined the criteria for inclusion in our analysis.

1. The work had to be empirical. Although non empirical literature and literature reviews were selected as sources of relevant research, this literature was not included in the analysis.

2. The characteristics of the learning environment had to fit the previously described core model of PBL.

3. The dependent variables used in the study had to be an operationalisation of the knowledge and/or skills (i.e., knowledge application) of the students.

4. The subjects of study had to be students in higher education.

5. To maximise ecological validity, the study had to be conducted in a real-life classroom or programmatic setting rather than under more controlled laboratory conditions.

\section{Literature search}

The review and integration of research literature begins with the identification of the literature. Locating studies is the stage at which the most serious form of bias enters a meta-analysis (Glass, McGaw \& Smith, 1981): "How one searches determines what one finds; and what one finds is the basis of the conclusions of one's integration" (Glass, 1976, p. 6).

The best protection against this source of bias is a thorough description of the procedure used to locate the studies.

A first literature search was started in 1997. A wide variety of computerised databases were screened: the Educational Resources Information Center (ERIC) catalogue, PsycLIT, ADION, LIBIS. Also, the Current Contents 
(for Social Sciences) was searched. The following keywords were used: problemsolving, learning, problem-based leaming, higher education, research, and review. The literature was selected based on reading the abstracts. This reading resulted in the selection of 14 publications that met the above criteria. Next, we employed the 'snowball method" and reviewed the references in the selected articles for additional works. Review articles and theoretical overviews were also gathered to check their references. This method yielded 17 new studies.

A second literature search, started in 1999, followed the same procedure. In addition we contacted several researchers active in the field of PBL and asked them to provide relevant studies or to identify additional sources of studies. This second search yielded 9 different new studies.

\section{Coding study characteristics}

Using other literature reviews as a guide (Albanese \& Mitchell, 1993; Dochy, Segers \& Buehl, 1999; Vernon \& Blake, 1993), we defined the characteristics central to our review and analysed the articles we selected on the basis of these characteristics. Specifically, the following information was recorded in tables:
a) first author and the year of publication;
b) study domain;
c) number of subjects;
d) dependent variable (i.e., method of assessment) and independent variable;
e) principal outcomes of the research; and
f) method of analysis and the statistical values.

As a result of a first analysis of the studies, it became clear that other variables could also be of importance. The coding sheet was completed with the following information:

g) the year of the study in which the assessment of the dependent variable was clone;

h) if there was a retention period;

i) the name of the PBL institute.

With respect to the dependent variable, we must note that only the outcomes related to knowledge and skills (i.e., knowledge application) were coded. Some studies have examined other effects of PBL, but those were not included in the analysis.

The dependent variable was used to distinguish test that assess knowledge from tests that assess knowledge application. The following operational definitions were used in making this distinction. A knowledge test primarily measures the knowledge of facts and the meaning of concepts and principles (Segers, 1997). This type of knowledge is often defined as declarative knowledge (Dochy \& 
Alexander, 1995). A test that assesses skills (i.e. knowledge application) measures to what extent students can apply their knowledge (Glaser, 1990). It is important to remark that there is a continum between knowledge and skills rather than a dichotony. Some studies treat both aspects. In coding those studies, both aspects were separated and categorised under different headings.

Two condensed tables were created (one for knowledge and one for skills) that contain potential critical characteristics. These tables are included at the end of this dissertation in Appendices A and B (legend in Appendix C). In the tables, the statistical values were, as much as possible, summarised and reported as effect sizes (ES) and p-values.

\section{Synthesising research}

There are three methods to review literature: narrative reviews, quantitative methods, and statistical meta-analysis. In a narrative review, the author tries to make sense of the literature in a systematic and creative way (Van IJzendoom, 1997). Quantitative methods utilise elementary mathematical procedures for synthesising research studies (e.g., counting frequencies into box scores). These methods are more objective but give less in-depth information than a narrative review (Dochy, Segers \& Buehl, 1999). Glass (1976) systematised the approach of quantitative procedures and introduced the term meta-analysis: The analysis of analyses, i.e., the statistical analysis of a large collection of analysis results from individual studies for the purpose of integrating the findings (Kulik \& Kullik, 1989)

For our purposes, a statistical meta-analysis was conducted. This analysis was supplemented by more inclusive vote counts and the associated sign test.

\section{Vote-counting methods}

The simplest and most conservative methods for combining results of independent comparisons are the vote-counting methods. Only limited information is necessary. To do a vote count of directional results, the reviewer must count the number of comparisons that report significant results in the positive direction and compare this to the number of comparisons reporting significant results in the negative direction (Cooper, 1989). Once counted, a sign test is performed to discover if the cumulative results suggest that one direction occurs more frequently than chance would suggest (Cooper, 1989; Hunter \& Schmidt, 1990). In performing this procedure, one assumes that under the null hypothesis of no relation in the population of any study, the frequency of significant positive results and negative results are expected to be equal (Hedges \& Olkin, 1980). In performing the vote count, the number of experiments with significant positive and negative findings was counted. If one study contained multiple experiments, they were all counted. 
A statistical meta-analysis is the quantitative accumulation and analysis of effect sizes and other descriptive statistics across studies (Hunter \& Schmidt, 1990).

\section{Metric for expressing effect sizes.}

The metric that we used to estimate and describe the effects of PBL on knowledge and skills was the standardised mean difference ( $d$-index) effeet size. This metric is appropriate when the means of two groups are being compared (Cooper, 1989, Glass et al., 1981). The $d$-index expresses the distance between the two group means in terms of their common standard deviation. This common standard deviation is calculated by using the standard deviation of the control group since it is not affected by the treatment.

\section{Identifying independent hypothesis tests.}

One of the assumptions underlying meta-analysis is that effects are independent from one another. A problem arising from calculating average effect sizes is deciding what will be considered as an independent estimate of effect when a single study reports multiple outcomes. This meta-analysis used the shifting units method from Cooper (1989). Each statistical test is initially coded as if it were an independent event. However, when examining potential moderators of the overall relation, a study's results are only aggregated within the separate categories of the influencing variable. This strategy is a compromise that allows studies to retain their maximum information value, while keeping to a minimum any violation of the assumption of independence of hypothesis tests.

\section{Combining effect sizes across studies.}

Once an effect size had been calculated for each study or comparison, the effects testing the same hypothesis were averaged. Unweighted and weighted procedures were used. In the unweighted procedure, each effect size was weighted equally in calculating the average effect. In the weighted procedure, more weight is given to effect sizes with larger samples (factor $w=$ inverse of the variance), based on the assumption that the larger samples more closely approximate actual effects (Cooper, 1989; Hedges \& Olkin, 1985). These weighted combined effect sizes were tested for statistical significance by calculating the $95 \%$ confidence interval (Cooper, 1989).

\section{Analysing variance in effect sizes across studies:}

The last step was to examine the variability of the effect sizes via a homogeneity analysis (Cooper, 1989; Hedges \& Olkin, 1985; Hunter \& Schmidt, 1990). This can lead to a search for potential moderators. So, we can gain insight into the factors that affect relationship strengths even though these factors may have never been studied in a single experiment (Cooper, 1989).

Homogeneity analysis compares the variance exhibited by a set of effect sizes with the variance expected by sampling error. If the result of homogeneity 
andysis suggests that the variance in a set of effect sizes can be attributed to sampling error alone, one can assume the data represent a population of students (Hunter, Schmidt \&acksoni, 1982).

To test whether a set of effect sizes is homogeneous, a Qt statistic (Chisquare distribution, $\mathrm{N}-1$ degrees of freedom) is computed. A statistically significant Qt suggests the need for further grouping of the data. The between-groups statistic (Qb) is used to test whether the average effect of the grouping is homogeneous. A statistically significant $\mathrm{Qb}$ indicates that the grouping factor contributes to the variance in effect sizes, in other words, the grouping factor has a significant effect on the outcome measure analysed (Springer, Stanne \& Donovan, 1999).

\section{Results}

From the studies that met the criteria for inclusion, 33 studies $(76.7 \%)$ presented data on knowledge effects and 25 studies $(58.1 \%)$ reported data on effects concerning the application of knowledge. These percentages add up to more than 100 since several studies presented outcomes of more than one category.

\section{Main effects of PBL}

The main effect of PBL on knowledge and skills is differentiated. The results of the analysis are summarised in Table 1. In general, the results of both the vote count and the combined effect size were statistically significant. These results suggest that students in PBL are better in applying their knowledge (skills). None of the studies reported significant negative findings.

Table 1: Main effects of PBL

\begin{tabular}{|c|c|c|c|c|c|c|}
\hline \multirow{2}{*}{ Outcome } & \multirow{2}{*}{$\begin{array}{c}\text { Sigin. } \\
+\end{array}$} & \multirow{2}{*}{ Sign. } & \multirow{2}{*}{$\begin{array}{c}\text { Studies } \\
\text { N }\end{array}$} & \multicolumn{2}{|c|}{ Average ES } & \multirow[t]{2}{*}{ Qt } \\
\hline & & & & Unweighned & Weighted (C195\%) & \\
\hline Knowledge & 7 & 15 & 18 & -0.776 & $-0.223(+1-0.058)$ & $\begin{array}{l}1379.6 \\
(p=0.000)\end{array}$ \\
\hline Skills & 14 & $0^{*}$ & 17 & 40.658 & $+0.460(+1-0.058)$ & $\begin{array}{l}57.1 \\
(p=0.000)\end{array}$ \\
\hline
\end{tabular}

*zo Two-sided sign-test is significant at the $5 \%$ level

Note: All weighted efrect sizes are statistically significant.

Sign. $+/ \cdots$ : number of studies with a significance (at the $5 \%$ level) positive / negative finding.

Srudies $N$ : the number of totall nonindependent outcomes measured

However, table 1 would indicate that PBL has a negative effect on the knowledge base of the students, compared with the knowledge of students in a conventional learning environment. The vote count shows a negative tendency with 14 studies yielding a significant negative effect and only 7 studies yielding a significant positive effect. This negative effect becomes significant for the weighted combined effect size. However, this significant negative result is mainly due to two 
outliers (Eisenstaedt, Bary \& Glanz, 1990; Baca, Mennin, Kaufman \& Moore-West, 1990). When these two studies are left aside, the combined effect sizes approaches zero (unweighted $\mathrm{ES}=-0.051$; weighted $\mathrm{ES}=-0.107$ ).

\section{Distribution of effect sizes}

The results of the homogeneity analysis reported in Table 1 suggest that further grouping of the knowledge and skills data is necessary to understand the moderators of the effects of PBL. As indicated by statistically significant Qt statistics, one or more factors other than chance or sampling error account for the heterogeneous distribution of effect sizes for knowledge and skills.

\section{Moderators of $P B L$}

\section{Methodological factors}

A statistical meta-analysis investigates the methodological differences between studies a posteriori (Cooper, 1989; Hunter \& Schmidt, 1990). This question about methodological differences will be handled through two different aspects: the way in which the comparison between PBL and the conventional learning environment is operationalised (research design) and the scope of implementation of PBL.

\section{Research design.}

The studies included in the meta-analysis can all be categorised as quasiexperimental (cf. criteria for inclusion). Studies with a randomised design deliver the most trustworthy data. Studies based on a comparison between different institutes or between different tracks are less reliable because randomisation is not guaranteed. Some studies attempt to compensate for this shortcoming by controlling (e.g., Antepoh! \& Herzig, 1997; Lewis \& Tamblyn, 1987) or matching the subjects (Anthepohl \& Herzig, 1997; Baca, Mennin, Kaufman \& Moore-West, 1990) for substantial variables. Most problematic are those studies having a historical design (Martenson, Eriksson \& Ingelman-Sundberg, 1985). Some studies comparing the PBL-outcomes with national means were also included.

The results of the homogeneity analysis reported in Table 2 suggest no significant variation in effect sizes for knowledge-related outcomes can be attributed to method-related influences $(\mathrm{Qb}=7.261, p=0.063)$. However, the most reliable comparisons (random) suggest that there is almost no negative effect on knowledge acquisition.

Contrary to the data conceming knowledge, the variation in effect sizes for skills outcomes was associated with the methodological factor research design $(\mathrm{Qb}=$ 7.177, $p=0.027$ ). The weighted combined effect sizes of the designs "between 
institutes" or "elective tracks" are higher than the combined effect size emanating from a historical-controllet research design.

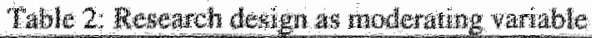

\begin{tabular}{|c|c|c|c|c|c|c|}
\hline$\therefore$ & $\begin{array}{c}\text { sigh } \\
4 \\
4\end{array}$ & Sign. & Suldes & Whenghed & $\begin{array}{l}\text { ws } \\
\text { Welghed (C) } 95 \%)\end{array}$ & Qb \\
\hline Whowhedge & & & & & & 7.261 \\
\hline Bewmern & 榤: & 3 & 2 & -3.242 & $-9049(+1-0152)^{25}$ & $(p=0.063)$ \\
\hline Romdon & 3 & 3 & 4 & -1.277 & $-9065(+1-0,197)^{13}$ & \\
\hline Hororored & 1 & 2 & 2 & $-0,680$ & $-0.202(+10082)$ & \\
\hline Eective & 3 & 6 & 10 & -0.722 & $-0.283(+40,112)$ & \\
\hline Natomal & 0 & 1 & & & & \\
\hline Suth & & & & & & 7.177 \\
\hline Betwern & 4 & 0 & 4 & 40.864 & $+0.360(+0.137)$ & $(p=0,027)$ \\
\hline Fiective & 8 & $0^{\text {特 }}$ & 10 & +0.567 & $+10.317(+/-0.103)$ & \\
\hline Historical & 2 & 0 & 3 & +0.685 & $+0.173(+1-0.083)$ & \\
\hline
\end{tabular}

Wwo-sided sign-tert is significm at the So level

Note : Untess noted "all weighted effect sizes are statichaly signficant

\section{Scope of implementation.}

PBL is implemented in environments varying in scope from one single course (e.g., Lewis Tamblyn, 1987) up to an entire curriculum (e.g., Kaufman et al., 1989). Whille the impact of PBL as a curriculum is certainly going to be more profound, a single course can offer a more controlled enviromment to examine the specific effects of PBL (Albanese \& Mitchell, 1993; Schmidt, 1990).

Table 3: Scope of limplementation as moderating variable

\begin{tabular}{|c|c|c|c|c|c|c|}
\hline & \multirow{2}{*}{$\begin{array}{c}\text { Sign. } \\
+ \\
\end{array}$} & \multirow{2}{*}{ Sign. } & \multirow{2}{*}{$\begin{array}{c}\text { Strudies } \\
\text { N }\end{array}$} & \multicolumn{2}{|c|}{ Combined ES } & \multirow[t]{2}{*}{$Q b$} \\
\hline & & & & Unweighted & Weighted (CI 95\%) & \\
\hline Knowledge & & & & & & 13.150 \\
\hline Single course & 6 & 4 & 9 & -0.578 & $-0.113(+/ 10.071)$ & $(p=0.001)$ \\
\hline Currictum & 1 & $10^{*}$ & 9 & -0.974 & $-0.339(+/-0.099)$ & \\
\hline Skills & & & & & & 4.213 \\
\hline Single course & 4 & $0^{*}$ & 6 & +0.636 & $+0.187(+/-0.081)$ & $(p=0.120)$ \\
\hline Curriculum & 9 & $0^{*}$ & 10 & +0.660 & $+0.311(t-0.085)$ & \\
\hline
\end{tabular}

Table 3 presents the result of the analysis with scope of implementation as the moderating variable. No significantly different effects on achievement of skills were recognised between a single course and a curriculum-wide implementation of PBL $(Q b=4.213, p=0.120)$. In both the single course as the curriculum-wide implementation a clear positive effect (see vote count and combined effect sizes) is established. However, the effect in a curriculum-wide implementation ( $E S=0.311$ ) is somewhat larger than the effect in a single-course $(\mathrm{ES}=0.187)$.

The analysis of studies examining the effect on knowledge shows that scope of implementation is associated with the variation in effect sizes $(\mathrm{Qb}=$ 13.150, $p=0.001$ ). If PBL is implemented in a complete curriculum, there is a significant negative effect (see vote count and $E S=-0.339$ ). Within a single-course design, the negative effect becomes smaller $(E S=0.113$ ) and the vote-counting 
suggests a tendency towards more positive effects (6 positive and 4 negative significant effects).

\section{Expertise-level of students}

The analysis of the moderators of PBL suggests that significant variation in effect sizes exists for knowledge $(\mathrm{Qb}=125.845, p=.000)$ and skills $(\mathrm{Qb}=20.63, p=$ .009). The related outcomes are associated with the expertise level of the students. The results of these analyses are summarised in Table 4 . It should be noted that when conventional curricula are compared with $\mathrm{PBL}$, the conventional curriculum tends to be characterised by a two-year basic science segment composed of formal courses drawn from various basic disciplines (Albanese \& Mitchell, 1993; Richards. et al., 1996). On the other hand, in a problem-based leaming environment, the students are immediately compelled to apply their knowledge to the problems that they confront. After the first two years of the curriculum, the conventional curriculum emphasises the application of knowledge. The conventional and the problem-based learning environment become more similar (Richards et al., 1996).

Table 4: Expertise-level of students as moderating variable

\begin{tabular}{|c|c|c|c|c|c|c|}
\hline & \multirow{2}{*}{$\begin{array}{c}\text { Sign. } \\
+ \\
\end{array}$} & \multirow{2}{*}{ Sign. } & \multirow{2}{*}{$\begin{array}{c}\text { Stundies } \\
\mathrm{N}\end{array}$} & \multicolumn{2}{|c|}{ Combined $\mathbb{E S}$} & \multirow[t]{2}{*}{ Qb } \\
\hline & & & & Unwaighted & Weighted (Cl 95\%) & \\
\hline Knowledge & & & & & & 125.845 \\
\hline 16 year & 1 & 1 & 3 & -0.205 & $-0.153(+/-0.186)^{2 \mathrm{~s}}$ & $(p=0.000)$ \\
\hline $2^{\mathrm{e}}$ year & 0 & 6 & 12 & -1.489 & $-0.315(+/-0.067)$ & \\
\hline $3^{e}$ year & 2 & 0 & 5 & +0.338 & $+0.390(+/-0.129)$ & \\
\hline $4^{\mathrm{e}}$ year & 0 & 1 & 2 & -1.009 & $-0.138(+/-0.199)^{845}$ & \\
\hline $5^{\circ}$ year & 0 & 0 & 1 & -0.037 & $-0.037(+/-0.233)^{145}$ & \\
\hline Last year & 0 & $4^{*}$ & 3 & -0.523 & $-0.496(+/-0.166)$ & \\
\hline All & 0 & 1 & 1 & -0.919 & $-0.919(+/-0.467)$ & \\
\hline Graduated & 2 & 0 & 4t & +0.193 & $+0.174(+1-0.204)^{115}$ & \\
\hline Skills & & & & & & 20.630 \\
\hline $\mathbb{1}^{*}$ year & 1 & 0 & 2 & +0.414 & $+0.433(+4-0.340)$ & $(p=0.009)$ \\
\hline $2^{c}$ year & 1 & 0 & 4 & +0.473 & $10.318(+/-0.325)^{1 \times 3}$ & \\
\hline $3^{4}$ year & 4 & $0^{*}$ & II & +0.280 & $+0.183(+1-0.093)$ & \\
\hline $4^{2}$ year & 1 & 0 & I & +0.238 & $+0.235(+4-0.512)^{3+1 .}$ & \\
\hline $5^{\text {e }}$ yentit & 1 & 0 & 1 & +0.732 & $+0.722(+1-0.536)$ & \\
\hline Last year & 4 & $0^{\text {ta }}$ & 3 & +0.679 & $+0.444(+1-0.174)$ & \\
\hline $\mathrm{Al}$ & 0 & 0 & 1 & +0.310 & $+0.310(+2-0.161)$ & \\
\hline Gindurated & 1 & 0 & 1. & +1.193 & $+1.271 \quad(+f-0.630)$ & \\
\hline
\end{tabular}

* = Two-sided sign-test is significant at the $5 \%$ level

Note : Unless noted ${ }^{\mathrm{ns}}$, all weighted effect sizes are statistically significant.

The differences of the effect sizes between the levels of expertise of the students are remarkable, especially for knowledge-related outcomes. In the second year $(\mathrm{ES}=-0.315)$, the negative trend of the first year $(\mathrm{ES}=-0.153)$ becomes significant. This is also shown in the vote count. The picture changes completely in the third year. In the third year, both the vote-counting method (two significant positive effects versus zero negative) and the combined effect size ( $E S=0.390$ ) suggest a positive effect. Students in the fourth year show a negative effect of PBL 
on knowledge: a negative tendency in the vote-counting method and a negative combined effect size $(E S=-0.496)$. On the contrary, this negative effect is not found for students who graduated.

These results suggest that the differences arising in the first and the second year disappear if the reproduction of knowledge is assessed when the broader context asks all the students to apply their knowledge (both in the conventional and the PBL environment). The only exception is the results in the last year of the curriculum.

The effects of PBL on skills (i.e., application of knowledge) differentiated for expertise-level of students give a rather consistent picture. On all levels, there is a strong positive effect of $\mathrm{PBL}$ on the skills of the students.

\section{Retention period}

Table 5 surmmarises the results of dividing the studies into those that have a retention period between the treatment and the test and those that do not.

If the test measures knowledge, the division leads to more homogeneous groups $(\mathrm{Qb}=28.683, p=0.000)$. The experiments with no retention period show a significant negative combined effect size (ES $=-0.209$ ). The vote count also supports this conclusion. On the other hand, experiments using a retention period have the tendency to find more positive effects.

These results suggest that students in PBL remember more of the acquired knowledge. A possible explanation is the attention on elaboration in PBL (Schmidt, 1990): Elaboration promotes the recall of declarative knowledge (Gagné, 1978; Wittrock, 1989). Although the students in PBL would have slightly less knowledge (they do not know as many facts), their knowledge has been elaborated more and consequently they have better recall of that knowledge.

Table 5: Retention period as moderating variable

\begin{tabular}{|c|c|c|c|c|c|c|}
\hline & \multirow{2}{*}{$\begin{array}{c}\text { Signn. } \\
+\quad \\
\end{array}$} & \multirow{2}{*}{ Sign. } & \multirow{2}{*}{$\begin{array}{c}\text { Studies } \\
\mathbb{N}\end{array}$} & \multicolumn{2}{|c|}{ Combined ES } & \multirow[t]{2}{*}{$\mathrm{Qb}$} \\
\hline & & & & Unweightled & Weighted (Cl 95\%) & \\
\hline Knowledge & & & & & & 28.683 \\
\hline Retention & 4. & 2 & 9 & +0.003 & $+0.139(+1-0.116)$ & $(p=0.000)$ \\
\hline No Relantion & 3 & $13^{\text {*h }}$ & 24 & -0.826 & $-0.209(+/-0.053)$ & \\
\hline Skills & & & & & & 1.474 \\
\hline Retention & 3 & 0 & 5 & +0.511 & $+0.320(+/-0.198)$ & $(p=0.223)$ \\
\hline No Ruention & 11 & 0 & 22 & +0.500 & $+0.224(+1 / 0.057)$ & \\
\hline
\end{tabular}

For tests assessing skills, the results suggest that no significant variation in effect sizes can be attributed to the presence or absence of a retention period. The positive effect of PBL on the skills (knowledge application) of students seems to be immediately and lasting. 
The authentic studies assessed the effects of PBL on the knowledge and skills of students in very different ways. A description of the results of contrasting the knowledge- and skills-related outcomes by the type of assessment method follows. In other contexts, research has shown that assessment methods influence the effects findings (Dochy, Segers \& Buehl, 1999).

The following assessment tools were used in the studies included in this meta-analysis:

National Board of Medical Examiners: United States Medical Licensing

Step 1: MCQ about basic knowledge

Step 2: MCQ about diagnosing

Step 3: MCQ and cases about clinical management (Case, 1999)

Modified Essay Questions (MEQ)

The MEQ is a standardised series of open questions about a problem. The information on the case is ordered sequentially: The student receives new information only after answering a certain question (Verwijnen et all, 1982). The student must relate theoretical knowledge to the particular situation of the case (Knox, 1989).

Essay questions

A question requiring an elaborated written answer is asked (Mehrens \& Lehmann, 1991).

Short-answer questions

Compared to an essay question, the length of the desired answer is restricted.

Multiple-choice questions

Oral examinations

Progress tests

The progress test is a written test consisting of about 250 true-false items sampling the full domain of knowledge a graduate should master (Verwijnen, Pollemans \& Wijnen, 1995). The test is constructed to assess "rooted" knowledge, not details (Mehrens \& Lehmann, 1991).

Performance-based testing: Rating

Standardised rating scales are used to evaluate the performance of the students (performance assessment) (Shavelson, Gao \& Baxter, 1996; Verwijnen et al., 1989;). It can be used to evaluate knowledge as well as higher cognitive skills (Santos-Gomez et al., 1990).

Free recall

Students are asked to write down everything they can remember about a certain subject. This task makes a strong appeal to the students' retrieval strategies.

Standardised patient simulations

These tests are developed by the OMERAD Institute of the University of Michigan. A patient case is simulated and students' knowledge and clinical 
skills are assessed by asking the student specific questions (Jones, Bieber, Echt, Scheifley \& Ways, 1984).

Case(s)

Students have to answer questions about an authentic case.

If the "Key feature approach" is used, questions are asked on only the core aspects of the case (Bordage, 1987).

Table 6. Type of assessmen method as moderating wariable

\begin{tabular}{|c|c|c|c|c|c|c|}
\hline & \multirow{2}{*}{$\begin{array}{l}\text { Sigh } \\
+\end{array}$} & \multirow{2}{*}{ Sigin. } & \multirow{2}{*}{$\begin{array}{c}\text { Studies } \\
\mathrm{N}\end{array}$} & \multicolumn{2}{|c|}{ Combined ES } & \multirow[t]{2}{*}{ Ob } \\
\hline & & & & Unweighted & Weighted (Cl $95 \%)$ & \\
\hline Knowledge & & & & & & 254.501 \\
\hline NBME part I & 0 & $6^{\text {th }}$ & 5 & -1.740 & $-0.961(+40.152)$ & $(p=0.000)$ \\
\hline Short-antwer & 2 & 1 & 3 & +0.050 & $-0.123(+1-0.080)$ & \\
\hline $\mathrm{MCQ}$ & 3 & 7 & 12 & -1.138 & $-0.309(+1-0.109)$ & \\
\hline Ruting & 1 & 0 & 4 & +0.209 & $+0.301(+1-0.162)$ & \\
\hline Orall & 0 & 0 & 2 & -0.334 & $-0.350(+/-0.552)^{\text {aif }}$ & \\
\hline Piogress & 0 & 1 & 6 & +0.011 & $+0.005(+1-0.097)^{\mathrm{ms}}$ & \\
\hline Pree tecall & 1 & 0 & 1 & +2.171 & $+2.171(+/-0.457)$ & \\
\hline Skills & & & & & & 25.039 \\
\hline NBME part II & 1 & 0 & 4 & +0.094 & $+0.080(+/-0.125)^{n 2 x}$ & $(p=0.001)$ \\
\hline NBME part III & 1 & 0 & 2 & +0.265 & $+0.263(+1-0.153)$ & \\
\hline Caser $(s)$ & 5 & $0 *$ & 11 & +0.708 & $+0.416(+10.119)$ & \\
\hline MEQ & 1 & 0 & 1 & +0.476 & $+0.476(+1-0.321)$ & \\
\hline Sinulation & 1 & 0 & 2 & +0.854 & $+0.413(+/-0.311)$ & \\
\hline Oral & 1 & 0 & 2 & +0.349 & $+0.366(+1-0.554)^{13.5}$ & \\
\hline Essay & 2 & 0 & 3 & +0.415 & $+0.165(+1-0.083)$ & \\
\hline Rating & 2 & 0 & 3 & +0.387 & $+0.431(+/-0.182)$ & \\
\hline
\end{tabular}

$*=$ Two-sided sign-test is significant at the $5 \%$ lewel

Nore: Unless noted ${ }^{n s}$, all weighted effect sizes are statistically significant.

The results of the statistical meta-analysis are presented in Table 6 . In this analysis, we did not use the 'shifting units' method to identify the independent hypothesis tests, but the "samples as units" method (Cooper, 1989). This approach permits a single study to contribute more than one hypothesis test, if the hypothesis test is carried out on separate samples of people. In this way it was possible to gain more information on certain operationalisations of the dependent variable.

The results of the homogeneity analysis (Table 6) suggest that significant variation in effect sizes as well as effects on knowledge ( $\mathrm{Qb}=254.501, p=0.000$ ) and skills $(\mathrm{Qb}=25.039, \quad p=0.001)$ can be attributed to the specific operationalisation of the dependent variable. The results in the domain of the effects on skills are more coherent than the results for knowledge. The effects found with the different operationalisations of skills are all positive. A ranking of the operationalisation based on the size of the weighted combined effect sizes, gives the following:

NBME Step II (0.080); Essay (0.165); NBME III (0.263); Oral (0.366); Simulation (0.413); Case(s) (0.416); Rating (0.431); MEQ (0.476).

If this classification is compared with a continuum showing to what degree the tests assess the application of knowledge, rather than the reproduction of 
knowledge, the following picture emerges: The better an instrument is capable of evaluating students' skills (i.e., application of knowledge), the larger the ascertained effects of PBL (compared with a conventional learning enwironment).

Effects found with the NBME Step II are negligible. However, the NMBE Step II is also the least suitable instrument to examine the skills of the students. It assesses clinical knowledge rather than clinical performance (Vernon \& Blake, 1993). The essay questions give some opportunities to evaluate the integration of knowledge (Swanson et al., 1997), but they are not often used to make an application of knowledge. This is also the case for oral examination. In this case, however, there was a clear distinction between questions that examined knowledge and questions that assessed problem-solving skills (Goodman, Brueschke, Bone, Rose, Williams \& Paul, 1991). Only the latter are categorised as skills-related outcomes.

Excepting the NBME Step II, essay questions, and the oral examination of NBME Step III, all the other instruments can be classified as measuring the skills of the students to apply their knowledge in an authentic situation. On these tests, the students in PBL score consistently higher (ES between 0.416 and 0.476 ). The only exception is the results on the NBME step III ( $E S=0.265$ ). It should be noted that the exam consists only partially of authentic cases. A rating was made for the knowledge-related outcomes:

NBME I (-0.961); Oral (-0.350); MCQ (-0.309); Short-answer (-0.123); Progress test $(+0.005)$; Free recall $(+2.171)$ Rating $(+0.301)$

The results suggest a similar conclusion as the result presented in the retention period section. If the test makes a strong appeal to retrieval strategies, students in PBL do at least as good as the students in a conventional learning environment. A rating context, short-answer questions, or free recall tests make a stronger appeal to retrieval strategies than a recognition task (NBME step I and MCQ) (Tans et al., 1986). Also the progress test examines 'rooted' knowledge. The fact that students in a conventional learning environment score better on the NBME step 1 and on the MCQ (see vote count), suggests that they have more knowledge. The fact that the difference between students in conventional learning environments and students in PBL diminishes or even disappears on a test appealing to retrievat strategies, suggests a better organisation of the students" knowledge in PBL. However, this conclusion is rather tentative. 


\section{Conclusion}

\section{Main effects}

The first research question in this meta-analysis dealt with the influence of PBL on the acquisition of knowledge and the skills to apply that knowledge. The vote count as well as the combined effect size (ES $=0.460$ ) suggest a robust positive effect from PBL on the skills of students. Also no single study reported negative effects.

A tendency to negative results is discerned when considering the effect of PBL on the knowledge of students. The combined effect size is significantly negative ( $E S=-0.223$ ). However, this result is strongly influenced by two studies. Also the vote count does not reach a significant level.

Evaluating the practical significance of the effects requires additional interpretation. Researchers in education and other fields continue to discuss how to evaluate the practical significance of an effect size (Springer, Stanne \& Donovan, 1999). Cohen (1988) and Kirk (1996) recommend that $d=0.20$ (small effect), $d=$ 0.50 (moderate effect) and $d=0.80$ (large effect) serve as general guidelines across disciplines. Within education, conventional measures of the practical significance of an effect size range from 0.25 (Tallmadge, 1977 in Springer et al., 1999) to 0.50 (Rossi \& Wright, 1977). Many education researchers (Gall, Borg \& Gall, 1996) consider an effect size of 0.33 as the minimum to establish practical significance.

If we compare the main effects with these guidelines, it can be concluded that the combined effect size for skills is moderate, but of practical significance. The effect on knowledge, already described as non-robust, is also small and not practically significant.

\section{Moderators of PBL effects}

The moderator analysis is presented as exploratory because of the relatively small number of independent studies involved.

\section{Methodological factors}

The most important conclusion resulting from the analysis of the methodological factors seems to be the diminished negative effect of PBL on knowledge, if the quality of the research is categorised as higher. Further, the scope of implementation is also associated with the variation in effects of PBL on knowledge. Within a single-course design, the significant negative effect resulting 
from a curriculum-wide implementation becomes smaller and the vote-counting suggests a tendency towards more positive effects.

\section{Expertise-level of students}

The analysis suggested that both for knowledge- and skills-related outcomes the expertise-level of the student is associated with the variation in effect sizes. Nevertheless, the results for skills give a consistent positive picture. For knowledge-related outcomes the differences of the effects between the expertise levels of the students are remarkable. The results suggest that the differences encountered in the first and the second year disappear if the reproduction of knowledge is assessed in a broader context that asks all the students to apply their knowledge.

\section{Retention period}

This moderator analysis indicates that students in PBL have slightly less knowledge, but remember more of the acquired knowledge. A possible explanation is the attention for elaboration in PBL: The knowledge of the students in PBL is elaborated more and, consequentially, they have a better recall of their knowledge (Gagné, 1978; Wittrock, 1989). For skills-related outcomes, the analysis indicates no significant variation in effect sizes. The positive effect of PBL on the skills of students seems immediately and lasting.

\section{Type of assessment method}

In other contexts, research has shown that assessment methods influence the findings (Dochy, Segers \& Buehl, 1999). In this review, the effects of PBL are moderated by the way the knowledge and skills were assessed. The results seem to indicate that the more an instrument is capable of evaluating the skills of the student, the larger the ascertained effect of PBL.

Although it is not so clear, an analogue tendency is acknowledged for the knowledge-related outcomes. Students do better on a test if the test makes a stronger appeal on retrieval strategies. This could be due to a better structured knowledge base, a consequence of the attention for knowledge elaboration in PBL. This is in line with the conclusion presented previously in the retention period.

\section{Results of other studies: Different methods, same results?}

The interest in the effects of PBL has already produced two good and often cited reviews (Albenese \& Mitchell, 1993; Vernon \& Blake, 1993). These reviews were published in a short period and mostly rely on the same literature. The two 
reviews used a different methodology. Albanese and Mitchell (1993) relied on a narrative integration of the literature, while Vernon and Blake (1993) used statistical methods. Methodologically, this analysis is more similar to Vernon and Blake. Both reviews, however, concluded that at that moment there was not enough research to draw reliable conclusions.

The main results of this meta-anallysis are similar to the conclusions of the two reviews. They had found a robust positive effect of PBL on skills. Vernon and Blake (1993, p. 560) express it as follows: "Our analysis suggests that the clinical performance and skills of students exposed to PBL are superior to those of students educated in a traditional curriculum." The reviews also drew similar conclusions about the effects of PBL on the knowledge base of students. Albanese and Mitchell (1993, p.57) concluded very carefully: "While the expectation that PBL students not do as well as conventional students on basic science tests appears to be generally true, it is not always true."

Vernon and Blake (1993) specified this doubt with their statistical metaanalysis: "Data on the NBME I (...) suggest a significant trend favouring traditional teaching methods. However, the vote count showed no difference between problem-based learning and traditional tracks" (p.555). And: "Several other outcome measures that appeared to be primarily tests of basic science factual knowledge. The trend in favor of traditional teaching approaches was not statistically significant" (p.556).

This meta-analysis also made similar conclusions about the effect of PBL on knowledge and provides a further validation of the findings from the two mentioned reviews. This meta-analysis then went further by analysing potential moderators of the main effects.

Finally, a remark should be made concerning the limitations of this review. Perhaps the greatest limitation of this meta-analysis is strongly related to its greatest strength. By including only field studies (quasi-experimental research), the metaanalysis gains a lot of ecological validity, but sacrifices some internal validity relative to more controlled laboratory studies (Springer et al., 1999). As a consequence, its results should be interpreted from this perspective, from which we try to bridge the gap between research and educational practice (De Corte, 2000).

\section{References}

Aaron, S., Crocket, J., Morrish, D., Basualdo, C., Kovithavongs, T., Mielke, B., Cook, D. (1998). Assessment of exam performance after change to problem-based learning: Differential effects by question type. Teaching and Learning in Medicine, 10 (2), 86-91.

Albanese, M.A., \& Mitchell, S. (1993). Problem-based learning: A review of literature on its outcomes and implementation issues. Academic Medicine, 68, 52-81.

Albano, M.G., Cavallo, F., Hoogenboom, R., Magni, F., Majoor, G., Mananti, F., Schuwirth, L., Stiegler, I. \& Van Der Vleuten, C. (1996). An international 
comparison of knowledge levels of medical students: The Maastricht progress test. Medical Education, 30, 239-245.

Antepohl, W., \& Herzig, S. (1997). Problem-based learning supplementing in the course of basic pharmacology-results and perspectives from two medical schools. Naunyn-Schmiedeberg's Archives of Pharmacology, 355, R18.

Antepohl, W., \& Herzig, S. (1999). Problem-based learning versus lecture-based learning in a course of basic pharmacology: A controlled, randonized study. Medical Education, 33 (2), 106-113.

Ausubel, D., Novak, J., \& Hanesian, H. (1978). Educational Psychology: A cognitive view (2nd ed.). New York: Holt, Rinehart \& Winston.

Baca, E., Mennin, S.P., Kaufman, A., \& Moore-West, M. (1990). Comparison between a problem-based, community-oriented track and a traditional track within one medical school. In Z.M. Nooman, H.G. Schmidt, \& E.S. Ezzat (Eds.), Innovation in medical education: An evaluation of its present status (pp.9-26). New York: Springer.

Barrows, H. (1994). Practice-based learning: Problem-based learning applied to medical education. Springfield, Illinois: Southern Illinois University, School of Medicine.

Barrows, H.S. (1984). A Specific, problem-based, self-directed learning method designed to teach medical problem-solving skills, self-learning skills and enhance knowledge retention and recall. In H.G. Schmidt \& M.L. de Volder (Eds.), Tutorials in problem-based learning. A new direction in teaching the health profession. Assen: Van Gorcum.

Barrows, H.S. (1996). Problem-based learning in medicine and beyond: A brief overview. In L. Wilkerson \& W.H. Gijselaers (Eds.), New directions for teaching and learning, Nr.68 (pp. 3-11). San Francisco: Jossey-Bass Publishers.

Barrows, H.S., \& Tamblyn, R.M. (1976). An evaluation of problem-based learning in small groups utilizing simulated patient. Journal of Medical Education, 51,52-56.

Baxter, G.P., \& Shavelson, R.J. (1994). Science performance assessments: Benchmarks and surrogates. International Journal of Educational Research, 21, 3, 279-299.

Bickley, H., Donner, R.S., Walker, A.N., \& Tift, J.P. (1990). Pathology education in at problem-based medical curriculum. Teaching and Learning in Medicine, 2 (1), 38-41.

Birenbaum, M. (1996). Assessment 2000: Towards a pluralistic approach to assessment. In M. Birenbaum \& F.J.R.C. Dochy (Eds.), Alternatives in assessment of achievements, learning processes and prior knowledge. Boston/Dordrecht/London: Kluwer Academic Publishers.

Block, S.D., \& Moore, G.T. (1994). Project evaluation. In D.C. Tosteson, S.J. Adelstein, Carver, S.T. (Eds.), New pathways to medical education: Learning to leam at Harvard medical school. Cambridge, MA: Harvard University Press. 
Boekaerts, M. (1999a). Self-regulated learning: Where are we today? International Journal of Educational Research, 31,445-457.

Boekaerts, M. (1999b). Motivated learning: The study of student $x$ situation transactional units. Earopean Journal of Psychology of Education, 14 (4), 41-55.

Bordage, G. (1987), An altenative approach to PMP's : The 'key-features' concept. In I.R Hart \& R. Harden (Eds.), Further developments in assessing clinical competences, proceedings of the second Ottawa conference (pp. 59-75). Montreal: Can-Heal Publications Inc.

Boshuizen, H.P.A., Sehmidt, H.G., \& Wassamer (1993). Curriculum style and the integration of biomedical \& clinical knowledge. In P.A.J. Bouhuys, H.G. Schmidt \& H.J.M. van Berkel (Eds.), Problem-based learning as an educational strategy, (pp. 33-41). Maastricht: Network Publications.

Bruner, J.S. (1959). Learning and thinking. Harvard Educational Review, 29, 184192.

Bruner, J.S. (1961). The act of discovery. Harvard Educational Review, 31, $21-32$.

Case, S. (Scase@mail.nbme.org): (1999, december 07). Questions NBME / USMLE. E-mail to Piet Van den Bossche

(P.vandenbossche@educ.unimaas.nl).

Chi, M.T., Glaser, R., \& Rees, E. (1982). Expertise in problem solving. In R. Sternberg (Ed.), Advances in the psychology of human intelligence, (pp.776). Hillsdale, N.J.: Erlbaum.

Cohen, J. (1988). Statistical power analysis for the behavioral sciences (second edition). Hillsdale, NJ: Erlbaum.

Cooper, H.M. (1989). Integrating research. A guide for literature reviews: Applied social research methods series ( 2 nd volume). London: Sage Publications.

De Corte, E. (1990a). A state-of-the-art of research on learning and teaching. Keynote lecture presented at the first European conference on the first year experience in higher education, Aalborg University, Denmark, April 23-25.

De Corte, E. (1990b). Toward powerful learning environments for the acquisition of problem-solving skills. European Journal of Psychology of Education, 5 (1), $5-19$.

De Corte, E. (1995). Fostering cognitive growth: A perspective from research on mathematics learning and instruction. Edacational Psychologist, 30 (1), 3746.

De Corte, E. (2000). Marrying theory building and the improvement of school practice: A permanent challenge for instructional psychology. Learning \& Instruction, 10 (3), 249-266.

Dewey, J. (1910). How we think. Boston: Health \& Co.

Dewey, J. (1944). Democracy and education. New York: Macmillan Publishing Co.

Distlehorst, L.H., \& Robbs, R.S. (1998). A comparison of problem-based learning and standard curriculum students: Three years of retrospective data. Teaching and Learning in Medicine, 10 (3), 131-137.

Dochy, F., Segers, M., \& Buehl, M.M. (1999). The relation between assessment practices and outcomes of studies: The case of research on prior knowledge. Review of Educational Research, 69 (2), 145-186. 
Dochy, F.J.R.C., \& Alexander, P.A. (1995). Mapping prior knowledge: A framework for discussion among researchers. European Journal for Psychology of Education, 10, (3), 225-242.

Donner, R.S., \& Bickley, H. (1990). Problem-based learning: An assessment of its feasibility and cost. Human Pathology, 21,881-885.

Doucet, M.D., Purdy, R.A., Kaufman, D.M., \& Langille, D.B. (1998). Comparison of problem-based learning and lecture format in continuing medical education on headache diagnosis and management. Medical Education, 32 (6), 590-596.

Eisenstaedt, R.S., Barry, W.E.y \& Glanz, K. (1990). Problem-based learning: Cognitive retention and cohort traits of randomly selected participants and decliners. Academic Medicine, 65 (9, september suppl.), 11-12.

Engel, C. E. (1997). Not just a method but a way of learning. In D. Boud \& G. Feletti (Eds.), The challenge of problem based learning (second edition, pp. 17-27). London : Kogan Page.

Farquhar, L.J., Haf, J., \& Kotabe, K. (1986). Effect of two preclinical curricula on NMBE part I examination performance. Journal of Medical Education, 61, 368-373.

Finch, P.M. (1999). The effect of problem-based learning on the academic performance of students studying pediatric medicine in Ontario. Medical Education, 33 (6), 411-417.

Gagné, E.D. (1978). Long-term retention of information following learning from prose. Review of Educational Research, 48, 629-665.

Gall, M.D., Borg, W.R., \& Gall, J.P. (1996). Educational research (sixth edition), White Plains, NY: Longman.

Gijselaers, W. (1995). Perspectives on problem-based learning. In W. Gijselaers, D. Tempelaar, P. Keizer, J. Blommaert, E. Bernard \& H. Kasper (Eds.), Educational innovation in economics and business administration: The case of problem-based learning (pp 39 - 52). Norwell, Mass.: Kluwer.

Glaser, R. (1990). Toward new models for assessment. International Journal of Educational Research, 14, 475-483.

Glass, G.V. (1976). Primary, secondary and meta-analysis. Educational Researcher, 5, 3-8

Glass, G.V., McGaw, B., \& Smith, M.L. (1981). Mera-analysis in social research. London: Sage Publications.

Goodman, L.J., Brueschke, E.E., Bone, R.C., Rose, W.H., Williams, E.J., \& Paul, H.A. (1991). An experiment in medical education: A critical analysis using traditional criteria. Joumal of the American Medical Association, 265, 2373-2376.

Hedges, L.V., \& Olkin, I. (1980). Vote counting methods in research synthesis. Psychological Bulletin, 88, 359-369.

Hedges, L.V., \& Olkin, I. (1985). Statistical methods for meta-analysis. Orlando, FL: Academic Press. 
Hmelo, C.E. (1998). Problem-based learning: Effects on the early acquisition of cognitive skill in medicine. The Joumal of the Leaming Sciences, 7, 173236.

Hmelo, C.E., Gotterer, G.S., \& Bransford, J.D. (1997). A theory-driven approach to assessing the cognitive effects of PBL. Instructional Science, 25, 387-408.

Honebein, P.C, Duffy, T.M, \& Fishman, B.J. (1993). Constructivism and the disign of leaming environments: Context and authentic activities for learning. In T.M. Duffy J. Lowyck \& D.H. Jonassen (Eds.), Designing environments for constructive learning. Berlin: Springer Verlag.

Hunter, J.E., \& Schmidt, F.L. (1990). Methods of meta-analysis. Correcting error and bias in research findings. California: Sage Publications.

Hunter, J.E., Schmidt, F.L., \& Jackson, G.B. (1982). Meta-analysis: Cumulating research findings across studies. Beverley Hills, California: Sage.

Imbos, T., \& Verwijnen, G.M. (1982). Voortgangstoetsing aan de medische faculteit Maastricht [Progress testing at the faculty of medicine of Maastricht]. In H.G. Schmidt, Probleemgestuurd onderwijs: Bijdragen tot onderwijsresearchdagen 1981 (pp. 45-56). Harlingen: Stichting voor Onderzoek van het Onderwijs, Flevodruk Harlingen b.v.

Imbos, T., Drukker, J., van Mameren, H., \& Verwijnen, M. (1984). The growth in knowledge of anatomy in a problem-based curriculum. In H.G. Schmidt \& M.L. de Volder (Eds.), Tutorials in problem-based learning. New direction in training for the health professions (pp. 106-115). Assen: Van Gorcum.

Jones, J.W., Bieber, L.L., Echt, R., Scheifley, V., \& Ways, P.O. (1984). A problembased curriculum, ten years of experience. In H.G. Schmidt \& M.L. de Volder (Eds.), Tutorials in problem-based learning. New direction in training for the health professions (pp. 181-198). Assen: Van Gorcum.

Kaufman, A., Mennin, S., Waterman, R., Duban, S., Hansbarger, C., Silverblatt, H., Obenshain, S.S., Kantrowitz, M., Becker, T., Samet, J., \& Wiese, W. (1989). The New Mexico experiment: Educational innovation and institutional change. Academic Medicine, 64, 285-294.

Knox, J.D.E. (1989). What is... a Modified essay question? Medical Teacher, II (1), $51-55$.

Kirk, R.E. (1996). Practical significance: A concept whose time has come. Educational and Psychological Measurement, 56, 746-759.

Kulik, J.A., \& Kulik, C.L. (1989). The concept of meta-analysis. International Journal of Educational Research, 13 (3), 227-234.

Lewis, K.E., \& Tamblyn, R.M. (1987). The problem-based learning approach in baccalaureate nursing education: How effective is it? Nursing Papers, 19 (2), 17-26.

Mandl, H., Gruber, H., \& Renkl, A. (1996). Communities of practice toward expertise: Social foundation of university instruction. In P.B. Baltes \& U.M. Staudinger, Interactive minds. Life-span perspectives on the social foundation of cognition (pp. 394-412). Cambridge: Cambridge University Presss. 
Martenson, D., Eriksson, H., \& Ingelman-Sundberg, M. (1985). Medical chemistry: Evaluation of active and problem-oriented teaching methods. Medical Education, 19, 34-42.

Mennin, S.P., Friedman, M., Skipper, B., Kalishman, S., \& Snyder, J. (1993). Performances on the NMBE I, II, III by medical students in the problembased learning and conventional tracks at the University of New Mexico. Academic Medicine, 68, 616-624.

Mehrens W.A. \& Lehmann, I.J.(1991). Measurement and evaluation in education and psychology. New York: Holt, Rinehard and Winston.

Moore G.T., Block S.D., Briggs-Style C., \& Mitchell R. (1994). The influence of the New Pathway curriculum on Harvard medical students. Academic Medicine, 69, 983-989.

Morgan, H.R. (1977). A problem-oriented independent studies programme in basic medical sciences. Medical Education, 11, 394-398.

Neufeld, V., \& Sibley, J. (1989). Evaluation of health sciences education programs: Program and student assessment at McMaster University. In H.G. Schmidt, M. Lipkin Jr., M.W. de Vries \& J.M. Greep (Eds.) New directions for medical education: Problem-based learning and community-oriented medical education (pp.165-179). New-York: Springer Verlag.

Neufeld, V.R., \& Barrows, H.S. (1974). The "McMaster philosophy": An approach to medical education. Journal of Medical education, 49, 1040-1050.

Neufeld, V.R., Woodward, C.A., and MacLeod, S.M. (1989). The McMaster M.D. program: A case study of renewal in medical education. Academic Medicine, $64,423-432$.

Nonaka, I. \& Takeuchi, H. (1995). The knowledge-creating company. New York: Oxford University Press.

Owen, E., Stephens, M., Moskowitz, J., \& Guillermo, G. (2000). From 'horse race' to educational improvement: The future of international educational assessments. In: INES (Ed.), The INES compendium. Contributions from the INES networks and working groups (pp. 7-18), Tokyo: OECD. [available on-line: http://www.pisa.oecd.org/Docs/Download/GA(2000)12.pdf]

Patel, V.L., Groen, G.J, \& Norman, G.R. (1991). Effects of conventional and problem-based medical curricula on problem-solving. Academic Medicine, $66,380-389$.

Piaget, J. (1954). The construction of reality in the child. New York: Basic Books.

Poikela, E., \& Poikela, S. (1997). Conceptions of learning and knowledge-impacts on the implementation of problem-based learning. Zeitschrift fur Hochschuldidacrik, $1,8-21$.

Quinn, J. B. (1992). Intelligent enterprise, a knowledge and service based paradigm for industry. New York: The Free Press.

Richards, B.F., Ober, P., Cariaga-Lo, L., Camp, M.G., Philp, J., McFarlane, M., Rupp, R., \& Zaccaro, D.J. (1996). Rating of students" performances in a third-year internal medicine clerkship: A comparison between problembased and lecture-based curricula. Academic Medicine, 7/ (2), 187-189. 
Rogers, C.R. (1969). Freedom to leam. Colombus, Ohio: Charles E. Merill Publishing Company.

Rossi, P., \& Wright, S. (1977). Evaluation research: An assessment of theory, practice and politics. Evaluation Quarterly, 1, 5-52.

Salganik, L.H., Rychen, D.S., Moser, U. \& Konstant, J.W. (1999). Projects on competencies in the $O E C D$ context: Analysis of theoretical and conceptual foundations. Neuchâtell: SFSO, OECD, ESSL.

Santos-Gomez, L., Kalishman, S., Rezler, A., Skipper, B., \& Mennin, S.P. (1990). Residency performance of graduates from a problem-based and a conventional curriculum. Medical Education, 24, 366-377.

Saunders, N.A., Mcintosh, J., Mcpherson, J., \& Engel, C.E. (1990). A comparison between University of Newcastle and University of Sydney final-year students: Knowledge and competence. In Z.H. Nooman, H.G. Schmidt, \& E.S. Ezzat (Eds.), Innovation in medical education: An evaluation of its present status (pp. 50-54). New York: Springer.

Schmidt; H.G. (1990). Innovative and conventional curricula compared: What can be said about their effects? In Z.H. Nooman, H.G. Schmidt, \& E.S. Ezzat (Eds.), Innovation in medical education: An evaluation of its present status (pp. 1-7). New York: Springer.

Schmidt, H.G., Machiels-Bongaerts, M., Hermans, H., ten Cate T.J., Venekamp, R., \& Boshuizen, H.P.A. (1996). The development of diagnostic competence: Comparison of a problem-based, an integrated, and a conventional medical curriculum. Academic Medicine, 71, 658-664.

Schuwirth, L.W.T. (1998). An approach to the assesment of medical problemsolving: Computerized case-based testing. Maastricht: Datawyse.

Schuwirth, L. W. T., Verhoeven, B.H., Scherpbier, A.J.J.A., Mom, E.M.A, CohenSchotanus, J., van Rossum, H.J.M., \& Van der Vleuten, C. (1999). An Inter-and intra-university comparison with short case-based testing. Advances in Health Sciences Education, 4, 233-244.

Schwartz, R.W., Burgett, J.E., Blue, A.V., Donnelly, M.B., \& Sioan, D.A. (1997). Problem-based learning and performance-based testing: effective alternatives for undergraduate surgical education and assessment of student performance. Medical Teacher, 19, 19-23.

Segers, M.S.R. (1996). Assessment in a problem-based economics curriculum. In M. Birenbaum \& F. Dochy (Eds.), Alternatives in assessment of achievements, leaming processes and prior learning (pp. 201-226). Boston: Kluwer Academic Press.

Segers, M.S.R. (1997). An alternative for assessing problem-solving skills: the OverAll Test. Studies in Educational Evaluation, 23 (4), 373-398.

Segers, M., Dochy, F., \& De Corte, E. (1999). Assessment practices and students' knowledge profiles in a problem-based curriculum. Learning Environments Research, 12 (2), 191-213.

Shavelson, R.J., Gao, X., Baxter, G.P. (1996). On the content validity of performance assessments: Centrality of domain specification. In $M$. Birenbaum \& F. Dochy (Eds.), Alternatives in assessment of achievements, 
learning processes and prior leaming (pp. 131-143). Boston: Kluwer Academic Press.

Son, B., \& Van Sickle, R.L. (2000). Problem-solving instruction and students' acquisition, retention, and structuring of economics knowledge. Journal of Research and Development in Education, 33 (2), 95-105.

Springer, L., Stanne, M.E., \& Donovan, S.S. (1999). Effects of small-group learning on undergraduates in science, mathematics, engineering, and technology: A meta-analysis. Review of Educational Research, 69 (1), 2151.

Swanson, D.B., Case, S.M., \& van der Vleuten, C.P.M. (1997). Strategies for student assessment. In D. Boud \& G. Feletti (Eds.), The challenge of problem-based learning (second edition) (pp.269-282). London: Kogan Page.

Tans, R.W., Schmidt, H.G., Schade-Hoogeveen, B.E.J., \& Gijselaers, W.H. (1986). Sturing van het onderwijsleerproces door middel van problemen: een veldexperiment [Guiding the learning process by means of problems: A field experiment]. Tijdschrift voor Ondenwijsresearch, $11,35-46$.

Tynjälä, P. (1999). Towards expert knowledge? A comparison between a constructivist and a traditional learning environment in the university. International Journal of Educational Research, 33, 355-442.

Van Hessen, P.A.W., \& Verwijnen, G.M. (1990). Does problem-based learning provide other knowledge? In W. Bender, R.J. Hiemstra, A.J.J.A. Scherpbier, \& R.P. Zwierstra (Eds.), Teaching and assessing clinical competence (pp. 446-451). Groningen: Boekwerk publications.

Van IJzendoorn, M.H. (1997). Meta-analysis in early childhood education: Progress and problems. In B. Spodek, A.D. Pellegrini, and O.N. Saracho (Edls.), Issues in early childhood education, yearbook in early childhood education. New York: Teachers College Press.

Verhoeven, B.H., Verwijnen, G.M., Scherpbier, A.J.J.A., Holdrinet, R.S.G., Oeseburg, B., Bulte, J.A., \& Van Der Vleuten, C.P.M. (1998). An analysis of progress test results of PBL and non-PBL students. Medical Teacher, 20 (4), 310-316.

Vernon, D.T.A., \& Blake, R.L. (1993). Does problem-based leaming work? A meta-analysis of evaluative research. Academic Medicine, 68, 550-563.

Verwijnen, G.M., Pollemans, M.C., \& Wijnen, W.H.F.W. (1995). Voortgangstoetsing [Progress Testing]. In J.C.M. Melz, A.J.J.A. Scherpbier \& C.P.M. Van der Vleuten (Eds.). Medisch Onderwijs in de Praktijk (225232). Assen: Van Gorcum.

Verwijnen, M., Imbos, T., Snellen, H., Stalenhoef, B., Sprooten, Y., \& Van der Vleuten, C. (1982). The evaluation system at the medical school of Maastricht. In H.G. Schmidt, M. Vries, \& J.M. Greep (Eds.), New directions for medical education: Problem-based learning and communityoriented medical education (pp.165-179). New York: Springer.

Verwijnen, M., Van Der Vleuten, C., \& Imbos, T. (1990). A comparison of an innovative medical school with traditional schools: An analysis in the 
cognitive domain. In Z.H. Nooman, H.G. Schmidt, \& E.S. Ezzat (Eds.), Innovation in medical education: An evaluation of its present status (pp.4149). New York: Springer.

Wittrock, M.C. (1989). Generative processes of comprehension. Educational Psychologist, 24, 345-376. 


\section{Chapter 5}

\section{Effects of problem-based learning: A meta-analysis from the angle of assessment ${ }^{4}$}

\section{Abstract}

In the present chapter, we investigate the influence of assessment on the reported effects of PBL. Hereto we use Sugrue's (1995) model of cognitive components of problem solving. Three levels of the knowledge structure that can be targeted by assessment of problem solving are used as the main independent variables: (1) understanding of concepts, (2) understanding of the principles that link concepts, and (3) linking of concepts and principles to conditions and procedures for application. A statistical meta-analysis was conducted, supplemented by more inclusive vote counts and an associated sign test. Results show that there is a difference in the reported effects of PBL between each of the three levels in the knowledge structure. Different from studies suggesting that the effects of PBL are larger when the method of assessment is more capable of evaluating complex levels of the knowledge structure, the effect size for the third level of the knowledge structure is smaller compared to the effect size of the second level and not statistically significant.

\footnotetext{
${ }^{4}$ Based on: Gijbels, D., Dochy, F., Van den Bossche, P., \& Segers, M. (2004), Effects of problembased learning: A meta-analysis from the angle of assessment. Accepted for publication in Review of Educational Research.
} 


\section{Introduction}

Problem-based learning (PBL) represents a major development in higher educational practice that continues to have a large impact across subjects and disciplines worldwide. As indicated by many authors (Engel, 1997: Gagné, Yekovich \& Yekovich, 1993; Poikela \& Poikela, 1997; Segers, 1997), today's society expects graduates to be able to solve complex problems in an efficient way. The claims made for PBL promise an important improvement in outcomes for higher education. Results from studies examining the effects of PBL are conclusive regarding the problem-solving ability of students. However, results are inconclusive regarding the effects on the acquisition of knowledge (Albanese \& Mitchell, 1993; Vernon \& Blake, 1993). This seems to be in contradiction with the vast amount of research showing knowledge acquisition as a prerequisite for successful problemsolving (Bransford, Vye, Adams \& Perfetto, 1989; Glaser, 1992; Schoenfeld, 1985; Segers, Dochy \& De Corte, 1999; Smith, 1991; Spilich, Vesonder, Chiesi \& Voss, 1979). However, in other contexts, research has shown that assessment methods influence the findings of studies. Dochy, Segers \& Buehl (1999) reviewed 183 studies related to prior knowledge and concluded that while prior knowledge generally had positive effects on students' performance, the effects varied as a function of the method used for assessment. More specifically, prior knowledge was very likely to have negative or no effects on performance when so-called "flawed" assessment measures were used such as methods measuring aspects other than the possession of prior knowledge (e.g. familiarity with the topic, as indicated by the participants in the study, or participants' perceptions of the possession of prior knowledge). This means that the findings on the effect of prior knowledge on students" performances were influenced by the assessment method and the feature it was measuring.

Prior reviews (e.g. Albanese \& Mitchell, 1993; Vernon \& Blake, 1993) gave an overview of the effects of the implementation of PBL in comparison with mote conventional educational methods. The meta-analysis on the effects of PBL presented in chapter 4 included the method of assessment as a moderator variable and indicated that the larger an instrument's efficacy to evaluate the student's knowledge application, the larger the ascertained effect of PBL. In this chapter, we want to go one step further and investigate the influence of assessment as the main independent variable. However, whether different methods of assessment per se tap different aspects of a student"s knowledge base remains unclear (Bennett, 1993). Messick (1993) suggests a separation of variation in assessment method from variance relevant to the focal constructs being measured in the assessment. The latter is taken as a unit of analysis in this study. As a consequence, a theoretical framework describing the underlying focal constructs to be measured in higher education is needed in order to further investigate the influence of assessment on the reported effects of PBL compared to conventional educational settings. Before describing a theoretical framework on the components of problem solving, we first elaborate on problem-based learning and assessment in problem-based learning. 


\section{Problem-based learning}

Although new in some aspects, PBL is based on ideas that originated much earlier and have been nurtured by many researchers (e.g. Ausubel, Novak \& Hanesian, 1978; Bruner, 1959, 1961; Dewey, 1910, 1944; Piaget, 1954; Rogers, 1969). The idea that learning is fostered when students have the opportunity to formulate and achieve their own learning-goals, is mentioned clearly in the work of Dewey $(1910,1944)$ and can also be found in the work of Piaget (1954) and Bruner $(1959,1961)$. Other aspects go back much further. The fact that learning should take place in concrete situations that have a relationship with students" prior knowledge and experiences goes back to the Greek:

In 'The Meno' (370 B.C.), Plato presents a famous passage where Menon pushes Socrates on the issue of how one is able to leap ahead of what is known in the search for new understanding. Understanding depends on prior learning, Menon argues. When new knowledge is incompatible with this learning, one lacks a base on which to build. (Prawat, 1999, p. 48)

PBL, as it is known today, originated in the 1950 s and 1960s starting with the dissatisfaction of the common medical education practice in Canada (Barrows, 1996). Although originally developed for medical training in Canada at Mc Master, the Mc Master version of PBL has been applied globally in many disciplines, not necessarily related to the study of medicine (Gijselaers, 1995). For instance, it has been applied in architecture (Donaldson, 1989; Maitland, 1991), business administration (Merchant, 1995), economics (Garland, 1995), engineering studies (Cawley, 1989), geology (Smith \& Hoersch, 1995), law (Kurtz, Wylie \& Gold, 1990; Pletinckx \& Segers, 2001), nursing (Higgings, 1994), social work (Heycox \& Bolzan, 1991), psychology (Reynolds, 1997), and other domains of postsecondary education (Boud, 1987).

\section{Definition}

In the literature, PBL has been defined and described in different ways. PBL is used to refer to many contextualised approaches to instruction sharing that much of the learning and teaching is anchored in concrete problems (Evenson \& Hmelo, 2000). This focus on concrete problems initiating the learning process is central in most definitions of PBL. Barrows \& Tamblyn (1980, p. 18) define the concept of PBL as "the learning that results from the process of working toward the understanding or resolution of a problem. The problem is encountered first in the learning process and serves as a focus or stimulus for the application of problem solving or reasoning skills, as well as for the search for or study of information or knowledge needed to understand the mechanisms responsible for the problem and how it might be resolved". Boud $(1987$, p. 13) states "it is that the starting point for learning should be a problem, a query or a puzzle that the learner wishes to solve". 
A much-quoted definition is the one given by Albanese and Mitchell (1993, p. 53): "Problem-based learning at its most fundamental level is an instructional method characterised by the use of patient problems as a context for students to learn problem-solving skills and acquire knowledge about the basic and clinical sciences". Vernon en Blake (1993, p. 550) define PBL by its instructional design components, students" cognitive processes and teachers'role: "A method of learning (or teaching) that emphasises (1) the study of clinical cases, either real or hypothetical, (2) small discussion groups, (3) collaborative independent study, (4) hypothetico-deductive reasoning, and (5) a style of faculty direction that concentrates on group progress rather than imparting information".

Other authors, such as Boud and Feletti (1997, p. 15), have related PBL to a way of approaching a curriculum: "Problem based learning is an approach to structuring the curriculum which involves confronting students with problems from practice which provide a stimulus for learning".

This range of the different definitions illustrates how difficult it is to come to one universal definition (Chen, Cowdroy, Kingsland \& Ostwald, 1995). PBL can adopt various forms depending on the nature of the domain and the specific goals of the programs it is part of (Barrows, 1986; Boud, 1987). Savin-Baden (2000) argues that there simply are no narrowly defined characteristics of $\mathrm{PBL}$, only people working in different contexts using different PBL-approaches.

However, in spite of the many variations of PBL that aim to match PBL with the specific educational or discipline context, for comparative research, a core model or basic definition is needed to which other educational methods can be compared. Based on the original method from McMasters Univerisity, Barrows (1996) developed a core model. The McMaster approach that originated in the context of medical education has served as a robust basis for many other contexts (Boud \& Feletti, 1997). Six core characteristics of PBL are distinguished in Barrows' (1996) core model and they can be described as follows. The first characteristic is that learning needs to be student-centred. Secondly, learning has to occur in small student groups. The third characteristic refers to the presence of a tutor as a facilitator or guide. Fourthly, authentic problems are primarily encountered in the learning sequence, before any preparation or study has occurred. Fifthly, the problems encountered are used as a tool to achieve the required knowledge and the problem-solving skills necessary to eventually solve the problem. Finally, new information needs to be acquired through self-directed learning.

It should be noted that just as the definition of PBL is ambiguous, the definition of what constitutes a conventional lecture-based program is also ambiguous. For the most part, conventional instruction is marked by large group lectures and instructor-provided learning objectives and assignments (Albanese \& Mitchell, 1993). 
Problem-based learning environments in higher education intend to guide students to become experts in a certain field of study, so-called professionals or graduates who can identify the problems of different disciplines and who are capable of analysing and contributing to the solutions of these problems. The findings of cognitive psychological research, especially results from expert versus novice studies, have contributed to the insights in the nature of expertise. Two general characteristics of expert performance can be identified (Feltovich, Spiro \& Coulson, 1993; Gagné et al., 1993; Glaser, 1990).

Experts' knowledge is coherent. Experts possess a well-structured network of concepts and principles about the domain that accurately represents key phenomena and their relationships. Beginners' knowledge is not only patchy, consisting of isolated definitions, it also lacks the principles underlying surface features of a problem presented. In contrast, experts' knowledge is structured and cognisant of underlying principles and patterns.

Novices often know facts, concepts, principles without knowing the conditions under which this knowledge applies and how it can be used most effectively. "Experts and novices may be equally competent at recalling specific items of information, but the more experienced relate these items to the goals of problem solution and conditions for action" (Glaser, 1990, p. 447). Experts are able to use the relevant elements of knowledge in a flexible way in order to describe and solve novel problems.

These findings have provided a basis for unraveling the general goal of PBL, the development of successful problem-solving into two dimensions which are the acquisition as well as the application of knowledge.

\section{Effects of $P B L$}

If one ponders the implementation of $\mathrm{PBL}$, a major question is: Do students, using PBL, reach the goals in a more effective way than students who receive conventional instruction? Albanese and Mitchell (1993, p.56) pose this question as follows: "Stated bluntly, if problem-based learning is simply another route to achieving the same product, why bother with the expense and effort of undertaking a painfull curriculum revision?" The interest in this question has produced, until now at least, six systematic reviews on the effects of problem-based learning. Three of these were published in the same year and the same journal (Albanese \& Mitchell, 1993; Berkson, 1993; Vernon \& Blake, 1993). Recently, Colliver (2000) and Smits, Verbeek \& Buisonjé (2002) undertook a systematic review, each from a different point of view. The most recent meta-analyses is presented in chapter 4 of this dissertation.

The review by Albanese \& Mitchell (1993) is probably the most wellknown. The core question in this review "What are the effects of problem-based learning?' is investigated by means of five sub questions: (1) What are the costs 
compared with lecture-based instruction?, (2) do PBL-students develop the cognitive scaffolding necessary to easily assimilate new basic sciences information?, (3) to what extent are PBL students exposed to an adequate range of content?, (4) do PBL students become overly dependent on a small group environment? (5) do faculty dislike PBL because of the concentrated time commitment required? The study categorises and lists the qualitative results of studies in medical education from 1972-1993. The results are presented in a review that reports effect sizes and $p$-values with the institutions as the unit of analysis. The main results from this review are that $\mathrm{PBL}$ is more nurturing and enjoyable and that PBL-graduates perform as well, and sometimes better, on clinical examinations and faculty evaluations than students in more conventional instruction. However, PBL students score lower on basic science examinations and view themselves as less well prepared in the basic sciences in comparison to their conventionally trained counterparts. Further, PBL-graduates tend to engage in backward reasoning rather than the forward reasoning experts engage in. Finally, the costs of PBL are high when class sizes are larger than 100.

At the same time Vernon \& Blake (1993) synthesised all available research from 1970 through 1992 comparing $\mathrm{PBL}$ with more conventional methods of medical education. Five separate statistical meta-analyses resulted in the following main results: PBL is found to be significantly superior with respect to students attitudes and opinions about their programs and measures of students clinical performance. Contrary to the previous reviews findings, the results of students in PBL do not have significantly different scores from conventionally taught students on miscellaneous tests of factual knowledge and tests of clinical knowledge. However, students from conventional education perform significantly better than their PBL counterparts on the National Board of Medical Examiners (NBME) stepl (see method section in this chapter for a description of this test).

Berkson (1993) also searched for evidence of the effectiveness of PBL in the medical PBL-literature till 1992. Six topics on the effectiveness of PBL compared to conventional curricula underlie this narrative meta-analysis in the medical domain: Problem-solving, the impart knowledge motivation to leam medical science, promoting self-directed learning skills, student and faculty satisfaction and the financial costs. The results showed no distinction between graduates from PBL and conventional instruction, but PBL can be stressful for both students and faculty and a PBL curriculum may be unreasonably expensive.

More recently Colliver (2000) questioned the educational superiority of PBL relative to standard approaches. Colliver focuses on the credibility of the claims about the ties between PBL and educational outcomes and the magnitude of the effects by means of a review of medical education literature starting with three reviews published in 1993 and moving on to research published from 1992 through 1998 in the primary sources for research in medical education. For each study, a summary is written, which includes the study design, outcomes measures, effect sizes, further information relevant to the research conclusion. Colliver concludes that their is no convincing evidence that PBL improves the student's knowledge base and clinical performance, at least not of the magnitude that would be expected 
given the resources required for a PBL curriculum. Nevertheless, PBL may provide a more challenging, motivating and enjoyable approach to medical education.

One of the more recent reviews by Smits et al. (2002) is limited to the effectiveness of PBL in continuing medical education. This review only includes controlled evaluation studies in continuing medical education from 1974-2000. In sum, Smits and colleagues conclude that there is limited evidence for PBL to increase participants' knowledge, performance, and patients' health. However, there was only moderate evidence that doctors are more satisfied with PBL.

The most recent review is presented in chapter 4 of this dissertation. This is the first review searching for studies beyond the domain of medical education. The main question is very similar, but much more itemised than the other reviews: What are the main effects of PBL on students' knowledge and knowledge application and what are the potential moderators of the effect of PBL? The results of this metaanalysis suggest that problem-based learning has statistically and practically significant positive effects on the students' knowledge application. The effect of problem-based learning on the knowledge base of the students tends to be negative. However, this effect is found to be strongly influenced by outliers and the moderator analysis suggests that students in a problem-based learning environment can rely on a more structured knowledge-base.

\section{Assessment in problem-based learning}

A wide range of assessment methods have been used to assess students" learning in PBL from traditional multiple-choice exams and essay exams to new modes of alternative assessment techniques such as case-based assessment, selfand peer assessment, performance-based assessment and portfolio assessment. Since the early $90 \mathrm{~s}$, many educators and researchers have advocated new modes of assessment in order to be congruent with the educational goals and instructional principles of PBL (Segers, Dochy \& Cascallar, 2003). It is generally recognised that a seventh characteristic should be added to the six characteristics in Batrows (1996) core model of PBL. It is essential to PBL for students to learn by analysing and solving representative problems. Consequently, a valid assessment system would evaluate students' problem-solving competencies in an assessment environment that is congruent with the PBL environment. This means the assessment in PBL should take into account both the organisation of the knowledge base as well as the students' problem solving skills (Segers et al., 2003). Additionally, congruency with the learning environment implies:

1. Students' problem-solving skills in an authentic assessment environment. i.e. using authentic assessment tasks or problems (Baxter \& Shavelson, 1994; Shavelson, Gao, \& Baxter 1996).

2. The authentic problems are novel to the students, asking them to transfer the knowledge and skills acquired previously and to demonstrate the understanding of the influence of contextual factors on problem analysis as well as on problem solving (Birenbaum \& Dochy, 1996). 
3. Problem analysis assessment tasks ask students to argue their ideas on the basis of various relevant perspectives (Segers, 1997).

4. The assessment of the application of knowledge when solving problems is the heart of the matter. Therefore, test items require examinees to apply their knowledge to commonly occurring and important problem-solving situations (Segers et al, 1999 , Swanson, Case \& van der Vleuten, 1991). Because a sufficient level of domain-specific knowledge is a determinant of productive problem-solving items measuring the coherence of students" knowledge base serve at least as a feedback function. For feedback reasons, the use of knowledge profiles instead of unidimensional scores is preferable (for an example see Dochy, 1992). Dochy (1992) defines knowledge profiles as "a plotting as a graph of raw or standardised scores of a group or individual on certain parameters" (p. 143). These indicate strengths and weaknesses in the student's knowledge base. Research has shown that such knowledge profiles can be seen as basic determinants of academic achievement and can accurately identify specific deficits that contribute significantly to low achievement (Dochy, 1992; Letteri, 1980; Letteri \& Kuntz, 1982). In the current situation, this implies that items assessing knowledge have to indicate the weaknesses in a student's knowledge base. For example, is s/he able to define or describe the central concepts of the domain studlied and does s/he understand their interrelations? This information enhances future learning of students in the direction of the knowledge base necessary to tackle problems.

5. The test items ask for more than the knowledge of separate concepts. The assessment of integrative knowledge, requiring the integration of relevant ideas and concepts, is stressed. Since real life problems are mostly multidimensional, and as such integrate different disciplines within one field of study, assessment focuses on problems with this integrative characteristic (Segers, 1997).

\section{Theoretical framework on problem solving}

The literature on problem-solving is characterised by a wide variety of theoretical frameworks (e.g. De Corte, 1996; Glaser, Raghavan and Baxter, 1992; O'Neil \& Schacter, 1997; Schoenfeld, 1985; Smith, 1991). Despite their differences in details and terminology, all models agree that an organised and structured domain specific knowledge base, and metacognitive functions that operate on that knowledge, are essential parts for successful problem-solving. There is also a fairly broad consensus that differences in motivation and beliefs account for problemsolving style.

Starting from a review of three comprehensive models of the components of problem solving (Glaser et al., 1992; Schoenfeld, 1985; Smith, 1991), Sugrue (1993, 1995) presents an integrated theory-based model of the cognitive components of problem-solving. The great benefit, for our purpose, of this model over the Glaser et al. model, the Schoenfeld model and the Smith model is that the Sugrue model is translated into specifications for the assessment of the main cognitive components of problem-solving. Sugrue assumes that successful problemsolving in a given domain results from the interaction of knowledge structure, 
metacognitive functions and motivation. For each of the three categories of cognitive components, Sugrue describes a limited set of variables that should be targeted by assessment. Since it would be impracticable to measure all of the variables that relate to the three cognitive components of problem solving, two criteria guided the selection of variables in each category: (1) variables are shown to be critical by research or (2) when research based conclusions are not clear; variables selected are open to instructional intervention (this second criterion was suggested by Snow, 1990). These two criteria led to a model of the cognitive components of problem solving that should be targeted by assessment as presented in Figure 1.

\begin{tabular}{|c|c|c|}
\hline Knowledge structure & Metacognitive functions & Motivation \\
\hline 1) concepts & 1) planning & 1) perceiwed self efficacy \\
\hline 2) principles & 2) monitoring & $\begin{array}{l}\text { 2) perceived demands of the } \\
\text { task }\end{array}$ \\
\hline $\begin{array}{l}\text { 3) links from concepts and } \\
\text { principles to conditions and } \\
\text { procedures for application }\end{array}$ & & $\begin{array}{l}\text { 3) perceived attraction of the } \\
\text { task }\end{array}$ \\
\hline
\end{tabular}

Figure 1: Cognitive components of problem solving to be assessed (after Sugrue, 1995)

In line with the aforementioned main goals of PBL, we will focus in what follows on the influence of the assessment of students' knowledge and knowledge application on the reported effects in studies comparing PBL with more conventional learning environments. Both the acquisition as well as the application of knowledge can be situated in the knowledge structure component of the problemsolving model as will be outlined below. Sugrue (1995) argues that good problem solvers

draw on a store of automated task-specific procedures. Assessment should permit identification of the nature and extent of a student's knowledge of principles and procedures in the domain of interest. In addition, since principles are rules that involve relationships among concepts, then the student's knowledge of the individual concepts should also be measured. It may be that a student has knowledge of individual concepts but has little or no knowledge of the general rules (principles) governing the relationships among the concepts. Finally, one should be able to identify students who have knowledge of principles, but whose knowledge of specific procedures is limited. (p.29-30)

This supports a distinction between three aspects of the knowledge structure that can be targeted by assessment of problem solving. First, the understanding of concepts, which can be defined as "a category of objects, events, people, symbols or ideas that share common defining attributes or properties and are identified by the same name" (Sugrue, 1993, p.9). It bellongs to the category of what cognitive psychologists have called declarative knowledge. Next, understanding of the principles that link concepts should be distinguished. Sugrue (1993, p. 9) defines a principle as "a rule, law, formula, or if-then statement that characterises the relationship (often crusal) between two or more concepts. 
Principles can be used to interpret problems, to guide actions, to troubleshoot systems, to explain why something happened, or to predict the effect a change in some concept(s) will have on other concepts". If-then production rules or sequences of steps have often been called procedural knowledge (Anderson, Reynolds, Schallert \& Goetz, 1977). Finally, the linking of concepts and principles to conditions and procedures for application should also be targeted by assessment. A "procedure' defined as "a set of steps that can be carried out either to classify an instance of a concept or to change the state of a concept to effect a change in another" (Sugrue, 1993, p. 22) and "conditions" as "aspects of the environment that indicate the existence of an instance of a concept, and/or that a principle is operating or can be applied and/or that a particular procedure is appropriate" (Sugrue, 1993, p. 22) can be placed in the category of conditional knowledge (Paris, Lipson \& Wixson, 1983). In this final aspect of the knowledge structure, linking of concepts and principles to conditions and procedures for application, declarative knowledge becomes encapsulated in procedural knowledge. To facilitate problemsolving, concepts and principles are linked to conditions and procedures to facilitate their use in unfamiliar situations (Gagné et al., 1993).

\begin{tabular}{|c|c|c|c|}
\hline $\begin{array}{l}\text { Elements of the } \\
\text { knowledge structure }\end{array}$ & $\begin{array}{l}\text { Method } \\
\text { Selection (MC) }\end{array}$ & $\begin{array}{l}\text { Generation } \\
\text { (open-ended) }\end{array}$ & $\begin{array}{l}\text { Explanation } \\
\text { (hands-on) }\end{array}$ \\
\hline concepts & Sielect examples & Generate examples & $\begin{array}{l}\text { Explain why examples } \\
\text { reflect concept } \\
\text { attributes } \\
\text { Select live examples }\end{array}$ \\
\hline Principles & $\begin{array}{l}\text { Select similar problems } \\
\text { Select best prediction } \\
\text { Select best explanation }\end{array}$ & $\begin{array}{l}\text { generate predictions or } \\
\text { solutions } \\
\text { explain an event }\end{array}$ & $\begin{array}{l}\text { explain predictions or } \\
\text { solutions }\end{array}$ \\
\hline Application & $\begin{array}{l}\text { select contect procedure } \\
\text { for identifying } \\
\text { instances } \\
\text { select nost appropriate } \\
\text { procedure to change the } \\
\text { state of a concept by } \\
\text { manipulating another }\end{array}$ & $\begin{array}{l}\text { perform task-specific } \\
\text { procedures } \\
\text { generate (describe) a } \\
\text { procedure for... }\end{array}$ & $\begin{array}{l}\text { explain how to perform } \\
\text { a procedure }\end{array}$ \\
\hline
\end{tabular}

Figure 2: Construct-by-format matrix for measuring constructs related to the knowledge structure (after Sugrue; 1995).

Sugrue translated her model into specifications for the assessment of the main cognitive components of problem-solving (Sugrue, 1993, 1995).Various assessment methods for measuring each of the three levels of the knowledge structure can be identified (see Figure 2). Whether the assessment method used to assess the knowledge structure is a multiple choice, open-ended or hands-on format, the focus should be on the level of assessment: The extent to which the student's knowledge structure is organised around key concepts and principles that are linked to conditions and procedures for application. As described above, three different levels can be distinguished in the knowledge structure. In the first level the assessment of the understanding of concepts is the core issue. For example, voltage and resistance are physical concepts. At the second level, understanding of the 
principles that link concepts is the subject of assessment. In physics, for example, the law of Ohm is a principle that prescribes current as a function of voltage and resistance in an electrical circuit. The third and final level targets the linking of concepts and principles to conditions and procedures for application. At this level the organised knowledge is applied under the appropriate circumstances, for instance to connect up an electrical circuit with bulbs and batteries in such a way that a certain level of current flows through it (Sugrue, 1995).

\section{Research questions}

Prior reviews gave an overview of the effect of the implementation of PBL compared with more conventional educational methods. The meta-analysis presented in chapter 4 included the method of assessment as a moderator variable suggesting that the more an instrument is capable of evaluating the students' competence in knowledge application, the larger the ascertained effect of PBL. In the study presented in this chapter, we want to go a step further and investigate the influence of assessment as the main independent variable. The goal of this studly is to describe these effects of PBL from the angle of the underlying focal constructs being measured with the assessment. Using Sugrue's model $(1993,1995)$ as a frame of reference, the research questions can be formulated as follows. What are the effects of PBL when the assessment of its main goals focuses on respectively (1) the understanding of concepts, (2) the understanding of the principles that link concepts and (3) the linking of concepts and principles to conditions and procedures for application?

From the described main goals of PBL, and the suggestion made from the moderator analysis in the review presented in chapter 4 , it is expected that compared to conventional educational methods, the effect of $\mathrm{PBL}$ should increase with each level of the knowledge structure.

\section{Method}

\section{Criteria for inclusion}

Before searching the literature for work pertaining to the effects of PBL, we determined the criteria for inclusion in our analysis. First, each study had to be empirical, meaning that some data collection on students had to be included. Although more non-empirical literature and literature reviews were selected as sources of relevant research, this literature was not included in the analysis. Secondly, the characteristics of the problem-based learning environment, had to fit the previously described core model of PBL (Barrows, 1996). Thirdly, each study 
had to include some course or curriculum comparison. Specifically, it had to compare students in a PBL environment with students in a more conventional educational setting. The dependent variables used in the studies had to be operationalised aspects of the main goals of PBL (i.e. knowledge acquisition and knowledge application). Fourthly, the subjects of study had to be students in higher education (including college and university students in all possible domains of interest). Finally, to maximise ecological validity, each study had to be conducted in a real-life classroom or programmatic setting rather than under more controlled laboratory conditions.

\section{Literature search}

The review and integration of research literature begins with the identification of the literature. Locating studies is the stage at which the most serious form of bias enters a meta-analysis (Glass, McGaw \& Smith, 1981): "How one's search determines what one finds; and what one finds is the basis of the conclusions of one's integration" (Glass, 1976, p. 6). The best protection against this source of bias is a thorough description of the procedure used to locate the studies.

A literature search was started in 1997 which included both published and unpublished studies. A wide variety of computerised databases were utilised including: the Educational Resources Information Center (ERIC) catalogue, PsycLIT, ADION, and LIBIS as well as the Current Contents (for Social Sciences). The following keywords were used: problem-solving, learning, problem-based learning, higher education, research, and review. The literature was selected based on the abstracts. This reading resulted in the selection of 14 publications that met the above criteria. Next, we employed the 'snowball method' and reviewed the references in the selected articles for additional works. Review articles and theoretical overviews were also gathered to check their references. This method yilelded 17 new studies.

A second literature search that began in 1999 followed the same procedure. In addition, we contacted several researchers active in the field of PBL and asked them to provide relevant studies or to identify additional sources of studies. This second search yielded 9 additional studies.

Although our search for literature was not limited to one single domain of interest, almost all studies meeting the criteria for inclusion were conducted in the domain of medical education. Only one study (Son \& VanSickle, 2000) was situated outside the medical domain, in the field of economics. The strategies used to search for literature were meant to uncover both published and unpublished studies to prevent for publication bias. A great deal of papers was traced, but further reading revealed that eventually all papers had been published as an article in a peer-reviewed journal (e.g. Schmidt et al, 1996) or as chapter in an edited book (e.g. Boshuizen, Schmidt \& Wassamer 1990). 


\section{Coding study characteristics}

Using our research question as a guide we defined the characteristics central to our review and analysed the articles we selected on the basis of these characteristics. Specifically, the following information was recorded in tables:

- first author and the year of publication;

- number of subjects;

- method of assessment

- level of assessment

- principal outcomes of the research; and

- statistical values.

In coding this information and constructing overview tables, we used the following coding guidelines. Only the outcomes related to the main goals of PBL were coded. The studies included in our review assessed the effects of PBL in very different ways. Some studies were more broadly-based and also examined other effects of PBL (e.g. satisfaction), but the inclusion of results was narrowed to the main goals of PBL (i.e. knowledge acquisition and knowledge application). To classify the outcomes at one of the three levels in the model of Sugrue (1995), an extended description of the assessment and constructs being assessed was added to the study characteristics coding table. Additional information was searched when the original data was too limited or unclear (e.g. Donner \& Bickley, 1990; Kaufman, Mennin, Waterman, Duban, Hansbarger, Silverblatt et al., 1989). Some assessment methods were always classified at the same level. Other methods, such as the use of essay questions, did not always measure at the same conceptual level and were classified at different levels depending on the particular study. For the main methods of assessment, the classification as a result of the rating at the three levels by three independent raters, is summarised in the next section. When there was disagreement among the raters, the classification was discussed until a clear consensus was reached. A complete overview can be found at the end of this dissertation in appendix $\mathrm{D}$.

National board of medical examiners: United States Medical Licensing Examination. USMLE is the examination doctors need to succeed in order to be allowed to practice medicine in the United States. The examination consists of three parts: 'step 1' (at the end of year 2), 'step 2' (after the 3d year) and 'step 3' (at the end of the study) (Case, 1999). The focus of each part is different. 'Step l' stresses important concepts of the basic sciences to the practice of medicine, with special emphasis on principles and mechanisms underlying health, disease, and methods of therapy, 'step 2' assesses whether you can apply medical knowledge and understanding of clinical science essential for the provision of patient care under supervision, and includes emphasis on health promotion and disease prevention, and 'step $3^{\text {' }}$ assesses whether you can apply medical knowledge and understanding of biomedical and clinical science essential for the unsupervised practice of medicine, with emphasis on patient management in ambulatory settings (Federation of State Medical Boards \& NBME, n.d.). The 'FLEX' examination (Jones, Bieber, 
Echt, Scheifley \& Ways, 1984) was a similar examination administered in the past (Case, 1999). The 'NBME medicine shelf test' used in the study of Richards, Ober, Cariaga-Lo, Camp, Philip, McFarlane ef al. (1996) is a test from the NBME with items from the 'step 2' examination (Case, 1999).

From this information we coded in every study using the NBME or USML examinations 'step 1' as assessing the first level of the knowledge structure, step 2 as assessing the second level and step 3 as assessing the third level.

Modified essay questions (MEQ). The MEQ is a standardised series of open questions about a problem. The information on the case is ordered sequentially: The student receives new information only after answering a certain question (Verwijnen, Imbos, Snellen, Stalenhoef, Sprooten \& Van der Vleuten, 1982). The student must relate theoretical knowledge to the particular situation of the case (Knox, 1989). Because the context of the particular situation of the case plays an important role in these questions, all MEQ-questions were classified as assessing the third level of the knowledge structure.

Progress tests. The progress test is a written test consisting of about 250 true-false items sampling the full domain of knowledge a graduate should be able to recall. The progress test is designed by a 'progress test review committee' based on a predefined blueprint of content domains to provide a longitudinal assessment of the progress toward the final curricular objectives (Verwijnen et al., 1982). The test is constructed to assess also 'rooted' knowledge, not only details (Mehrens \& Lehmann, 1991). All progress tests were classified as assessing the first level of the knowledge structure.

Free recall. Students are asked to write down everything they can remember about a certain subject. This task makes a strong appeal to the students' retrieval strategies. Free recall was used in the study by Tans, Schmidt, SchadeHoogeveen and Gijselaers (1986) as a retention test, and makes in this study a relatively large appeal on the organisation of the knowledge base (Patel \& Groen, 1986). As such, in the study by Tans et al. (1986), the free recall test was classified as assessing the second level of the knowledge structure. In the study by Moore, Block, Style and Mitchell (1994) students had to recall in their fourth year the material learned in two courses in year one and two, there was no attention for the structure of the material. In the study by Moore et al. (1994) the free recall test is classified as assessing the first level of the knowledge structure.

Standardised patient simulations. These tests are developed by the OMERAD Institute of the University of Michigan. A patient case is simulated and students' knowledge and clinical skills are assessed by asking the student specific questions (Jones, Bieber, Echt, Scheifley \& Ways, 1984). In the study of Barrows \& Tamblyn (1976) and Distlehorst \& Robbs (1998) standardised patient simulations were both classified as assessing the third level of the knowledge structure.

Essay questions. Questions requiring an elaborated written answer are asked (Mehrens \& Lehmann, 1991). The classification of essay questions was dependent on the kind of response that was required. In the study of Aaron, Crocket, Morrish, Basualdo, Kovithavongs, Mielke et al. (1998) students had to use their knowledge in a new context, thus the essay-questions were classified as measuring the third level of the knowledge structure. In the study of Martenson, 
Eriksson \& Ingelman-Sundberg (1985) the focus was on understanding and representing the second level of the knowledge structure.

Short-answer questions. Compared to an essay question, the length of the desired answer is restricted. But as with the classification of essay questions, the kind of response to be given is determinant. The study of Martenson et al. (1985) focused on understanding (2nd level) and in both of the Antepohl \& Herzig studies $(1997,1999)$ the questions were used to assess factual knowledge, representing the first level of the knowledge structure.

Multiple-choice questions. Multiple choice questions can be used to assess all three levels in the knowledge structure, as indicated in figure 2. However, in all the studies using the multiple-choice format in this review, the focus was on reproduction. As a consequence, all multiple-choice questions were classified as assessing the first level of the knowledge structure.

Oral examinations. The classification of oral examinations was dependent on the kind of response that was required. In the study of Goodman et al. (1991) the oral examination was classified as assessing the first level, but in the same study it was also assessing the second level of the knowledge structure.

Performance-based testing: Rating. Standardised rating scales are used to evaluate the performance of the students (performance assessment) (Shavelson et al., 1996). They can be used to evaluate all three levels in the knowledge structure. Ratings are used to assess the amount of factual knowledge (first level) but also, for example, to assess the organisation of information (second level), such as in the study of Richards et al. (1996). They are used to assess the third level way by rating, for example the communication with patients and teamwork in the study of Santos-Gomez, Kalishman, Rezler, Skipper and Mennin (1990).

Case-based examinations. Students have to answer questions about an authentic case. In most studies, cases were classified at level 2 of the knowledge structure (e.g. Schmidt 1996; Hmelo, 1998) Only in the study of Schuwirth et al.(1999) after studying the examples of the cases and questions in Schuwirth (1998), the cases were classified as assessing the third level of the knowledge structure.

\section{Synthesising research}

There are three methods to review literature: Narrative reviews, quantitative methods, and statistical meta-analysis. In a narrative review, the author tries to make sense of the literature in a systematic and creative way (Van IJzendoorn, 1997). Quantitative methods utilise elementary mathematical procedures for synthesising research studies (e.g., counting frequencies into box scores). These methods are more objective but give less in-depth information than a narrative review (Dochy et al., 1999). Glass (1976) systematised the approach of quantitative procedures and introduced the term meta-analysis: The analysis of analyses, i.e., the statistical analysis of a large collection of analysis results from individual studies for the purpose of integrating the findings (Kulik \& Kulik, 1989). An important advantage is that large numbers of studies that vary substantially can 
be integrated, and that this integration is not greatly influenced by the interpretation and the use of findings by the reviewers.

The oldest procedure to integrate studies is the narrative review. In the narrative or qualitative review, results from each study are considered at "face value', and one tries to integrate the findings in an umbrella theory (Hunter \& Schimidt, 1990). This takes place in a systematic, and at the same time, creative way: However ${ }^{2}$ this integration often arises from taking only a small number of studies into account, classifying all other studies as deficient (Glass, 1976).

Van Uzendoorn (1997) points out that the narrative and the quantitative reviewer set about the formulation of hypotheses and the systematic gathering of relevant studies in the same way. However, at the stage of data-analysis, their methods diverge. Nevertheless, the interpretation of the more statistical quantitative meta-analysis presupposes the narrative reviewers strength: creativity and intuition. With Van Ijzendoorn $(1997$, p.4) we conclude that "(...) a narrative component should always be integrated in the meta-analytic approach".

For our purposes, a statistical meta-analysis was conducted, using the MetaStat 1.5 software. This analysis was supplemented by more inclusive vote counts and the associated sign test. The simplest and most conservative methods for combining results of independent comparisons are the vote-counting methods. To do a vote count of directional results, the reviewer must count the number of comparisons that report significant results in the positive direction and compare this to the number of comperisons reporting significant results in the negative direction (Cooper, 1989). Once counted, a sign test is performed to discover if the cumulative results suggest that one direction occurs more frequently than chance would suggest (Cooper, 1989; Hunter \& Schmidt, 1990). In performing this procedure, one assumes that under the null hypothesis of no relation in the population, the frequency of significant positive results and negative results are expected to be equal (Hedges \& Olkin, 1980). In performing the vote count, the number of experiments with significant positive and negative findings was counted. If one study contained multiple experiments, they were all counted.

In order to perform this procedure only limited information is needed. In this context, Cooper (1989, p.94) suggests that "Vote counts should always be described in quantitative reviews, but (...) should always be supplemented with more sensitive procedures". In our review, the vote counts allow us to include studies which reported insufficient exact statistical data to be included in the more sensitive procedure we used: the statistical meta-analysis. Hunter and Schmidt (1990) define the statistical meta-analysis as the quantitative accumulation and analysis of effect sizes and other descriptive statistics across studies.

\section{Metric for expressing effect sizes}

The statistical meta-analysis integrates statistically empirical studies investigating the same phenomenon. The findings of all these studies have to be expressed in a common form, the effect size in order to make any comparison possible. Regarding the nature of the studies included in our statistical metaanalysis, we used the standardised mean difference ( $d$-index) effect size. 
This metric is appropriate when the means of two groups are being compared (Cooper, 1989; Glass et al., 1981). The $d$-index expresses the distance between the two group means in terms of their common standard deviation. This common standard deviation is calculated by using the standard deviation of the control group since it is not affected by the treatment.

In the present study, the calculation of the effect size was sometimes hampered or even out of the question because research reports and articles varied in their completeness of reporting research results (e.g. Mennin, Friedman, Skipper, Kalishman \& Snyder, 1993). Several research reports failed to report the mean and standard deviation of the control group. In that case, the effect size was calculated. as much as possible by means of the transformation of $t$, Chi-square en $F$ w statistics (Cooper, 1989; Glass et al., 1981). In some cases the effect size was calculated starting from data on the significance level (e.g. Santos-Gomez et al., 1990). When no exact $p$-values were reported, the $p$-value corresponding to the highest value in the probability range reported by the researchers was used. (e.g. when in the original work ' $p<.05$ ' was mentioned, the value on the basis of which the effect size was calculated became $p=.05$; e.g. Schuwirth et al., 1999). As a consequence, the effect sizes calculated and used in the analysis represent a conservative approach and tend to underestimate the real values. Effect sizes were not deduced from unreliable data in the reported findings (e.g. from graphs). In such cases, only the sign of the difference between the two conditions was reported.

\section{Identifying independent hypothesis tests}

Sometimes a single study may contain multiple tests of the same hypothesis. Since one of the assumptions underlying meta-analysis is that effects are independent from one another, a decision must be made about what will be considered as an independent estimate of effect when a single study reports multiple outcomes. Several strategies can be suggested regarding how to decide on the unit of analysis when calculating average effect sizes. In this study, we used the shifting units method from Cooper (1989). Each effect size resulting from hypothesis tests with independent samples was initially coded as if it were an independent event. However, study outcomes resulting from the same sample are also aggregated within the separate categories of the influencing variable (e.g. Anthepol \& Herzig, 1999, see appendix D, aggregated effect sizes in bold). This strategy is a compromise that allows studies to retain their maximum information value, while keeping any violation of the assumption of independence of hypothesis tests to a minimum.

\section{Combining effect sizes across studies}

Once an effect size had been calculated for each study or comparison, the effects testing the same hypothesis were averaged. Unweighted and weighted procedures were used. In the unweighted procedure, each effect size was weighted 
equally in calculating the average effect. In the weighted procedure, more weight is given to effect sizes with larger samples (factor $w=$ inverse of the variance), based on the assumption that the larger samples more closely approximate actual effects (Cooper, 1989; Hedges \& Olkin, 1985). These weighted combined effect sizes were tested for statistical significance by calculating the $95 \%$ confidence interval (Cooper, 1989).

\section{Analysing variance in effect sizes across studies.}

The last step was to examine the variability of the effect sizes via a homogeneity analysis (Cooper, 1989; Hedges \& Olkin, 1985; Hunter \& Schmidt, 1990). First a Q-statistic is calculated for each subgroup of comparisons. Then the value of these statistics is added up to obtain a value Qw ("within-group chisquare'). Then, this value is subtracted from Qt (Chi-square distribution, N-1 degrees of freedom) to obtain $\mathrm{Qb}$ ('between-group chi-square') $(\mathrm{Qb}=\mathrm{Qt}-\mathrm{Qw}$ ). The statistic $\mathrm{Qb}$ is used to test the homogeneity of the mean effect of grouping. If $\mathrm{Qb}$ reached a significant level, the grouping factor provided a significant contribution to the variance in the set of effect sizes. Qw is comparable to Qt, meaning that if this statistic reaches a significant level, there is a need for further grouping of the data (Hunter, Schmidt \& Jackson, 1982; Springer, Stanne \& Donovan, 1999).

\section{Results}

Forty studies met the inclusion criteria for the meta-analysis, 31 studies were published in peer-reviewed journals, 9 studies were published in edited books. Of the 40 studies, $31(77 \%)$ presented data on knowledge-concepts effects, 17 studies $(42 \%)$ presented data on knowledge principles-effects and $8(20 \%)$ reported data on effects concerning the application of knowledge (conditions and procedures). These percentages add up to more than 100 since several studies presented outcomes of more than one calegory (see also appendix D).

Plotting the effect sizes by study, three studies show to be serious outliers (Eisenstaedt, Barry \& Glanz, 1990; Mennin et al. 1993; Tans et al., 1986). When these three studies (all situated at the concept-level of the knowledge structure) are left aside, the main effect of PBL on the three levels of the knowledge structure measured emerge to be different. The results of the analysis are summarised in Table 1.

In general, the results of the vote count were statistically significant, except for the assessment of the first level of the knowledge structure. These results suggest that students in PBL perform better at the second and third level of the knowledge structure. None of the studies reported significant negative findings at the third level of the knowledge structure. Only one study reported negative 
findings at the second level of the knowledge structure. At the level of understanding concepts (first level), the vote count shows a negative tendency with 5 studies yielding a significant negative effect and only 3 studies yielding a significant positive effect. However, the latter difference is not significant at the 5\%-level. If we look to the weighted combined effect sizes, the latter negative effect is close to zero but positive (ES=0.068) based on 21 studies. Based on 15 studies, students studying in PBL classes demonstrated better understanding of the principles that link concepts ( $E S=0.795$ ) than students who were exposed to conventional instruction. Based on 13 studies, students in PBL were better at the third level of the knowledge structure $(E S=0.339$ ) than students in conventional classes. Importantly, the average weighted effect size of 0.795 belonging to the second level of the knowledge structure was the only statistically significant result.

Table 1: Main effects of PBL

\begin{tabular}{|c|c|c|c|c|c|c|c|}
\hline \multirow[t]{2}{*}{ Outcome } & \multirow{2}{*}{$\begin{array}{c}\text { Sign. } \\
+\end{array}$} & \multirow{2}{*}{ Sign. } & \multirow{2}{*}{$\begin{array}{c}\text { Studies } \\
N\end{array}$} & \multicolumn{2}{|c|}{ Average ES } & \multirow[t]{2}{*}{$\mathrm{Qb}$} & \multirow[t]{2}{*}{ Qw } \\
\hline & & & & Unweighted & Weighted (Cl 95\%) & & \\
\hline Concepts & 3 & 5 & 21 & -0.042 & $0.068(+1-0.864)^{265}$ & 18.99 & $113.563^{\circ}$ \\
\hline Principles & 17 & $1^{*}$ & 15 & +0.748 & $+0.795(+/-0.782)$ & & 82. $196^{\text {4. }}$ \\
\hline Application & 6 & $0^{*}$ & 13 & $+0,401$ & $+0.339(+/-0.662)^{1 \mathrm{~s}}$ & & $23356^{* *}$ \\
\hline
\end{tabular}

Two-sided sign-test is significant at the $5 \%$ level

$p<0.05$

Sign. $+1-$ : number of studies with a significant (at the $5 \%$ level) positive $/$ negative finding.

Studies $N$ : the number of total indepenclent outcomes measured

Note: Unless noted ${ }^{\text {th }}$ all weighted effect sizes are statistically significant (the $95 \%$ confidence intervals do not include zero). Unweighted effect sizes were not tested for significance.

As can be seen from the statistically significant Qb statistics reported in Table 1, the grouping into three llevels of assessment, allows to get a better insight into the effects of PBL. However, the results of the homogeneity analysis suggest that further grouping of the data is necessary to fully understand the moderators of the effects of PBL. As indicated by statistically significant Qw statistics, one or more factors other than chance or sampling error account for the heterogeneous distribution of effect sizes.

\section{Conclusion and discussion}

The purpose of this chapter was to examine the effects of PBL from the angle of the underlying focal constructs being measured with the assessment. We were interested in empirical and quasi-experimental studies with a clear description of the conditions and measures used to assess the effects of PBL. As a result, our search for literature examining the effects of PBL yielded 40 studies, reviewed by means of a statistical meta-analysis supplemented by the more inclusive vote counts 
and the associated sign test. When appropriate, some narrative comments have been made. The model of Sugrue (1995) on the cognitive components of problem solving was used to classify the methods of assessment used in different studies into three categories of analysis. These three categories were the three levels of the knowledge structure that can be targeted by assessment of problem solving: the understanding of concepts, understanding of the principles that link concepts, and finally, the linking of concepts and principles to conditions and procedures for application.

Before discussing the conclusions we can draw from the analysis, it is impertant to consider the limitations of the review presented in this chapter. The selection of studies for a review of any type is subject to selection bias. Bias, for example, can be caused by selecting only published work, which tends to report only statistically significant results (Glass, 1976). We attempted to avoid this form of bias by also searching for unpublished work. However, all of the studies involved turned out to be published eventually, 31 studies were published in a peer-reviewed journal, 9 studies were published in an edited book. Another remarkable fact is that, although our literature search was broad, except for one study which was in the field of economics (Son \& VanSickle, 2000), all studies that met the criteria for inclusion were situated in the domain of medical education. Although PBL originated in medical education, it has been applied globally for many years in several disciplines. However, claims on the effects of PBL until now seem to rely almost exclusively on literature in medical education. Generalisations should therefore be made with special caution. It is also known that selection bias problems are sometimes inherent in 'between institution' or 'elective track' studies. Another criticism to meta-analysis, known as the 'garbage in and garbage out' issue (Hunt, 1997) meaning mixing together good and bad studies also possibly applies to our review. A clear description of our criteria for inclusion and the use of a weighting technique that takes into account the sample size of studies - based on the assumption that the larger samples more closely approximate actual effects (Cooper, 1989; Hedges \& Olkin, 1985) should overcome these critiques to a certain extent.

A final limitation of this study is related to the theoretical framework used to concretise the research question and to interpret and code the studies involved in the studly. The model presented by Sugrue $(1993,1995)$ is only one possible framework on the components of problem solving. The translation of the model into specifications for the assessment of problem-solving made the model useful for our purpose. The strength of the model is at the same time the greatest weakness of the model. The classification in the three levels of the knowledge structure can relatively easily be done in most domains, such as mathematics, science, economics and medical education. The extraction of unambiguous principles governing relationships among concepts might not be easy to use in other domains such as history (Sugrue, 1995).

Despite these limitations, we feel that several useful conclusions may be drawn from the analysis of studies in this review. In general, the effect of PBL differs according to the levels of the knowledge structure being measured. PBL had most positive effects when the focal constructs being assessed were at the level of understanding the principles that link concepts, the second level of the knowledge 
structure. Only one study presented significant negative findings (Martenson et al, 1985). No negative findings were found at the third level of the knowledge structure. This seems to be in line with the tentative conclusion of chapter 4 suggesting that the more an instrument is capable of evaluating the application of knowledge by the student, the larger the ascertained effect of PBL. This conclusion is confirmed when looking at the first level of the knowledge structure: More studies report negative effects of PBL when assessing the understanding of concepts. However, when taking the weighted effect sizes into account, a different picture emerges. PBL has a small positive effect size (ES $=0.068$ ), meaning that when the understanding of concepts are the subject of the assessment, students in PBL perform at least as good as students in conventional learning environments. However, the effect size is not statistically significant. In line with the conclusion of chapter 4, the effect of PBL is more positive when understanding of the principles that link concepts is at the heart of the assessment $(E S=0.795)$. Different from to the suggestion that effects of PBL should be larger when more complex levels of the knowledge structure are being assessed, the effect size belonging to the third level of the knowledge structure, although still positive, is smaller $(E S=0.339)$ but not statistically significant.

Linking these results to the main goals of PBL and the expert-novice studies, it could be concluded that students' path towards expertise has been accelerated (Glaser, 1990). First, students in PBL seem to posses a highly structured network of concepts and principles (level 2). Secondly, students in PBL are equally competent at recalling specific items of information compared to students in more conventional learning environments. Although students in PBL are better in relating their knowledge base to the goals of problem solution and conditions for action, the magnitude of the effect belonging to the third level of the knowledge is not very large and not statistically significant. The question is to what extent students' year of study is a moderating variable. It might be expected that when the students' assessment is close to graduation, the results show higher positive effect sizes than in research settings measuring at an earlier stage of the study. The expertise level of the students was one of the moderating variables in the meta-analysis presented in chapter 4 . Te results suggested that the advantage of the conventional educational method in knowledge acquisition disappears after the second year. The effects of PBL on the application of knowledge differentiated for expertise-level of students showed a positive effect of PBL.

PBL aims to educate students that are able to solve complex problems. In order to be congruent with its educational goals and resulting instructional principles and practices, the assessment of the application of knowledge when solving problems is at the heart of the matter in PBL. Therefore, one could expect students in PBL performing better at this level of the knowledge structure. The effect of $\mathrm{PBL}$ is larger when assessment appeals to the understanding of principles that link concepts. In only 8 of the 40 studies the assessment focused at the third level of the knowledge structure. Most studies $(\mathrm{N}=31)$ report assessment at the level of understanding of concepts. There is an implicit challenge for PBL and comparative research on PBL in these results to pay more attention to this third 
level of the knowledge structure. If PBL aims to educate better problem solvers, more attention should be paid to this, both during the learning activities that take place and students' assessment in PBL. Since the aim of educating graduates being able to solve complex problems in an efficient way is a general goal in higher education, this concern counts for all learning environments in the context of higher education and probably beyond.

The evaluation of the practical significance of an effect size is a subject of discussion between researchers in education and other fields (Springer et al, 1999). Cohen (1988) and Kirk (1996) recommend that $d=0.20$ (small effect), $d=0.50$ (moderate effect), and $d=0.80$ (large effect) serve as general guidelines. Within education, in general an effect size of 0.33 is seen as the minimum to establish practical significance (Gall, Borg \& Gall, 1996). In this light, the results of the present meta-analysis are of practical significance $(E S=0.339)$ for the assessment of the organisation of the knowledge structure, but certainly when assessment addresses the linking of concepts and principles to application conditions and procedures $(E S=0.795$ ). The latter comes closer to the desired effect for major curricula interventions of $\mathrm{ES}=\mathbb{1 . 0 0}$ as assumed in the critical overview of Colliver (2000).

From the homogeneity analysis, it is clear that the method of assessment has an important influence in the reported effects of PBL, as stated above, but also that other moderators of PBL play a substantial role when the effects of PBL are examined. Other moderators such as study design, scope of implementation and year of study have been shown to be possible other moderating variables in the reporting of the effects of PBL (see chapter 4). However, the scope of this chapter was to investigate the assessment of the three levels of the knowledge structure, as main independent variable. Related to the influence of assessment as a moderator variable, it would be interesting for future research to take also the context of assessment (for licensure and grading purposes or only for research purposes) into account. Nevertheless, it became clear from this study that the implications of assessiment and the levels in the knowledge structure being measured must be considered when examining the effects of problem-based learning and probably in all comparative educational research.

\section{References}

Asterisks indicate articles analysed in this study (see Appendix D)

*Aaron, S., Crocket, J., Morrish, D., Basualdo, C., Kovithavongs, T., Mielke, B., Cook, D. (1998). Assessment of exam performance after change to problem-based leaming: Differential effects by question type. Teaching and Learning in Medicine, 10 (2), 86-91.

Albanese, M.A., \& Mitchell, S. (1993). Problem-based learning: A review of literature on its outcomes and implementation issues. Academic Medicine, $68,52-81$. 
Albano, M.G., Cavallo, F., Hoogenboom, R., Magni, F. Majoor, G., Mananti, F. Schuwirth, L., Stiegler, I. \& Van Der Vleuten, C. (1996). An international comparison of knowledge levels of medical students: The Maastricht progress test. Medical Education, $30,239-245$.

Anderson, R. C., Reynolds, R. E., \& Schallert, D. L., \& Goetz, E. T. (1977). Frameworks for comprehending. American Edwcational Research Jownal. 14, 367-381.

*Antepohl, W., \& Herzig, S. (1997). Problem-based learning supplementing in the course of basic pharmacology-results and perspectives from two medical schools. Namyn-Schniedeberg's Archives of Phamacology, 355, R18.

*Antepohl, W., \& Herzig, S. (1999). Problent-based leaming versus lecture-based learning in a course of basic pharmacology: A controlled, randomized study. Medical Education, 33 (2), 106-113.

Ausubel, D., Novak, J., \& Hanesian, H. (1978). Educational Psychology: A cognitive view (2nd ed.). New York: Holt, Rinehart \& Winston.

*Baca, E., Mennin, S.P., Kaufman, A., \& Moore-West, M. (1990). Comparison between a problem-based, community-oriented track and a traditional track within one medical school. In Z.M. Nooman, H.G. Schmidt, \& E.S. Ezzat (Eds.), Innovation in medical education: An evaluation of its present status (pp.9-26). New York: Springer.

Barrows, H. S. (1986). A taxonomy of problem-based learning methods. Medical Education, 20, $481-486$

Barrows, H.S. (1996). Ploblem-based learning in medicine and beyond. In L. Wilkerson, \& W.H. Gijselaers (Eds.), Bringing problem-based learning to higher education: Theory and practice. New directions for teaching and learning, No. 68. (pp. 3-13). San Francisco: Jossey-Bass Inc. Publishers.

*Barrows, H.S., \& Tamblyn, R.M. (1976). An evaluation of problem-based learning in small groups utilizing simulated patient. Journal of Medical Education, $51,52-56$.

Barrows, H.S., \& Tamblyn, R.M. (1980). Problem-based learning, An approach to medical education. New York: Springer.

Baxter, G.P., Shavelson, R.J. (1994). Science performance assessments: Benchmarks and surrogates. Intemational Joumal of Educational Research 21 (3), 279-299.

Bennett, R.E. (1993). On the meanings of constructed response. In R. Bennett \& W. Ward (Eds.), Construction versus choice in cognitve measurement: Issues in constructed responce, performance testing, and portfolio assessment (pp. 1-28). Hilsdale, NJ: Lawrence Erlbaum Assocates.

Berkson, L. (1993). Problem-based learning: Have the expectations been met? Academic Medicine, 68 (10), S79-S88.

*Bickley, H., Donner, R.S., Walker, A.N., \& Tift, J.P. (1990). Pathology education in a problem-based medical curriculum. Teaching and Learning in Medicine, 2 (1), 38-41. 
Birenbaum, M., \& Dochy, F. (Eds.)(1996). Alternatives in assessment of achievements, leaming processes and prior knowledge. Boston: Kluwer Academic Publishers.

Block, S.D., \& Moore, G.T. (1994). Project Evaluation. In D.C. Tosteson, S.J. Adelstein, \& Carver, S.T. (Eds.), New pathways to medical education: Learning to learn at Harvard medical school. Cambridge, MA: Harvard University Press.

Boshuizen, H.P.A., Schmidt, H.G., \& Wassamer (1993). Curriculum style and the integration of biomedical \& clinical knowledge. In P.A.J. Bouhuys, H.G. Schmidt \& H.J.M. van Berkel (Eds.), Problem-based learning as an educational strategy, (pp. 33-41). Maastricht: Network Publications.

Boud, D. (1987). Problem-based learning in perspective. In D. Boud (Red.), Problem-based learning in education for the professions (pp 13-18). Sydney: Higher Education Research and Development Society of Australia. Boud, D., \& Feletti, G. (1997). Changing problem-based learning. Introduction to the second edition. In D. Boud \& G. Feletti (Eds.), The challenge of problem-based learning (2nd ed., pp. 1-14). London: Kogan Page.

Bransford, J.D., Vye, N.J., Adams, L.T., Perfetto, G.A. (1989). Learning skills and the acquisiton of knowledge. In A. Lesgold, \& R. Glaser (Eds.), Foundations for a psychology of education (pp. 199-249). N.J.: Erlbaum Associates, Publishers.

Bruner, J.S. (1959). Learning and thinking. Harvard Educational Review, 29, $184-$ 192.

Bruner, J.S. (1961). The act of discovery. Harvard Educational Review, 31, 21-32.

Case, S. (Scase@mail.nbme.org). (1999, december 07). Questions NBME / USMLE. E-mail to Piet Van den Bossche

(P.vandenbossche@educ.unimaas.nl).

Cawley, P. (1989). The introduction of a problem-based option into a conventional engineering degree course. Studies in Higher Education, 14, 83-95.

Chen, S.E., Cowdroy, R.M., Kingsland, A.J., \& Ostwald, M.J. (Eds.)(1995). Reflections on problem-based leaming. Campbelltown, NSW: Australian Problem-based Learning Network.

Cohen, J. (1988). Statistical power analysis for the behavioral sciences $\left(2^{\text {nd }}\right.$ edition). Hillsdale, NJ: Erlbaum.

Colliver, J.A. (2000). Effectiveness of problem-based learning curricula: Research and theory. Academic Medecine, 75 (3), 259-266.

Cooper, H.M. (1989). Integrating research. A guide for literature reviews: Applied social research methods series ( $2^{\text {nil }}$ volume). London: Sage Publications.

De Corte, E. (1996). Instructional psychology : Overview. In E. De Corte \& F.E. Weinert (Eds.), International encyclopedia of developmental and instructional psychology (pp. 33-43). Oxford: Elsevier Science Ltd.

Dewey, J, (1910). How we think. Boston: Health \& Co.

Dewey, J. (1944). Democracy and education. New York: Macmillan Publishing Co.

*Distlehorst, L.H., \& Robbs, R.S. (1998). A comparison of problem-based learning and standard curriculum students: Three years of retrospective data. Teaching and Learning in Medicine, 10 (3), 131-137. 
Dochy, F. J. R. C. (1992). Assessment of pmor knowledge as a detenminan for future learning. UtrechtLondon: Lemma B.V.Jessica Kingsley Publishers.

Dochy, F., Segers; M., \& Buehl, M. (1999). The relation between assessment practices and outcomes of studies: The case of research on prior knowledge. Review of Educational Research, 69 (2), 145-186.

Domaldson, R. (1989). A good start in architecture. In B. Wallis (Bd.), Problembased learning: The Newcastle workshop (pp. 41-53). University of Newcastle, Faculty of Medicine.

*Donner, R.S., \& Bickley, H. (1990). Problem-based learning: An assessment of its feasibility and cost. Human Pathology, 21,881-885.

* Doucet, M.D., Purdy, R.A., Kaufman, D.M., \& Langille, D.B. (1998). Comparison of problem-based learning and lecture format in continuing medical education on headache diagnosis and management. Medical Education, 32 (6), 590-596.

*Eisenstaedt, R.S., Barry, W.E., \& Glanz, K. (1990), Problem-based leaming: Cognitive retention and cohort traits of randomly selected participants and decliners. Academic Medicine, 65 (9), 11-12.

Engel, C. E. (1997). Not just a method but a way of learning. In D. Boud \& G. Feletti (Eds.), The challenge of problem-based learning ( 2 nd ed., pp.17. 27). London : Kogan Page.

Evenson, D.H. \& Hmelo, C.E. (eds) (2000). Problem-Based Learning: A research perspective on learning interactions. Lawrence Erlbaum Associates.

*Farquhar, LJ., Haf, J., \& Kotabe, K. (1986). Effect of two preclinical curricula on NMBE part I examination performance. Journal of Medical Education, 61 , 368-373.

Federation of State Medical Boards \& National Board of Medical Examiners (n.d.). The United States medical licensing examination. Retrieved February 6, 2003, from http://www.usmle.org.

Feltovich, P.J., Spiro, R.J., \& Coulson, R.L. (1993). Learning, teaching, and testing for complex conceptual understanding. In $N$. Frederksen, $\mathbb{R}_{n}$ J. Mislevey \& I.I. Bejar (Eds.), Test theory for a new generation of tests. Hilsdale, NJ: Eribaum.

*Finch, P.M. (1999). The effect of problem-based learning on the academic performance of students studying pediatric medicine in Ontario. Medical Education, 33 (6), 411-417.

Gagné, E. D., Yekowich, C. W., \& Yekovich, F, R. (1993). The cognitive psychology of school learning (2nd ed.). New York: HarperCollins College publishers.

Gall, M.D., Borg, W.R., \& Gall, J.P. (1996). Educational research (6th ed.). White Plains, NY: Longman.

Garland, N.J. (1995). Peer group support in economics: Innovations in problembased learning. In W. Gijselaers, D. Tempelaar, P. Keizer, E Bernard, \& H. Kasper (Eds.), Educational innovation in economics and business administration: The case of problem-based learning (pp. 331-337). Dordrecht: Kluwer. 
Gijselaers, W. (1995). Perspectives on problem-based learning. In W. Gijselaers, D. Tempelaar, P. Keizer, J. Blommaer, E. Bernard \& H.Kasper (Eds.), Edcarional innovation in economics and business administsration. The case of problem-based learning (pp. 39-52). Norwell, Mass.: Kluwer.

Glaser, R. (1990). Toward new models for assessment. International Journal of Educational Research, 14,475483 .

Glaser, R. (1992). Expert knowledge and processes of thinking. In D.F. Halpern (Ed.), Enhancing thinking skills in the sctences and mathematics (pp. 63 75). Hilsdale, NJ: Lawrence Erlbaum.

Glaser, R., Raghavan, K, Baxter, G.P. (1992). Cognitive theory as the basis for design of innowative assessment: Design characteristics of science asseswments (CSE Tech. Rep. No. 349) . Los Angeles: University of California, National Center for Research on Evaluation, Standards, and Student Testing.

Glass, G.V. (1976). Primary, secondary and meta-analysis. Educational Researcher, 5, 3-8.

Glass, G.V., McGaw, B., \& Smith, M.L. (1981). Meta-analysis in social research. London: Sage Publications.

"Goodman, L.J., Brueschke, E.E., Bone, R.C., Rose, W.H., Williams, E.J., \& Paul, H.A. (1991). An experiment in medical education: A critical analysis using traditional criteria. Joumal of the American Medical Association, 265. $2373-2376$.

Hedges, L. V., \& Olkin, I. (1980). Vote counting methods in research synthesis. Psychological Bulletin, 88, 359-369.

Hedges, L.V., \& Olkin, I. (1985). Statistical Methods for meta-analysis. Orlando, FL: Academic Press.

Heycox, K., Bolzan, N. (1991). Applying problem-based learning in first-year social work. In D. Boud \& G. Feletti (Eds.), The challenge of problembased learning (pp. 186-193). New York: St. Martin's Press.

Higgins, L. (1994). Integrating background nursing experience and study at the postgraduate level: An application of problem based learning. Higher Education Research and Development, 13, 23-33.

*Hmelo, C.E. (1998). Problem-based leaning: Effects on the early acquisition of cognitive skill in medicine. The Journal of the Leaming Sciences, 7, 173236.

*Hmelo, C.E. Gotterer, G.S., \& Bransford, J.D. (1997). A theory-driven approach to assessing the cognitive effects of PBL. Instructional Science, 25, 387408.

Hunt, M. (1997). How Science Takes Stock. New York: Russell Sage Found.

Hunter, J.E., \& Schmidt, F.L. (1990). Methods of meta-analysis. Correcting error and bias in research findings. Califomia: Sage Publications.

Hunter, J.E., Schmidt, F.L., \& Jackson, G.B. (1982). Meta-analysis: Cumulating research findings across studies. Beverley Hills, Califonia: Sage Publications.

*Imbos, T., Drukker, J., van Mameren, H., \& Verwijnen, M. (1984). The growth in knowledge of anatomy in a problem-based curriculum. In H.G. Schmidt \& 
M.L. de Volder (Eds.), Thtorials in problem-based lewming. New direction in training for the health professions (pp. 106-115). Assen: Van Corcum.

*mbos, T., \& Verwijnen, G.M. (1982), Voorgangstoetsing aan de medische faculteit Maastricht [Progress testing at the Maastricht faculty of medecine]. In H.G. Schmidt (Ed.), Probleengesturard Ondenwis: Bijdragen tot Onderwijsresearchdagen 1981 (pp. 45-56). Harlingen: Stichting voor Onderzoek van het Onderwijs, Flevodruk Harlingen b.v.

*Jones, J.W., Bieber, L.L., Echt, R., Scheifley, V., \& Ways, P.O. (1984). A Problem-based Curriculum, Ten Years of Experience. In H.G. Schmidt \& M.L. de Volder (Eds.), Tutorials in problem-based leaming. New direction. in training for the health professions (pp. 181-198). Assen: Van Gorcum.

*Kaufman, A., Mennin, S., Waterman, R., Duban, S., Hansbarger, C., Silverblatt, H., Obenshain, S.S., Kantrowitz, M., Becker, T., Samet, J., \& Wiese, W. (1989). The New Mexico experiment: Educational innovation and institutional change. Academic Medicine, 64, 285-294.

Kirk, R.E. (1996). Practical significance: A concept whose time has come. Educational and Psychological Measurement, 56, 746-759.

Knox, J.D.E. (1989). What is... a Modified Essay Question? Medical Teacher, 11 (1), $51-55$.

Kulik, J.A., \& Kulik, C.L. (1989). The concept of meta-analysis. International Journal of Educarional Research, 13 (3), 227-234.

Kurtz, S., Wylie, M., Gold, N. (1990). Problem-based learning: An alternative approach to legal education. Dalhousie Law Joumal, 13, 787-816.

Letteri, C.A. (1980). Cognitive profile: basic determinant of academic achievement. The Journal of Educational Research, 5, 195-198.

Letteri, C.A., \& Kuntz, S.W. (1982, March). Cognitive profiles: examining selfplanned learning and thinking styles. Paper presented at the annual meeting of the American Educational Research Association (AERA), New York City.

*Lewis, K.E., \& Tamblyn, R.M. (1987). The problem-based learning approach in baccalaureate nursing education: How effective is it? Nursing Papers, 19 (2), 17-26.

Maitland, B. (1991). Problem-based learning for an architecture degree. In D. Boud \& G. Feletti (Eds.), The challenge of problem-based learning (pp.203. 210). New York: St. Martin's Press.

*Martenson, D., Eriksson, H.s \& Ingelman-Sundberg, M. (1985). Medical chemistry: Evaluation of active and problem-oriented teaching methods. Medical Education, 19, 34-42.

Mehrens W.A. \& Lehmann, I.J.(1991). Measurement and evaluation in education and psychology. New York: Holt, Rinehard and Winston.

* Mennin, S.P., Friedman, M., Skipper, B., Kalishman, S., \& Snyder, J. (1993). Performances on the NMBE I, II, III by medical students in the problembased learning and conventional tracks at the University of New Mexico. Academic Medicine, 68, 616-624. 
Merchand, J.E (1995). Problem-based learning in the business curriculurn. An alterative to traditional approaches. In W. Gijselaers, D. Tempelaar, P. Keizer, E. Bernard, H. Kasper (Eds.), Educational innovation in economics and business administration: The case of problem-based learning (pp. 261-267). Dordrecht: Kluwer

Messick, S. (1993). Trait equivalence as construct validity of score interpretation across multiple methods of measurement. In R. Bennett \& W. Ward (Eds.), Construction versus choice in cognitive measurement: Issues in constructed response, performance testing, and portfolio assessment (pp. 61-74). Hilsdale, NJ: Lawrence Erlbaum Assocates

*Moore G.T., Block S.D., Style C. B., \& Mitchell R. (1994). The influence of the New Pathway curriculum on Harvard medical students. Academic Medicine, 69, 983-989.

*Morgan, H.R. (1977). A problem-oriented independent studies programme in basic medical sciences. Medical Education, 11, 394-398.

*Neufeld, V., \& Sibley, J. (1989). Evaluation of health sciences education programs: Program and student assessment at McMaster University. In H.G. Schmidt, M. Lipkin Jr., M.W. de Vries \& J.M. Greep (Eds.), New directions for medical education: Problem-based learning and communityoriented medical education (pp.165-179). New-York: Springer Verlag.

O'Neil, H.F., \& Schacter, J. (1997). Test specifications for problem-solving assessment (CSE Tech. Rep. No. 463). Los Angeles: University of Caiifornia, National Center for Research on Evaluation, Standards, and Student Testing.

Paris, S. G., Lipson, M. Y., \& Wixson, K. K. (1983). Becoming a strategic reader. Contemporary Educational Psychology, 8, 293-316.

Patel, V. L., \& Groen, G. J. (1986). Knowledge based solution strategies in medical reasoning. Cognitive Science, 10, 91-116.

*Patel, V.L., Groen, G.J, \& Norman, G.R. (1991). Effects of conventional and problem-based medical curricula on problem-solving. Academic Medicine, $66,380-389$.

Piaget, J. (1954). The construction of reality in the child. New York: Basic Books.

Pletinckx, J. \& Segers, M. (2001). Programme evaluation as an instrument for quality-asurance in a student-oriented educational system. Studies in Educational Evaluation, 27, 355-372.

Poikela, E., \& Poikela, S. (1997). Conceptions of learning and knowledge - impacts on the implementation of problem-based learning. Zeitschrift fur Hochschuldidactic, 21 (1), 8-21.

Prawat, R.S. (1999). Dewey, Peirce and the learning paradox. American Educational Research Journal, $36(1), 47-76$.

Reynolds, F. (1997). Studying psychology at degree level: Would problem-based learning enhance students' experiences. Studies in Higher Education, 22 (3), $263-275$.

*Richards, B.F., Ober, P., Cariaga-Lo, L., Camp, M.G., Philp, J., McFarlane, M., Rupp, R., \& Zaccaro, D.J. (1996). Rating of students' pertormances in a 
third-year internal medicine clerkship: A comparison between problembased and lecture-based curricula. Acadenic Medicine, 71 (2), 187-189.

Rogers, C.R. (1969). Freedom to leam. Colombus, Ohio: Charles E. Merill Publishing Company.

*Santos-Gomez, L., Kalishman, S., Rezler, A., Skipper, B., \& Mennin, S.P. (1990). Residency performance of graduates from a problem-based and a conventional curriculum. Medical Education, 24, 366-377.

*Saunders, N.A., Mcintosh, J., Mcpherson, J., \& Engel, C.E. (1990). A comparison between University of Newcastle and University of Sydney final-year students: Knowledge and competence. In Z.H. Nooman, H.G. Schmidt, \& E.S. Ezzat (Eds.), Innovation in medical education: An evaluation of its present status (pp. 50-54). New York: Springer.

Savin-Baden, M. (2000). Problem-based learning in higher education: Untold stories. Buckingham. Society for Research in Higher Education and Open University Press.

*Schmidt, H.G., Machiels-Bongaerts, M., Hermans, H., ten Cate T.J., Venekamp, R., \& Boshuizen, H.P.A. (1996). The development of diagnostic competence: Comparison of a problem-based, an integrated, and a conventional medical curriculum. Academic Medicine, 71, 658-664.

Schoenfeld, A.H. (1985). Mathematical problem solving. San Diego, CA: Academic Press.

*Schuwirth, L. W. T., Verhoeven, B.H., Scherpbier, A.J.J.A., Mom, E.M.A, CohenSchotanus, J., van Rossum, H.J.M., \& Van der Vleuten, C. (1999). An Inter-and intra-university comparison with short case-based testing. Advances in Health Sciences Education, 4, 233-244.

Schuwirth, L.W.T. (1998). An approach to the assessment of medical problemsolving: Computerized case-based testing. Maastricht: Datawyse.

*Schwartz, R.W., Burgett, J.E., Blue, A.V., Donnelly, M.B., \& Sloan, D.A. (1997). Problem-based learning and performance-based testing: effective alternatives for undergraduate surgical education and assessment of student performance. Medical Teacher, 19, 19-23.

Segers, M. S. R. (1997). An alternative for assessing problem-solving skills: The overall test. Studies in Educational Evaluation, 23 (4), 373-398.

Segers, M., Dochy, F. \& Cascallar, E. (2003). Optimizing new modes of assessment: In search of qualities and standards. Boston/Dordrecht: Kluwer Academic.

Segers, M., Dochy, F., \& De Corte, E. (1999). Assessment practices and students' knowledge profiles in a problem-based curriculum. Learning Environments Research: An International Journal, 2, 191-213.

Shavelson, R.J., Gao, X., Baxter, G.P. (1996). On the content validity of performance assessments: Centrality of domain specification. In $M$. Birenbaum \& F. Dochy (Eds.), Alternatives in assessment of achievements, learning processes and prior learning (pp. 131-143). Boston: Kluwer Academic Press.

Smith, D., Hoersch, A.L. (1995). Problem-based learning in the undergraduate geology classroom. Journal of Geological Education, 43, 149-152. 
Smith, M. U. (1991). Toward a unified theory of problem-solving: Views from the content domains. Hilsdale, NJ: Lawrence Erlbaum.

Smits, P.B.A., Verbeek, J.H.A.M., De Buisonje, C.D. (2002). Problem based learning in continuing medical education: A review of controlled evaluation studies. British Medical Journal, 321, 153-156

Snow, R.E. (1990). New approaches to cognitive and conative structures in education. International Journal of Educational Research, 14 (5), 455-473.

*Son, B., \& VanSickle, R.L. (2000). Problem-solving instruction and students acquisition, retention, and structuring of economics knowledge. Journal of Research and Development in Education, 33 (2), 95-105.

Spilich, G.J., Vesonder, G.T., Chiesi, H.L., \& Voss, J.F. (1979). Text processing of domain-related information for individuals with high and low domain knowledge. Journal of Verbal Learning and verbal behaviors, 18, 275-290.

Springer, L., Stanne, M.E., \& Donovan, S.S. (1999). Effects of small-group learning on undergraduates in science, mathematics, engineering, and technology: A meta-analysis. Review of Educational Research, 69 (1), 2151.

Sugrue, B. (1993). Specifications for the design of problem-solving assessments in science. Project 2.1 designs for assessing individual and group problemsolving. Los Angeles: National Centre for Research on Evaluation, Standards, and Student Testing.

Sugrue, B. (1995). A theory-based framework for assessing domain-specific problem solving ability. Edcuational Measurement: Issues and Practice 14 (3), 29-36.

Swanson, D.B., Case, S.M., \& van der Vleuten, C.M.P. (1991). Strategies for student assessment. In D. Boud \& G. Feletti (Eds.), The challenge of problem-based learning (pp. 260-273). London: Kogan Page.

*Tans, R.W., Schmidt, H.G., Schade-Hoogeveen, B.E.J., \& Gijselaers, W.H. (1986). Sturing van het onderwijsleerproces door middel van problemen: een veldexperiment [Guiding the learning process by means of problems: $A$ field experiment]. Tijdschrift voor Onderwijsresearch, 11, 35-46.

*Van Hessen, P.A.W., \& Verwijnen, G.M. (1990). Does problem-based learning provide other knowledge? In W. Bender, R.J. Hiemstra, A.J.J.A. Scherpbier, \& R.P. Zwierstra (Eds.), Teaching and assessing clinical competence (pp. 446-451). Groningen: Boekwerk publications.

Van IJzendoorn, M.H. (1997). Meta-analysis in early childhood education: Progress and problems. In B. Spodek, A.D. Pellegrini, and O.N. Saracho (Eds.), Issues in early childhood education, yearbook in early childhood education. New York: Teachers College Press.

*Verhoeven, B.H., Verwijinen, G.M., Scherpbier, A.J.J.A., Holdrinet, R.S.G., Oeseburg, B., Bulte, J.A., \& Van Der Vleuten, C.P.M. (1998). An analysis of progress test results of PBL and non-PBL students. Medical Teacher, 20 (4), 310-316.

Vernon, D.T.A., \& Blake, R.L. (1993). Does problem-based learning work? A meta-analysis of evaluative research. Academic Medicine, 68, 550-563. 
Verwijnen, M., Imbos, T., Snellen, H., Stalenhoef, B., Sprooten, Y., \& Van der Vleuten, C. (1982). The evaluation system at the medical school of Maastricht. In H.G. Schmidt, M. Vries, \& J.M. Greep (Eds.), New directions for medical education: Problen-based leaming and conmunityoriented medical education (pp. 165-179). New York: Springer.

*Verwijnen, M., Van Der Vleuten, C., \& Imbos, T. (1990). A comparison of an innovative medical school with traditional schools: An analysis in the cognitive domain. In Z.H. Nooman, H.G. Schmidt, \& E.S. Ezzat (Eds.), Innovation in medical education: An evaluation of its present siatus (pp.4149). New York: Springer. 


\title{
Chapter 6
}

\section{Effects of problem-based learning: A quasi-experimental study within a single course $^{5}$}

\begin{abstract}
In the present chapter, performances of students in short term implementations of problem-based learning are compared with students' performances in more conventional educational settings. Data were collected and analysed in two institutions for teacher training. In each institution, a problem-based and a conventional class worked for four weeks on a specific topic. A pre-test was used to assess students' prior knowledge on the topic. One week after the treatment, knowledge and application of knowledge in the specific topics were assessed.

With regard to the knowledge of the students, no unequivocal conclusions can be drawn, since the results of both institutions went in opposite directions. At the level of knowledge application, the results are similar for both institutions: Notwithstanding the time limited implementation, students from the problem-based learning environments tend to be more successful in applying their knowledge than students from conventional educational settings.
\end{abstract}

\footnotetext{
${ }^{5}$ Based on two earlier publications: Gijbels, D., Dochy, F., Van den Bossche, P., \& Segers, M. (2003). Effects of short term implementations of problem-based learning within teacher training. International Joumal of Educational Policy, Research \& Practice, 3 (4), 55-72.

$\&$

Gijbels, D., Van den Bossche, P., Dochy, F., \& Segers, M. (2002). Effecten van probleemgestuurd onderwijs in de lerarenopleiding. Tijdschrift voor Hoger Onderwijs 20, (1), 60-72.
} 


\section{Introduction}

For some time now, education, especially higher education, has come under increasing ariticism from the labour market, because it is failing to develop the necessary expert knowledge in students. In many programs, lectures, by themselves or complemented by other teaching modes, continue to be the most frequently used form of instruction and are seen as an effective way to transfer knowledge and skills. Students work mainly on their own, and collaboration, especially in the initial stages of their studies, is often not allowed. Furthermore, on many occasions students are encouraged to merely memorise the knowledge acquired and reproduce it during examinations (Entwistle, 1995). Such traditional lecture-based instruction produces mainly inert knowledge (Mandl, Gruber \& Renkl, 1996). Society, however, requires experts, who are capable of communicating, working in teams, sharing knowledge with colleagues in pursuit of a common goal and looking for new knowledge in order to apply this knowledge to new situations (Tynjälä, 1999).

In view of these developments, the question needs to be asked as to what qualities graduates need to posses. The literature offers a number of answers, which share a common view: Society requires graduates who are capable of efficiently resolving complex problems (Engel, 1997; Poikela \& Poikela, 1997; Segers, 1997). Concomitant with recent developments in society, insights have been formulated in cognitive psychology and instructional theories, such as constructivism, which have consequences for educational practice. In the literature, powerful learning environments are proposed as the answer to students" deficient conceptual knowledge and weak learning strategies in higher education. Research into learning and instruction has collected an empirically grounded knowledge base, on the basis of which student approaches to learning tasks as well as to other instructional methods employed by teachers may be improved through designing powerful learning environments (De Corte, 1996).

As a result of these developments in society and in educational sciences, a number of concrete innovations have been introduced in recent years, which may be labeled 'student-centred education'. Changes are mainly taking place in the following three directions: From knowledge as a goal to knowledge as a tool; from passive to active and independent leamers; and from directive to coaching teachers. Students' activities and learning processes are always at the center (Vermetten, 1999). An example of such a student-centred approach in higher education is problem-based learning. Although originally developed for medical training in Canada, the orthodox version of problem-based learning (PBL) has been modified and applied globally in many disciplines (Gijselaers, 1995). In Europe, problembased learning is at present receiving more and more attention in various programs of higher education. Many curricula or parts thereof are modeled on the basis of problem-based learning. The desire to implement problem-based learning as an alternative for existing teaching practices inevitably raises the question as to whether problem-based learning is an alternative capable of effectively replacing conventional expository instruction (Albanese \& Mitchell, 1993). Although 
contemporary educational practice increasingly consists of a blend of conventional and student-centred methods, there seems to be a need to compare the merits of the two approaches.

In chapter 4 we sought to answer this question by conducting a statistical meta-analysis. The results of this review suggest a strong and practical effect of PBL on the application of student knowledge. As to student knowledge after a single course based on PBL, virtually no difference was observed in comparison with students learning through conventional methods. Conventional instuction must be taken to mean those forms of education which are characterised by large group lectures and instructor-provided learning objectives and assignments. As to the effect of a fully problem-based curriculum on student knowledge, the outcome showed a slight tendency towards negative results.

In the study presented in this chapter, the effects of PBL in teacher-training courses were investigated. In spite of the fact that several experiments with various forms of PBL are conducted in higher education, not many educators change a course totally towards a fully thematic curriculum. In most instances, specific themes are presented in a student-centred manner during a limited period of time. In this study, the effects on students" knowledge and knowledge application of a short term implementation of PBL were investegated. The following core questions needed to be answered:

To what degree do students studying for a limited period of time in a PBLcourse acquire an accessible knowledge base of the subject studied compared to students to whom the subject was presented in conventional way?

Are students who have been subjected for a limited period of time to a PBL-course better equipped to apply the knowledge of the subject studied than students to whom the subject was presented in the conventional way?

On the basis of the results derived from the statistical meta-analysis in chapter 4 regarding the effects of PBL, it was expected that students acquired at least the same knowledge base of the subject studied (knowledge hypothesis) and that they would be able to better apply that knowledge (application of knowledge hypothesis) compared to students who studied the same subject by means of the conventional way.

\section{Method}

\section{Subjects}

For the purposes of the study presented in this chapter, several schools for higher education offering teacher-training courses were contacted. The experiment took place in two similar institutions for teacher training in one European country, offering identical programs for future teachers. These two institutions met the criteria for inclusion, meaning they had two existing parallel classes and were willing to participate in the experiment. In each institution, two teachers 
participated in the study. At institution A, for a period of four weeks, the theme 'punishment and reward' was treated by means of the PBL-approach during the first-year 'pedagogy and psychology' course of the first year program. The same theme was presented to a parallel class in the conventional way (conventional or control group). A total of 19 students from the experimental and 26 from the conventional group participated in the study. At institution B, during the first year program for teacher training, the subject of "assessment" was treated for four weeks during a course in "instructional psychology" course in year 2 by means of the PBLapproach (experimental group). The parallel class was thought the course in a conventional way (conventional or control group). A total of 27 students from the experimental group and a total of 23 from the conventional group participated in the study.

\section{Design}

True experimental designs using random assignment of subjects to experimental and control groups can be very disruptive of the normal classroom procedures and organisation. Since we used existing classes to implement PBL, a random distribution of the subjects over experimental and conventional groups was not feasible. For this reason, one of Cambell and Stanley's (1963) quasiexperimental designs, the 'nonequivalent control group design', was used. Although in this design internal validity is more vulnerable than in a genuine experimental design and generalisability can be merely presumed, it can be usefull to rule out some plausible rival hypotheses when the use of a true experimental design is not possible (Huck, cormier \& Bounds, 1974). In view of the quasi-experimental nature of the sludy, the choice of themes was left to the participating teachers.

The study followed a pre-test-intervention-post-test pattern. Inasmuch as the comparability of prior knowledge of the 'reward and punishment' theme of the experimental group and the conventional group could neither be presumed on the basis of preceding courses on 'pedagogy and psychology' commonly taken, nor on the basis of teacher opinions based on prior exam results, it was decided at institution A that prior knowledge was to be measured by means of a pre-test. This pre-test was taken not less than one week before the commencement of the intervention. One week after the intervention had ended, both groups were given a post-test.

At institution $\mathrm{B}$, the prior knowledge was compared by using the exam results students obtained in their first year of training in the subject of instructional psychology, since all the students in either condition had followed the same course in instructional psychology in year 1 .

\section{Procedure}

The selection of the samples was based on several considerations as follows. At both institutions, the sample consisted of those students who were attending the lessons in which the (pre- or post-) tests were administred. Both the 
pre- and post-tests were taken unannounced during regular classes. All students present were requested to complete the test. On each occasion. the students were given one hour to take the test. The students were given g garantee that the results would be processed anonymously for the purposes of the study only.

\section{Experimental intervention}

Students in the experimental conditions discussed the theme by means of the PBL-approach during four weeks. Barrows (1996) lists six essential characteristics of PBL: (a) student-centered learning; students are responsible for their own learning; (b) learning takes place in small groups; (c) the tutor facilitates the learning process; (d) authentic problems are the organising principle and the incentive for learning; (e) the use of authentic problems and (1) new information is acquired through self-directed learning.

Below a brief description is offered as to how these principles were given shape. During the first meeting of the four-week intervention, the concept of PBL was explained and the students received a syllabus. The syllabus contained the problem assignments, which the students had to complete during the four-week course based on the (PBL) steps described in the syllabus.

The experimental group met on a weekly basis under the supervision of a teacher (tutor). At institution. A, the experimental group was divided into 3 subgroups of 8 students each, who took on a different authentic problem assignment. The experimental group at institution B was split up into 6 subgroups of 5 students each, who took on the same authentic problem. The problem assignments that were used are shown in Figures 1 and 2. Each session was chaired by a different student and students also took turns taking notes. Contingent on the progress made, the groups continued to work on the problem during the second session. At each session, the students reported their findings based on the materials they had looked for, found and studied. During the third session, the results were collected and the solutions worked out. The fourth and final sessions served as presentation sessions with each group presenting its own results.

The syllabus informed the students of the fact that in addition to the moment of examination, at which the application of the knowledge acquired was to be tested through new authentic problem tasks, there was to be both a processoriented and product-oriented evaluation.

"Bart (4 years) never goes immediately to the line after the break: He lingers around in a coner near" the slide. Miss Nathalie intends to have all children in line within two minutes after the bell has rung."

Draft a suggestion how Miss Nathalie can achieve this.

"Céline ( 5 years) systematically refuses to clean up in class. While the other children are cleaning up, she just wanders around and persists in doing what she wass doing. Miss Chris wonders how she can best tackle this problem."

"Martin ( 3 years) continues to wet his pants on many occasions. Miss Daisy had him stand in the comer after the most recent instance. Martin is terrified that the next time he goes 10 school, he will wet lais pants again and be stood in the comer."

Figure 1: Problem assignments for institution A. 
Teacher Jef Gillair has worked though the book "Assessment in the class room," during class room hours in the second year of his teacher-training program. The working method is as follows: The students study the book thoroughly at home, completing the assignments. The assignments are to be found in the book after each chapter. In class, Jef is able to discuss the book rather quickly. He briefly discusses the important points, emphistising where necessary. The students may interrupt him at any moment in ask questions that may have cropped up. The assignments are corrected in class.

The annual exams are a recurring problem for Jef Gilair. It is also a very busy time for him. He restricts himself therefore to the existing assignments and distills exam questions from these. Aware that thas is not an ideal approach, he promises himself that when time permits he will compose the exam according 16 the rites in future.

Through an intermediary he addresses the tutorial groups requesting them to perform this far from simple task. Write an exam, which contains questions appropriately cowering the learning content of the book 'Assessment in the classroom'.

Figure 2; Problem assignment for institution $\mathrm{B}$.

\section{Conventional Education}

At either institution, the conventional groups were given the course in plenary sessions, through the lecturing method.

\section{Research instrument}

In order to formulate an answer to the questions under study, both the extent to which the students acquired knowledge and were able to apply this knowledge were tested in the various conditions. An instrument was developed to this end, which consisted of a multiple-choice test (MCT) and a short case test (SCT).

\section{Developing the instrument}

In order to develop the instrument, the teachers in question at both institutions were asked to formulate the objectives of the course theme and a number of examples of (earlier) test questions pertaining to the theme. In addition to this, the course materials of the previous year, supplemented by new course materials also used by the teacher of the conventional group for his lessons, were used as a basis for constructing this testing instrument. Prior to test administration, a first version of the test with an answer key for each question, was presented to the participating teachers and a test expert for validation. On the basis of their comments, the final testing insirument and answer keys were created, which were to serve as both a pre-testing and a post-testing instrument. It was considered a valid instrument by all parties involved. 
The MCT measured factual knowledge, the meaning of symbols and the concepts and principles pertaining to a particular theme. This type of knowledge is called declarative knowledge (Anderson, 1983; Dochy \& Alexander, 1995). The items in the MCT required the students to reproduce their knowledge and/or demonstrate insight. Posing multiple-choice questions is considered an efficient and reliable way of testing (basic) knowledge (Norman, 1997; Swanson, Case \& van der Vleuten, 1997). The MCT consisted of multiple-choice questions including of a stem, four alternative answers and a fifth possibility, namely 'don't know'. Only one single alternative answer is the right answer. The students who circle the option 'don't know' indicate that they did not master the subject matter being tested. If students circled the wrong answer, they lost one third of a point. If an answer was given correctly, they scored one point.

The scores for the MCT questions are an operationalisation of the degree to which the students possess an accessible knowledge base and allow the first research question to be answered. Figure 3 features a number of MCT item examples.

\footnotetext{
Item 1: Which statement is relevant to "operant conditioning'?

A. You learn to adapt your behavior, because there is a reward or because a negative situation ceases to exist or is prevented.

B. If a conditional stimulus frequently occurs alone, without being followed by an unconditional one, the acquired reaction will gradually disappear and cease to oecur.

C. After several repeated offers of the unconditional stimulus and the conditional stimulus the reaction will be stronger and the relation between the conditionall stimulus and the conditional reaction is reinforced.

D. Rewarding constitutes a positive reaction to positive behavior.

E. Don't know.
}

Item 2: Miss Ella is a remedial teacher, wishing to check the calculation speed of her pupils. Miss Ella wants the testing instrument she uses to in effect measure the calculation speed and not, for example, 'general knowledge'.

Miss Ella's situation is an example of the following:
A. Reliability
B. Content validity
C. Construct validity
D. Predictive validity
E. Don"i know.

Figure 3: Examples of items from the multiple-choice test (MCT)

These two sample items (see figure 3) test whether the students have gained an understanding of certain concepts and principles. The first item tests whether the students possess knowledge of the content of the concept 'operant conditioning'. The second item asks whether the students recognise the concept of "construct validity" in the given situation. 
Short case test ( $S C T)$

The SCT measured the extent to which the students are capable of identifying a problem on the basis of relevant concepts, models or principles. The SCT questions examined the extent to which the students are capable of applying their knowledge to analyse and resolve the problem (Segers, 1997).

The SCT offered students two short cases in relation to which essay questions were asked. Each essay question was to be answered comprehensively in writing. Essay questions encourage students to integrate their insights into a systematic frame instead of recognising isolated facts. As a result, they provide an evaluation of (problem-solving) skills (Swanson et al., 1997). The questions do not aim at aspects of general knowledge, but rather at decisions directly relevant to the case (Schuwirth, 1998). Each SCT question yielded a maximum of 5 points; the distribution of points per question was given in the answer key. No points were substracted for an incorrect answer.

The scores for the SCT questions constitute an operationalisation of the degree to which the students are capable of applying knowledge acquired. As a consequence, they make it possible to formulate an answer to the second research question. Figure 4 offers an example of a SCT question.

Case 1: Sophie is a 5-year-old who willfully knocks over a chair during playtime. The teacher, Miss Ella, had made in clear in advance that there was to be no knocking over or throwing of things. Miss Ella wants to punish Sophie for her act in an appropriate and effective way.

A. What punishment would you mete out?

B. Why is this an appropriate and effective punishment in your view?

C. What punishment do you find inappropriate and why?

Figure 4: Example of a SCT question

Answering the SCT questions required that students went through certain specific thinking processes. This is illustrated below in connection with the SCT question featured in Figure 4. In order to formulate a proper answer to the SCT question $\mathrm{A}$, the student had to compare the relevant case information and the theoretical knowledge. The answer may contain any punishment strategy, which, in this case, meets the characteristics of effective and appropriate punishment. For SCT question B, which is an explicitation of SCT question A, the student needed to go through the following mental steps:

Step 1: defining the concept of "appropriate and effective punishment";

Srep 2: selecting the pertinent information regarding "appropriate and effective punishment";

Step 3: comparing the punishment selected in question $A$ with the relevant characteristics of 'appropriate and effective punishment'.

For SCT question $\mathrm{C}$ the students needed to compare the relevant information regarding 'appropriate and effective punishment' with possible punishment strategies, deducing a punishment which does not fall within the definition of appropriate and effective punishment. 


\section{Analysis}

Independent $t$-tests were used to compare the experimental group with the control group. Because it was impossible to obtain a randomised sample in this study, also analysis of covariance (ANCOVA) was utilised for the design, using measures of students" prior knowledge as covariate. Preliminary analysis of the data involved inspection of normality and homogeneity of variance assumptions. Normal plots, stem-and-leaf plots and the calculation of skewness and kurtosis were used to check the normality of distribution. To test the equality of group wariances the Levene statistics was calculated. All assumptions for the analysis were met.

Effect sizes are reported along with a $p$ value in order to distinguish between "practically' significant results, or results being only" 'statistically" significant (Keselman, et al., 1998). The $d$-index for a two-group ANCOVA (Ray \& Shadish, 1996) was used as an estimate of effect size (ES) in this study. Guidelines for the interpretation of the $d$-index generally take $E S=0.2$ as a small effect, $E S=$ 0.5 as a moderate effect and $\mathrm{ES}=0.8$ as a large effect (Cohen, 1988, Kirk, 1996).

\section{Results}

The results are summarised in Table 1. The reporting of the results is headed by the analyses of the comparability of student's prior knowledge in both the experimental and the control group. First, the question is answerd to what degree students studying for a limited period in a PBL-course acquire an accessible knowledge base of the subject studied compared to students to whom the subject was presented in conventional way. Finally, the results are reported on the question whether students who have been subjected for a limited period to a PBL-course are better equipped to apply the knowledge of the subject studied than students to whom the subject was presented in the conventional way. For each question, the results for institution $A$ are reported seperatly from the results in institution $B$.

\section{Comparability of prior knowledge}

In order to determine the effects of PBL, existing class groups are compared in this study. It is important in this respect to examine whether the prior knowledge of the students in relation to the themes studied is comparable. In institution $\mathrm{A}$ students' mean scores on the $\mathrm{MCT}$ in the experimental group $(\mathrm{M}=2.7$, $S D=2.07)$ did not significantly differ from students in the conventional group $(\mathrm{M}=$ $3.0, S D=1.64, t(33)=-0.43, p=0.67)$. Also the mean scores on the SCT in the experimental group $(M=3.6, S D=1.32)$ did not significantly differ from students SCT - scores in the conventional group $(M=3.2, S D=1.56, t(33)=-0.84, p=0.41)$. In institution $\mathrm{B}$ the difference between the experimental $(\mathrm{M}=12.9, S D=1.76)$ and the conventional $(M=12.0, S D=1.54$ ) group was not statistically significant $(t(45)=-1.92, p=0.06)$. The results indicate that in both institutions students' prior 
knowledge in the experimental group is comparable with students" prior knowledge in the conventional group.

\section{Knowledge}

In institution $A$, the independent $t$-tests show that the difference between the two groups is not statistically significant $(t(41)=0.48, p=0.64)$. The effect size $d$ of 0.16 indicates a small practical effect. Also the results of the ANCOVA, taking into account the small but non-significant differences in pre-test scores was not statistically significant $(F(1,30)=0.75, M S E=2.90, p=0.40)$. The effect size $d$ of 0.29 however is an indication of a low practical significance.

The results at institution $B$ do show a significant difference in the post-test between the students from the experimental and those of the conventional group ( $t$ $(48)=-0.38, p<0.01)$. This difference yields a negative effect size $(d=-0.101)$.

The results of the ANCOVA indicate that, by taking into account the non significant differences in pre-test scores, the difference between the two groups in the post-test remains significant significant $(F(1,44)=21.79, M S E=2.90, p<$ $0,01)$. The practical significance takes on an even greater negative value $(d=-1.36)$.

As regards knowledge acquisition, there is a different conclusion for each institution. At institution A, compared to the pre-test, the post-test shows an improvement for both the experimental and the control group. The increase in knowledge, however, is not large in either group. Although no statistically significant difference was found between the two groups, a small practical significance was found after the non significant differences in the pre-test had been taken into account. Institution $B$, however, shows a different picture. The results at institution B do indicate a significant difference, but the control group achieves a higher score than the experimental group. The large negative effect size is an indication of there also being a practically significant difference.

Although the knowledge hypothesis seems to have been confirmed at instutution $\mathrm{A}$, it is rejected by the results at institution $\mathrm{B}$.

Tuble 1: Summary of results

\begin{tabular}{lcccc}
\hline & Experimental group & & \multicolumn{1}{c}{ Control group } & \\
\hline & $\mathrm{M}$ & $S D$ & $\mathrm{M}$ & \\
Instivution A & & & & 1.9 \\
$\mathrm{MCT}$ & 3.9 & 1.7 & 3.6 & 2.0 \\
SCT & 5.6 & 2.0 & 4.8 & 2.1 \\
Institution B & & & & 2.3 \\
MCT & 3.1 & 1.3 & 5.3 & 3.9 \\
SCT & 5.6 & 2.2 & & \\
\hline
\end{tabular}

\section{Application of knowledge}

When at institution $\mathrm{A}$ the difference between the means of the experimental group and the conventional group is subjected to a one-tailed $t$-test, the result does not show a statistically significant difference $(t(41)=0.79, p=0.43)$. The effect 
size of this difference, however, having a value of $d=0.24$, seems to point towards a low practical significant effect.

By applying an ANCOVA the difference between the two groups for the SCT is calculated again, in which the non significant differences in pre-test scores are taken into account, no significant difference is found $(F(1,30)=0.66, M S E=$ $3.26, p=0.42$ ). The effect size based on these results has a walue of $d=0.26$, which is an indication of a low practical significance.

The difference at institution B between the two groups on the SCT is statistically significant $(t(48)=1.78, p<0.05)$ in the post-test. The effect size of $d$ $=0.77$ can also be seen as practically significant.

When examining the ANCOVA results, and consequently the total SCTscores, in which the small but non-significant differences in pre-test scores have been taken into account, a statistically significant difference $(F(1,44)=4.314, M S E$ $=4.91, p<0.05)$ is found. There is a slight decline in effect size to $d=0.57$, when the non significant differences in pre-test scores are taken into account, which nevertheless can be seen as practically significant.

In conclusion, it can be stated that at both institutions the results with regard to the application of knowledge show a similar pattern. At institution A, there is no statistical significance demonstrating that PBL students acquire more or less knowledge. The practical significance does show, however, that PBL students apply their knowledge better. This practical significance remains the same when small but non-significant differences in pre-test scores are taken into account. The difference between the experimental and the control group is however statistically significant at institution $B$. The statistical significance is accompanied by a high practical significance, which decreases when the differences in the pre-test scores are taken into account.

\section{Conclusions and discussion}

In this chapter, we have tried to find an answer to two research questions. First, we wished to find the answer to the question as to the extent to which the students possess an accessible knowledge base of the subject matter after at single PBL-course in comparison with students who studied the subject in the conventional way. Secondly, we were looking for an answer to the question as to whether the students were able to apply their knowledge of a particular subject better after a single course based on PBL than students who studied the subject via the conventional way. It was anticipated that after a single course in PBL the students would possess a knowledge base of the subject studied that was at least as large as that of the students in the conventional condition, but that they were able to apply the knowledge acquired better than the students who studied the subject the conventional way.

The two research questions were examined in two teacher-training institutions with similar programs. It was established that in neither institution a 
statistically significant difference existed between the experimental and the conventional group with regard to relevant prior knowledge of the theme examined. Below we will discuss the results for each hypothesis.

\section{Hypothesis 1: knowledge}

The students at institution $A$, who during a period of four weeks were subjected to $\mathrm{PBL}$, did not score differently on knowledge than the students who studied the subject via the conventional way. When the small differences in prior knowledge are taken into account, the difference can be considered practically significant $(d=0.29)$.

The results obtained at institution $\mathrm{B}$, on the other hand, show a statistically and practically negative effect. When possible differences in prior knowledge are taken into account, the negative effect increases even to $d=-1.36$. Differences between the experimental group at the two institutions, which were not investigated, but which perhaps could well explain this effect, are the smaller student groups size at institution B, the difference in content and the difference in study year. A different, more tentative explanation would be that at institution $\mathrm{B}$ in either condition the same book was used, whereas the students from the experimental condition at institution A were required to consult their own sources. The positive effects of PBL are, among other things, ascribed to the use of a variety of sources. The use of multiple representations of perspectives, strategies, concepts and information is characterised as an important feature of a powerful learning environment (Tynjälä, 1999). It is possible that at institution B this feature failed to be exploited. The hypothesis that students will acquire at least the same knowledge after being exposed to a single course based on PBL compared to students following conventional education, is confirmed at institution $\mathrm{A}$, but not at institution B. Finally, with regard to the MCT a remark should be made of the small difference between the pre- and post-test. Compared to the pre-test, improvement was observed at institution A for both groups. The increase is, however, rather small in either group. A variety of causes may be underlying this small difference between the pre- and post test at institution $A$. The questions may have proved to be too difficult or alternatively the students may have had problems in dealing with the multiple-choice format.

\section{Hypothesis 2: application of knowledge}

As regards to the application of knowledge, the results at both institutions are rather similar. Although, at institution $\mathrm{A}$, the difference between the experimental and the control group is not statistically significant, there is a small practical significance. At institution $\mathrm{B}$, the difference between the experimental and the control group is not only large practically, but also statistically significant. The results indicate that the PBL students at either institution were more able to apply the knowledge acquired after a single course than students who followed the conventional path. This confirms the second hypothesis. 
The conclusion from the study above is not that PBL students acquire at least as much knowledge as students following the same course the conventional way. Although the results at institution A point in that direction, at institution B there is clear empirical evidence of the opposite. Explanations for this difference may be found in the different use of sources or the differences in subject matter between the themes treated at institutions $\mathrm{A}$ and $\mathrm{B}$. For both institutions, it was found, however, that PBL students were more able to apply the knowledge acquired than students from the conventional group. More attention for elaboration in a PBL environment could provide an explaination (Schmidt, 1990). In some instances, PBL students seem to possess less knowledge, as the results at institution B indicate, but this lesser knowledge is more readily available because of a greater attention paid to elaboration in PBL and is more useful if needed to be applied to solve problems. Integrated availability and usability of knowledge and skills are a precondition for countering the problem of inert knowledge through acquiring a disposition to learn, think and resolve problems skillfully (De Corte, 1996). In this context PBL seems to be better equipped than conventional education to develop expert knowledge in graduates to resolve problems, in spite of the fact that it was only implemented for a limited period of time of four weeks.

\section{Critical reflection and suggestions for further research}

Below, four critical comments on the study presented in this chapter are discussed, followed by suggestions for further research. The first concerns the critical success factors of PBL, the second deals with the one-sided attention given to the cognitive goals of education and the third comment points at the lack of data on long-term effects. Finally, some remarks are made on the validity of the study.

\section{Critical success factors}

This study examines the effects of a PBL learning enwironment. Even if the differences that were found were to be seen as a genuine effect of the learning environment, it remains difficult to single out those aspects of the learning environment, which caused that difference. It also remains unclear what aspects play a crucial role in establishing a powerful learning environment. Nevertheless, such information could play an important role in successfully implementing PBL (Pletinckx, Segers, Dochy \& Van den Bossche, 2001). Further research into the critical success factors of PBL is indicated. 


\section{Limitation to cogritive effects}

Although in the literature on education the importance of affective and motivational elements has been repeatedly pointed out (Boekaerts, 1993), the above study was limited to the cognitive effects of PBL, in particular knowledge and application of knowledge. For this reason, it seems necessary that more research, also aiming at the affective and motivational aspects of learning, is conducted in the future. Research into powerful learning environments, in particular problem-based learning environments, has shown an impact on students' positive attitude towards learning (Albanese \& Mitchell, 1993; Lieberman, Stroup-Beham, Peel \& Camp. 1997; Percac \& Armstrong, 1998; Vernon \& Blake, 1993).

\section{Long-term effects}

When explaining the results, we referred to the fact that PBL students in some instances acquire less factual knowledge, but that this knowledge is better organised and can be retrieved more easily. This implies that PBL students will possess this knowledge for the long-term and that they will be able to apply it also after completing their studies. The results from the meta-analysis presented in chapter 4 , which had retention period as the mediating variable, pointed in that direction. The data gathered from our own research does not permit, however, to draw a substantiated conclusion about subject matter retention. The effect was examined only one week after the intervention. In order to chart the effects of PBL in the long term a longitudinal study is required, which continues to follow the students after completing a single course or after graduation.

\section{Internal and external validity}

Finally, we want to make some remarks concerning the validlity of this study. Statements about internal validity must be interpreted cautiously as a result of the fact that the students were not distributed at random over the experimental and control conditions. Although efforts were made to examine the comparability of the groups, the best guarantee of countering selection bias is random group distribution. This, however, is hardly possible in ecologically valid research.

In view of the specific context of the institutions in which the study was conducted and the limited range of subject matters studied, caution must be exercised also where external validity is concerned. The fields of implementation i.e. psychology and pedagogy may be areas that inherently bring predetermined leaming styles to the table which may be difficult to overcome in such a short period. External validity may have been biased by the brief duration of the intervention. However, several other studies in the medical domain (e.g. Antepohl \& Herzig, 1997; Doucet, Purdy, Kaufman \& Langille, 1998; Hmelo, Geralds, Gotterer \& Bransford, 1997) have shown positive effects of brief implementations of PBL whithin a single course. 
The study was a first step towards investigating the eftects of PBL in various domains. The validity of the results of the study must surely be evaluated in the light of future similar studies (Son \& VanSickle, 1.993).

\section{References}

Albanese, M.A., \& Mitchell, S. (1993). Problem-based learning: A review of literature on its outcomes and implementation issues. Academic Medicine, $68,52-81$.

Anderson, J.R. (1983). The architecture of cognition. Cambridge, MA: Harvard University Press.

Antepohl, W., \& Herzig, S. (1997). Problem-based learning supplementing in the course of basic pharmacology-results and perspectives from two medical schools. Naunyn-Schmiedeberg's Archives of Phannacology, 355, R18.

Barrows, H.S. (1996). Problem-based learning in medicine and beyond. In $\mathbb{L}$. Wilkerson, \& W.H. Gijselaers (Eds.), Bringing problem-based leaming to higher education: Theory and practice. New directions for teaching and learning, $n^{\circ} 68$ (pp. 3-13). San Francisco: Jossey-Bass Inc. Publishers.

Boekaerts, M. (1993). Being concerned with well-being and with learning. Educational Psychologist, 28, 149-167.

Campbell, D.T., \& Stanley, J.C. (1963). Experimental and quasi-experimental designs for research. Chicago: Rand McNally.

De Corte, E. (1996). Instructional psychology: Overview. In E. De Corte \& F.E. Weinert (Eds.), International encyclopedia of developmental and instructional psychology (pp. 33-43). Oxford: Elsevier Science Ltd.

Dochy, F., \& Alexander, P.A. (1995). Mapping prior knowledge: A framework for discussion among researchers. European Journal of Psychology of Education, 10 (3), 225-242.

Dori, Y.J. (1994). Achievement and attitude evaluation of a case-based chemistry curriculum for nursing students. Studies in Educational Evaluation, 20, 337-348.

Doucet, M.D., Purdy, R.A., Kaufman, D.M., \& Langille, D.B. (1998). Comparison of problem-based learning and lecture format in continueing medical education on headache diagnosis and management. Medical Education, 32 (6), 590-596.

Engel, C. E. (1997). Not just a method but a way of learning. In D. Boud \& G. Feletti (Eds.), The challenge of problem-based learning (2nd ed., pp.1727). London: Kogan Page.

Entwistle, N. (1995). Frameworks for understanding as experienced in essay writing and in preparing for examinations. Educational Psychologist, 30, 47-54.

Gijselaers, W. (1995). Perspectives on problem-based learning. In W. Gijselaers, D. Tempelaar, P. Keizer, J. Blommaert, E. Bernard \& H. Kasper (Red.), 
Educational innovation in economics and business administration: The case of problem-based leariing (pp. $39-52$ ). Norwell, Mass: Kluwer.

Hmelo, C.E., Gotterer, G.S., \& Bransford, J.D. (1997). A theory-driven approach to assessing the cognitive effects of PBL. Instructional Science, 25, 387-408.

Huck, S.W., Cormier, W.H., \& Bounds W.G. (1974). Reading statistics and research. New York: Harper \& Row.

Lieberman, S.A., Stroup-Beham, C.A., Peel, J.L., \& Camp, M.G. (1997). Medical student perception of the academic environment: A prospective comparison of traditional and problem-based curricula. Academic Medicine, 72 (10), $\$ 13-815$.

Mandl, H., Gruber, H., \& Renkl, A. (1996). Communities of practice toward expertise: Social foundation of university instruction. In P.B. Baltes \& U.M. Staudinger, Interactive minds. Life-span perspectives on the social foundation of cognition (pp. 394-412). Cambridge: Cambridge University Press.

Norman, G.R. (1997). Assessment in problem-based learning. In D. Boud \& G. Feletti (Eds.), The challenge of problem-based learning (2nd ed., pp. 263269). London: Kogan Page.

Percac, S., \& Armstrong, E.G. (1998). Introducing a problem-based anatomy course in a traditional curriculum: A Croatian experience. Medical Teacher, 20 (2), 114-117.

Pletinckx, J., Segers, M., Dochy, F., \& Van den Bossche, P. (2001, August). Evaluating problem-based learning: Looking for critical succes factors. Paper presented at the 9 th biennieal conference of the European Association for Research on Learning and Instruction (EARLI), Fribourg, Switzerland.

Poikela, E., \& Poikela, S. (1997). Conceptions of learning and knowledge - impacts on the implementation of problem-based learning. Zeitschrift für Hochschuldidaktik, 21 (1), 8-21.

Schmidt, H.G. (1990). Innovative and conventional curricula compared: What can be said about their effects? In Z.H. Nooman, H.G. Schmidt, \& E.S. Ezzat (Eds.), Innovation in medical education: An evaluation of its present status (pp. 1-7). New York: Springer.

Schuwirth, L.W.T. (1998). An approach to the assessment of medical problemsolving: Computerized case-based testing. Maastricht: Datawyse Universitaire Pers.

Segers, M. (1997). An alternative for assessing problem-solving skills: The Overall Test. Studies in Educational Evaluation, 23 (4), 373-398.

Son, B., \& VanSickle, R.L. (1993, April). Problem-solving instruction and students' acquisition, retention and structuring of economics knowledge. Paper presented at the Anmual meeting of the American Educational Research Association (AREA). Atlanta, GA.

Swanson, D.B., Case, S.M., \& van der Vleuten, C.P.M. (1997). Strategies for Student Assessment. In D. Boud \& G. Feletti (Eds.), The challenge of problem-based learning (second edition, pp. 269-282). London: Kogan Page. 
Tynjälä, P. (1999). Towards expert knowledge? A comparison between a constructivist and a traditional leaming environment in the university. International Journal of Educational Research, 33, 355-442.

Vermetten, Y.J.M. (1999). Consistency and variability of student learning in higher education (Ph. D. Thesis). Tilburg: Katholieke Universiteit Brabant.

Vernon, D.T.A., \& Blake, R.L. (1993). Does problem-based learning work? A meta-analysis of evaluative research. Acadenic Medicine, 68, 550-563. 


\section{Chapter 7}

\section{Improving the effects of problem-based learning: Integrating assessment-tasks in the learning environment ${ }^{6}$}

\section{Abstract}

The purpose of this chapter is to get more insight in the effects of written assessment-tasks integrated in a problem-based learning environment. Both the influence on students" pertormances and students' perceptions were investigated. Students' final exam results were used to find out whether students who make the assessment-tasks do better than students who do not. Answers from questionnaires and semi-structured interviews were used to discover the most important concerns in students' and teachers' perceptions of the assessment-tasks. The results indicate that making the assessment-tasks had positive influence on the students' overall performance. From the questionnaires and interviews it appears that both the students and the teachers see the benefits of the assessment-tasks. It is concluded that small steps in the change of the assessment system can result in relatively big changes in students' learning and results.

\footnotetext{
${ }^{6}$ Based on: Gijbels, D., Van de Watering, G., \& Dochy, F. (2005). Integrating assessment tasks in a problem-based learning environment. Assessment and Evaluation in Higher Edwcation, 30 (1), 73-86.
} 


\section{Introduction}

The implementation of powerful learning environments in line with constructivist learning theories point to the necessity of reconceptualising the nature of assessment. It is generally believed and shown that assessment has an important impact on instruction and learning (Gibbs, 1999; Scouller, 1998). The alignment between the learning environments" objectives, and the assessment is a "magic bullet' in improving learning (Cohen, 1987). The direct and indirect impacts of assessment may be either positive or negative (Crooks, 1988). The main purpose is to make the assessment congruent with the instruction and align the assessment to what students should be learning (Biggs, 2003). Faced with such powerful contexts, assessment should be used strategically, designed to have educationally sound and positive influences. The traditionally view that the assessment of students' achievement is separate from instruction and only comes at the end of the learning process, is no longer tenable. As assessment, learning and instruction become more and more integrated, there is a strong support for representing assessment as a tool for learning (Dochy \& McDowell, 1997; Sambell, McDowell \& Brown, 1997). In this respect, Birenbaum (1996) has made a useful distinction between two cultures in the measurement of achievement. In the traditional so-called testing culture, instruction and testing are considered to be separate activities. The assessment culture is a consequence of the need to make learning and instruction more in congruence with assessment (Segers, Dochy \& Cascallar, 2003).

Bridging the gap between new developments in the assessment culture and the daily educational and assessment practice faces a number of difficulties (Black \& William, 1998). For one, assessment is still seen as separate from learning and instruction by many teachers (Torrance \& Pryor, 1995). In order to bridge this gap Gibbs and Simpson (in press) present a framework based on theory and research on strategic changes in assessment. The framework can be used to identify the potential for improving student learning by making principle changes to assessment. The framework consists of 5 dimensions, under which assessment supports student learning. First, the design of the assessment can be used to influence the quantity and distribution of student effort. This is the case when the assessed tasks capture sufficient study time and effort and distribute this effort evenly across the topics and weeks. Secondly, the quality and the level of the students' effort can be influenced by assessment. When the tasks engage students in productive learning activities and communicates clear and high expectations to the students, assessment supports student learning. The three last dimensions concern the importance of feedback in the design of assessment as a tool for learning. The third dimension stresses the quantity and timing of the feedback. Feedback should be provided quickly enough to be useful to students and should be given both often enough and in enough detail. Forthly, the quality of feedback is important. Feedback should focus on learning, be understandable for students and linked to the purpose of the tasks and the criteria. Finally, students' response to feedback should be taken into consideration. 
Feedback should be received by and attended to the students and students should act upon the feedback in order to improve their tasks or their learning.

However, the integration of assessment, learning and instruction remains a challenge for most teachers. A progressive step in the desired direction would be to integrate teacher made written assessment-tasks in the learning process (Struyf; Vandenberghe \& Lens, 2001). The central question in this chapter is whether integrating several well-designed teacher made written assessment-tasks in the learning environment can result in improvements in the overall-student performance? It is expected that students who make such assessment-tasks during a course will have higher grades on their final exam compared to students who do not participate in such assessment-tasks.

From empirical studies regarding the effects of integrated learningassessment environments it is known that these environments do not always demonstrate the expected learning outcomes (Segers, 1996). Recent research shows that the way the learning environment is perceived by the students, rather than the factual curriculum, affects to a large extent how students cope with the learning environment and consequently their learning results (Segers \& Dochy, 2001). It follows that educational interventions will be ineffective unless they modify students' perceptions (Lawness \& Richardson, 2002). This means that investigating the way the learning environment is perceived by the students seems to be crucial for interpreting their learning outcomes (Segers, et al., 2003). Therefore, students' and teachers' perceptions are also taken into account in this chapter.

In the present chapter, the case of written assessment-tasks integrated in the learning-environment of a European Law School, using problem-based learning is analysed. First, the characteristics of the problem-based learning environment and its assessment will be summarised. Secondly, the effects of the assessment-tasks on students' performance will be presented. Finally, students' and tutors' perceptions of the learning-assessment environment will be taken into consideration in order to get more insight into the effects.

\section{Problem-based learning}

Although originally developed for medical training in Canada, the orthodox version of problem-based learning (PBL) has been modified and applied globally in many disciplines (Gijselaers, 1995). Problem-based learning is at present receiving more and more attention in various programs of higher education. In the literature, PBL has been defined and described in different ways. In spite of the many variations of $\mathrm{PBL}$ that have evolved, a basic definition is needed to which other educational methods can be compared. Based on the original method as developed in McMasters Univerisity, Barrows (1996) developed six core characteristics of PBL. The first characteristic is that learning needs to be student-centred. Secondly, learning has to occur in small student groups under the guidance of a futor. The third characteristic refers to the tutor as a facilitator or guide. Fourthly, authentic problems are primarily encountered in the learning sequence, before any preparation or study has occurred. Fifthly, the problems encountered are used as a 
tool to achieve the required knowledge and the problem-solving skills necessary to eventually solve the problem. Finally, new information needs to be acquired through self-directed learning.

In the law school, in general students work in small tutorial groups (12-18 students) and meet twice a week under the supervision of a teacher (tutor) but chaired by a student-member of the group. Each session, students are confronted with a range of tasks or problems; which they analyse and try to solve by formulating 'learning goals' for their self-study. In the next session students report their findings on the basis of the materials they looked for, found and studied and start with analysing new problems. Besides this, students are enrolled on a weekly basis in somewhat larger 'practical groups' (24-36 students) and have one lecture a week. For a more extensive description of the legal curriculum and the problembased approach in the law school; see Moust (1998) or Pletinckx and Segers (2001).

\section{Assessment and PBL}

A wide range of assessment methods has been used to assess students learning in PBL. Ranging from traditional multiple-choice exams over essay exams to new modes of assessment such as case-based assessment, self- and peer assessment, performance-based assessment and portfolio assessment. Recently, many educators and researchers have advocated new modes of assessment in order to be congruent with the educational goals and instructional principles of PBL (Segers, et all., 2003). It is generally recognised that a seventh characteristic should be added to the six core characteristics of Barrows (1996). Essential for PBL is that students learn by analysing and solving representative problems; consequently, a valid assessment system evaluates students' problem-solving competencies in an assessment-environment that is congruent with the PBL environment. This means, the assessment in PBL should take into account both the organisation of the knowledge base, as the students" problem solving skills (Segers, et al., 2003).

In chapter 4 a meta-analysis was presented on the effects of PBL (compared to more conventional educational methods). The meta-analysis included the method of assessment as a moderator variable, suggesting that the more an instrument is capable of evaluating the students' competence in knowledge application, the larger the ascertained effect of PBL would be. A further exploration of the effect of what is measured with the assessment on the effects of PBL presented in chapter 5 showed that there is a difference in the reported effects of PBL between the different measurement-levels used in the study. As expected, the effect of PBL is larger compared to conventional education when the assessment method is focusing at 'the understanding of principles that link concepts'. Contrary to studies suggesting that the effects of PBL are larger when the more complex levels of the knowledge structure are being assessed, the effect size for 'application' (linking of concepts and principles to application conditions and procedures) was not statistically significant. These results implicate a challenge for PBL to pay more attention to 'application' in both the teaching and learning environment as the assessment. 
In the law faculty, for each course, a table of specification using Bloom's taxonomy (1956) is created in order to guarantee each subject matter is assessed on the desired level. Generally, assessment takes place immediately after each course by means of multiple-choice and/or essay questions. For more information about the assessment system in the law school, see Driessen, Van der Vleuten and Van Berkel (1999) or Driessen and Van der Vleuten (2000).

\section{Research questions}

In order to get more insight in the effects of written assessment-tasks integrated in the learning environment on students' performance two research questions are formulated. First, do students who make the assessment-tasks do better in their final exam compared to students who do not? Second, what are the most important concerns in students" and teachers' perceptions of the assessmenttasks?

\section{Method}

\section{Participants}

A total of 205 students, following a course on public law in the second year of their law study, participated. Out of these 205 students, 164 students completed all six assessment-tasks. These students will be considered as the participants in the 'assessment-task' condition. The remaining 41 students didn't complete the six assessment-tasks and are as a consequence considered as the participants in the "no assessment-task' condition. A total of 10 staff-members involved in the course participated in the study by completing the questionnaires and being interviewed.

\section{Procedure}

The research was carried out within the context of a compulsory second year law course. The study was carried out to evaluate the introduction of assessment-tasks in the faculty. A total of six assessment-tasks were distributed over different topics and weeks in the course. Assessment in the course was twofold. The final exam consisted of 40 multiple-choice questions and took place at the end of the course. During the course, students had the opportunity to complete the six assessment-tasks on a voluntary basis, which could result in an extra "bonus point', added to the score of the final exam. Both the assessment-tasks and the multiple-choice questions asked several cognitive activities from the students in line with the instructional goals of problem-based learning. 
The design of the assessment-tasks was to a great extent in line with the framework presented by Gibbs and Simpson (in press). Students were stimulated to produce qualitative learning activities by giving them one extra 'bonus-point' only if all six assessment-tasks showed to be of sufficient quality and effort. The feedback students got from their tutor or from the plenary discussion in the tutorial group could help them to make their next assessment-task better and to get a better understanding of the learning materials to be studied in order to pass the final exam at the end of the course.

Two methods for collecting data were employed: A quantitative and a qualitative approach. The quantitative approach will be presented first. Variables included are students' prior assessment scores, six assessment-tasks, a multiple choice-final exam and closed questions for both staff members and students.

\section{Prior assessment scores}

Since differences in performances between students making and succeeding all the assessment-tasks and students not doing so might be due to differences in prior academic achievement rather than in making or not making the assessment-tasks, the average scores of the students' previous academic exams was taken into account. Prior academic achievement is shown to be a good predictor of performance (House, Hurst \& Keely, 1996; Curall \& Kirk, 1986). As stated by Young (1993, p. 151) "the one aspect of student performance on which there is general consensus on importance is academic achievement, typically measured by the grade point average". In this case the grade point average (GPA) consisted of the scores students earned in the six previous final exams they took.

\section{Assessment-tasks}

With each of the six assessment-tasks, the students were asked to write an essay in which they had to go through a process of evaluation, synthesis, analysis or understanding of the study material or had to write down in detail the solution of a problem as presented in a case (see Figure 1). In order to succeed, each of the six. assessment-tasks had to be of sufficient effort and correctness. The tasks were discussed in the same way as the other problem tasks in the course after the students handed in their assessment-task. In this way the students got some plenary feedback. One week later, the students received back their assessment-task from the tutor, with the necessary feedback. 


\section{Case: Assessment-task}

Neighbour Smith from the previous case also received an amouncennent of the given (linited)

construction permit to Miss Jones on the 3rd of February 2003. He fears to have not that much light in his neighbouring garden, if the warehouse for flowers arises. He wonders whether he can stop the start of the building, although he is not involved in the ongoing procedure between the Miss Jones and the local authority. Moreower, it shouldn't be going to cost a lot since he's on social security. On the other hand, he is so untrained, that he could use legal aid.

Give your advice to neighbour Smith, write the necessary documents (maximum 2 A4).

Figure 1: example of an assessment task

\section{Final exam}

The objectives of the final exam are threefold and derived from Bloom's taxonomy (Bloom 1956): to investigate the student's ability to recall information (in terms of Bloom: Knowledge; defined as the remembering of previous learned material), to understand basic concepts and principles (comprehension; defined as the ability to grasp the meaning of material) and to apply information, concepts, and principles in new situations (application; refers to the ability to use learned material in new and concrete situations). The final exam consisted of 12 knowledge based questions (30\%), 14 comprehension based multiple choice questions (35\%) and 14 application based multiple choice questions ( $35 \%$ ). Out of these questions, 2 knowledge based, 4 comprehension based and 4 application based questions were orientated towards the topics related to the assessment tasks. The final exam was being found valid by the course supervisor. On average students scored $26.0 \mathrm{l}$ out of 40 on the exam ( $\mathrm{SD}=5.06)$. The internal consistency reliability coefficient was also measured and found appropriate (coefficient alpha $=0.74$ ).

\section{Closed questions}

The students' and tutors' survey consisted of three parts. The first part of the survey (both students and tutors) consisted of four questions concerning their view of working with the assessment tasks during the course. The items (e.g. "During the course it was made possible to make (assessment) tasks embedded in the curriculum") were rated on a five point Likert scale ( 1 = disagree completely 5 $=$ agree completely). The reliability of this part, questioning whether the assessment-tasks were perceived by the students and tutors as intended by the designers of the assessment-tasks, was high (coefficient alpha $=0.78$ ). The second part of the survey (both students and tutors) was developed to measure the students" and tutors' perception of different quality aspects of the (problem-based) learning environment, especially the assessment. The items are based on the characteristics of the learning-assessment environment and on the expectations of the staff concerning students "learning activities. This part of the questionnaire consisted of 15 items on a five point Likert scale concerning mostly the motivational aspects of the assessment tasks (e.g. "The use of assessment tasks stimulates me to work 
systematically"). The reliabifity was high (coefficient alpha $=0.84$ ). The third part of the survey (only for students) concerned the time students spend on the assessment tasks and their self-study activities.

\section{Qualitative instruments}

The qualitative aspect of this study took the form of an open ended questionnaire for both staff and students and a semi-structured interview with each staff-member. For example the students were asked to reflect on the assessment tasks embedded in the curriculum and making assessment tasks as part of the curriculum in general. The aim was to get more insight in the most important concerns in students" and teachers' perceptions of the assessment tasks.

\section{Results}

"The research questions will be reported one by one after the summary of the data of the prior" assessment scores of the students in both the "assessment-task' and the "no assessment-task" condition.

\section{Previous performance}

The difference between the previous final exams mean scores of the two assessment groups is significant $(r(70.64)=-3.36, p<0.05)$ meaning that the two groups indeed differ in academic achievement. The group of students making the assessment-tasks did significantly better on their previous final exams. In order to make both groups comparable, analyses of covariance (ANCOVA) are used as method of analysis in order to answer the first two research questions. Preliminary analysis of the data involved inspection of normality and homogeneity of variance assumptions. Normal plots, stem-and-leaf plots and the calculation of skewness and kurtosis were used to check the normality of distribution. To test the equality of group variances the Levene statistics was calculated. All assumptions for the analysis were met.

\section{Effect of participating in the assessment tasks on the final exam}

The ANCOVA was significant $(F(1,202)=9.63, M S E=10.39, p<0.01$, partial $\eta^{2}=0.05$ ). This means that, after correction for differences in students' prior performances, students who make and succeed all six assessment-tasks perform better on the final exam. The strength of relationship between the condition (assessment tasks or no assessment task) and the result on the final exam however was small, as assessed by a partial $\eta^{2}$, with the condition accounting for $5 \%$ of the variance of the dependent variable, holding constant the GPA. In order to 
investigate whether this effect is the result of a better preparation of the students for those topics treated with the assessment tasks only, our first research question is further divided in two more detailed research questions: First, do students who have completed and succeeded all the assessment tasks perform better on those questions in their final exam that are related to the topies treated with the assessment tasks compared to students who did not completed or succeedled all the assessment tasks? Secondly, do students who have completed and succeeded all the assessment tasks perform better on that part of the final exam that is not related to the topics treated with the assessment tasks compared to students who did not completed or succeeded all the assessment tasks?

\section{Effect of participating in the assessment tasks on relared final exam questions}

The results of the ANCOVA show that, after correction for differences in prior performances, there is a significant difference in outcome on that part of the final exam orientated towards the topics related to the assessment tasks between the two assessment groups $\left(F(1,202)=11.18, M S E=2.18, p<0.01\right.$, partial $\left.\eta^{2}=0.05\right)$. Students who took the assessment tasks and met the criteria of these tasks performed significantly better on the questions in the final exam related to the topics treated in the assessment-tasks.

Effect of participating in the assessment tasks on non-related final exam questions

The results of the ANCOVA indicate that, after correction for differences in prior performances, there is also a significant difference in the outcome for that part of the exam not orientated towards the topics related to the assessment tasks ( $F$ $(1,202)=3.97, M S E=6.46, p<0.05$, partial $\left.\eta^{2}=0.02\right)$. Apparently, working with assessment tasks has a positive influence on the performance not only of the related topics but also of the non-related topics. Although the statistical significance is smaller than with the related final exam question (significant at the 0.05 versus the 0.01 level) and the partial $\eta^{2}$ is relatively small (meaning that participating in the assessment tasks accounts for only 2 percent of the variance of the final exam if the prior performances of the students are hold constant) there is statistical significant evidence that working on the assessment tasks had a positive influence on the performance not only on the specific questions but atso on the whole final exam performance.

\section{Students' and teachers' perceptions of the learning-assessment environment}

In order to search for explanations for the results of these studies, students' and tutors' perceptions of the learning-assessment enviromment are investigated exploratively. This is also used as the input for recommendations for the 
improvement of educational practice. First, we will report the results of the closed questions:

\section{Closed questions}

In the tutors" view, the assessment tasks were embedded very well in the curriculum. All students, who took the assessment tasks, shared this point of view and were also positive about the way it was embedded. Both students and tutors share the opinion that by taking the assessment tasks more insight was gained into the extent of understanding the course material. There was, however, no significant correlation found between the assessment score and the perception of students on working with the assessment tasks during the course.

Students and tutors thought the assessment tasks were meaningful because they stimulated some desired learning activities. However, their opinions differed regarding the extent to which the learning activities were stimulating desired learning activities. Students were positive about the overall stimulus going out from the assessment tasks. They spend more time on the study material and in their view they worked more independent and more systematically as a result of the assessment tasks. Students found themselves more capable in the case of problem solving processes, critical thinking and reasoning. In a nutshell, according to the students, it was because of the assessment tasks they mastered the study material better, despite the fact that making these tasks was at the expense of the preparation of the group sessions. A small negative, but significant correlation was found between the two items asking whether making the assessment tasks was at the expense of the preparation of the tutorial and practical group sessions and the final exam score (respectively: $r=-0.26, p<0.01$ and $r=-0.27, p<0.01$ ). This suggests that students with a better time management perform slightly better on the final exam. Students preferred to work with assessment tasks in the future, highly motivated by the prospectus of the bonus point. In the view of the tutors the use of assessment tasks especially (or only) stimulated independent activities and reasoning. In contrast with the opinion of the students, the tutors did not think the students generally mastered the study material better.

Students who took the assessment tasks and met the criteria reported to have spend substantially more hours on self-study per week for the tutorial groups $(\mathrm{M}=18.44, S D=9.6)$ than the students who did not take or turn in the assessment tasks successfully $(\mathrm{M}=13.04, S D=8.60)$. However, there was no significant correlation between the amount of reported self-study hours and students" score on their final exam.

\section{Qualitative data results}

The open-ended questions and the interviews were found to have many features in common. Five important issues emerged: The learning effect, time 
management, the bonus point system, the usefulness of the assessment tasks, and the feedback.

\section{The learning effect}

The learning effect of the assessment tasks was very obvious for both students and tutors. As students stated: "Working with the tasks was very stimulating to work more intensive with the learning material". Consequently, the students were, according to the more experienced tutors, better prepared for the tutorial groups. This resulted according to the tutors in better, more in-depth discussions. Because of this effect, tutors argued for the use of assessment tasks strategically (also taking their time schedule into account, see feedback) in case of difficult tenets.

\section{Feedback}

Tutors reported that assessing a piece of work and giving appropriate feedback was only possible by checking it thoroughly. Furthermore they thought it was important for students to receive sound and detailed feedback. They found it inappropriate not to check students' work thoroughly and only looking for evidence of sufficient effort, as was proposed at first. However, for many tutors this resulted in a larger than planned amount of time for the tutors to evaluate the tasks. The presence of a well-constructed correction model was, according to the tutors, very helpful and time reducing to give their feedback. Also students reported to find the feedback useful.

\section{Time management}

Students spend more time on the learning material related to the assessment tasks. Though they spend more time on these tasks, they did not spend much more time overall. Taking the assessment tasks was mostly at the expense of students' preparation of other tutorial or practical group session as stated by the students themselves and as observed by the tutors. Because of the assessment tasks tutors spend more time evaluating the tasks, process the results and manage the data. Consequently, for some tutors this meant they were less prepared for the tutorial group sessions and for other tutors this meant they worked overtime.

\section{Bonus point system}

The students were very positive about the bonus point system. Nevertheless, they suggested a major change in the system. Their main consideration was about the way the bonus point was awarded. They thought that awarding a part of a bonus point for each assessment tasks is a more fair system instead of awarding a single bonus point for the total 6 assessment tasks. In this way students in circumstances beyond their control wouldn't be excluded for a bonus point. The tutors had two major considerations about the system. Their first consideration was about the weight of the bonus point. Their second consideration was about the amount of tasks. Several tutors suggested decreasing the amount of assessment tasks (three instead of six). In the eyes of the tutors the main benefit of 
this operation is that it reduces the amount of hours correcting/evaluating the assessment tasks and so this won't be at the expense of the preparation for the tutorial group sessions.

\section{The usefulness of the assessment tasks}

For students the criteria of the assessment tasks were not all stated clear and concrete enough: At first, most students didn't know exactly what was to be expected. Frequently students asked questions about its form and the content eriteria. The tutors" additional explanations and guiding had to set this problem right. Other indicated problems were more structural like problems with the timing of the assessment tasks: The spacing of the 6 assessment-tasks over the 8 weeks sometrmes was poor as was the tuning between the assessment tasks presented in the practical course book and the subject matter treated at that moment in the tutorial group. In other words, there was a need of especially constructed assessment tasks, capable of promoting long term learning effect, and containing an amount of topics handled in the previous settings. Although the present assessmenttasks meet these requirements to a large extent, improvements could be made.

\section{Conclusion and discussion}

By introducing teacher made assessment-tasks in a problem-based learning course, the PBL learning environment becomes more in alignment itself. The five dimensions in the framework under which assessment supports student learning (Gibbs and Simpson, in press) seem to be recognised by students and teachers in the assessment-tasks. When corrected for differences in prior academic performance, students who did make all the assessment-tasks successfully during the course, performed better on their final exam compared to students who did not make nor succeed the assessment-tasks. The fact that students did not only perform better on those parts of the final exam which were related to the assessment-tasks, but also on non-related questions indicates that the introduction of the assessment-task helped students to address more appropriate student learning activities, going beyond the six assessment-tasks and its content. The way in which the assessment tasks seem to have influenced the general learning approach of the students should be subject of further research.

From the closed questions it is clear that, in general, both students and tutors were happy about the way the assessment-tasks were embedded in the curriculum. Students reported to study more, more critically and more systematically as a result of the assessment tasks. It is suggested that students with a better time-management perform slightly better on their final exam.

Also the qualitative data seems to suggest that both the students and the teachers see the benefits of the assessment-tasks. Students are driven by the extra bonus-point to complete the assessment-tasks in the first place. Tutors are concerned about the feasibility of the whole project. As the students, they perceive a time-management problem: How to manage to give feedback on all the assessment- 
tasks. The presence of a correction model is helpful, but in the future the use of selfand peer-assessment can be considered to the benefit of the learning of the students and the time management of the tutors.

Several remarks can be made on the study presented in this chapter and the implementation of the assessment-tasks. First of all, the students were free to participate in the study. One could assume that only the better students would be willing to spend extra time on the assessment-tasks in order to gain an extra bonuspoint. Although the groups were corrected for their prior academic achievements, the study presented in this chapter was far from a randomised trial. Other factors, such as students' motivation, could have had an influence on students' choice to participate in the assessment-tasks. Another possible moderating variable that has not been taken into account is teacher time: Students participating in the assessment-tasks received more teacher time by means of the personal feedback on each assessment-task. Finally, the perspective of the bonus-point did motivate the students to participate in the assessment-tasks, but also hindered them seeing the assessment-tasks as a tool for learning.

In spite of its limitations, the study presented in this chapter is in line with and supports the framework Gibbs and Simpson (in press) have described and suggests that small steps in the change of the assessment system can result in relatively big changes in students' learning and results.

\section{References}

Barrows, H.S. (1996). Problem-based learning in medicine and beyond. In L. Wilkerson, \& W.H. Gijselaers (Eds.), Bringing problem-based learning to higher education: Theory and practice. New directions for teaching and learning, $n^{\circ} 68$ (pp. 3-13). San Francisco: Jossey-Bass Inc. Publishers.

Biggs, J. (2003). Teaching for quality learning at wniversity (second edition). Buckingham: Open University Press.

Birenbaum, M. (1996). Assessment 2000: Towards a pluralistic approach to assessment. In M. Birenbaum \& F. Dochy (Eds.), Alternatives in assessment of achievements, learning processes and prior knowledge (pp. 3-30). Boston: Kluwer Academic Publishers.

Black, P., \& William, D. (1998). Assessment and classroom learning. Assessment in Education: Principles, Policy \& Practice, 5 (1), 7-74.

Bloom B.S. (1956, Ed). Taxonomy of educational objectives, handbook I: The cognitive domain. New York: McKay.

Cohen, S.A. (1987). Instructional alignment: Searching for a magic bullet. Educational Researcher, 16 (8), 16-20.

Crooks, T. J. (1988). The impact of classroom evaluation practices on students. Review of Educational Research, 58 (4), 438-481.

Curall, S.C. \& Kirk, R.E. (1986). Predicting success in intensive foreign language courses. Modern Language Journal, 70 (2), 107-113. 
Dochy, F, \& McDowell, $\mathbb{L}$. (1997). Assessment as a tool for learming. Studies in Educational Evaluation, $23(4), 279-298$.

Driessen, E., \& Van der Vleuten, C. (2000). Matching student assessment to problem-based learning: Lessons from experience in a law faculty. Studies in Continumg Education, $22(2), 235-248$

Driessen, E., Van der Vleuten, C., \& Van Berkel, H. (1999). Beyond the multiplechoice $v$. essay questions controversy: Combining the best of both worlds. The Law Teacher, 33 (2), 159-171.

Cibbs, G. (1999). Using assessment strategically to change the way students learn. In S. Brown \& A. Glasner (Eds.), Assessment matters in higher education: Choosing and using diverse approaches (pp. 41-54). Buckingham: SRHE \& Open University Press.

Gibbs, G., \& Simpson, C. (in press). Does your assessment support your students' learning? Journal of Leaming and Teaching in Higher Education.

Gijselaters, W. (1995). Perspectives on problem-based learning. In W. Gijselaers, D. Tempelaar, P. Keizer, J. Blommaert, E. Bernard \& H. Kasper (Eds.), Educational innovation in economics and business Adninistsration: The case of problem-based leaming (pp. 39-52). Norwell: Kluwer Academic Publishers.

House, J.D., \& Hurst, R.S., \& Keely, E.J. (1996). Relationship between learner attitudes, prior achievement, and performance in a general education course: A multi-institutional study. Intenational Journal of Instructional Media, 23 (3), 157-271.

Lawness, C.J., \& Richardson, J.T.E. (2002). Approaches to studying and perceptions of academic quality in distance education. Higher Education, 44, $257-282$.

Moust, J.H.C. (1998). The problem-based education approach at the Maastricht Law School. The Law Teacher, 32, 5-37.

Pletinckx, J., \& M. Segers (2001). Programme evaluation as an instrument for quality assurance in a studentoriented educational system. Studies in Educational Evaluation 27, 355-372.

Sambell, L., McDowell, $\mathbb{L}_{\text {., }}$ \& Brow, S. (1997). "But is it fair?": An exploratory study of student perceptions of the consequential validity of assessment. Studies in Educational Evaluation, 23 (4), 349-371.

Scouller, K. (1998). The influence of assessment method on students" learning approaches: Multiple choice question examination versus assignment essay. Higher Education, 35, 453-472.

Segers, M, Dochy, ]., \& Cascallar, E. (2003). The era of assessment engineering: Changing perspectives on teaching and learning and the role of new modes of assessment. In M. Segers, F. Dochy \& E. Cascallar (Eds.), Optimising new modes of assessment: In search of qualities and standards (pp. 1-12). Dordrecht: Kluwer Academic Publishers.

Segers, M.. \& Dochy, F. (2001). New assessment forms in problem-based learning: The value-added of the students' perspective. Studies in Higher Education, $26(3), 327-343$. 
Segers, M. (1996). Assessment in a problem-based economics curriculum. In M. Birenbaum \& F. Dochy (Eds.), Altematives in assessment of achievennents, learning processes and prior learning (pp. 201-226). Boston: Kluwer Academic Press.

Struyf, E., Vandenberghe, R., \& Lens, W. (2001). The evaluation practice of teachers as a learning opportunity for students. Studies in Educational Evaluation, 27 (3), 215-238.

Torrance, H., \& Pryor, J. (1995, April). Making sense of "formative assessment". Investigating the integration of assessment with teaching and learning. Paper presented at the annual meeting of the American Educational Research Association (AERA), San Francisco.

Young, J.W. (1993). Grade Adjustment Methods. Review of Educational Research, $63(2), 151-165$. 


\section{Chapter 8}

\section{Discussion}

New learning environments, based on constructivist learning processes, claim to have the potential to improve the learning outcomes for students in higher education necessary to function successfully in today"s society (Simons, Van der Linden \& Duffy, 2000). A well known example of such a new learning environment in higher education is problem-based learning (Birenbaum, 2003; Hendry, Frommer \& Walker, 1999; Russel, Creedy \& Davis, 1994; Savery \& Duffy, 1995; Segers, Dochy \& De Corte, 1999). The main aim in this dissertation was to investigate the extent to which problem-based learning ( $\mathrm{PBL}$ ) is an effective learning environment.

Two meta-analyses (chapters 4 and 5) and a quasi-experimental study within a single course (chapter 6) were conducted to gain more insight into the effects of PBL on two broad categories of outcomes: Knowledge and knowledge application. In order to get more insight into the way students realise their learning outcomes, issues as students' perception of their learning environment and students' approaches to learning are investigated in three other studies: One investigating the relationship between students' approaches to learning and students' learning outcomes (chapter 3) and one comparing students' perceptions in PBL with students' perceptions in conventional lecture-based instruction (chapter 2). Finally, one study (chapter 7) partially took into account students' and teachers' perceptions of the learning environment while investigating the potential of integrating assessment tasks in the learning environment for improving the effects of PBL.

In this final chapter, the main results of each study will be summarised and discussed. The final section of this dissertation provides some suggestions for further research and future practices.

\section{Effects of $P B L$}

Chapter 4 reported a meta-analysis with two general aims: To address the main effects of problem based learning on the two categories of outcomes; knowledge and knowledge application and to address potential moderators of the effect of problem based learning. The overall conclusion was that there is a robust positive effect from PBL on the knowledge application of students. A tendency to 
negative results was discerned considering the effect of PBL on the knowledge of students. As possible moderators of PBL effects, methodological factors, the students" level of expertise, the retention period and the type of assessment method were investigated. The results from the moderator analysis showed that the negative effect of PBL on knowledge is decreasing if the quality of the research method is categorised as higher and that the negative effect of PBL on knowledge in a curriculum wide implementation of PBL decreases within a single course. Further, both for knowledge- and knowledge application-related outcomes the student's level of expertise is associated with the variation in effect sizes. Nevertheless, the results for the application of knowledge gave a consistent positive picture. For knowledge-related outcomes the results suggested that the differences encountered in the first and the second year disappeared more or less later on. Related to the retention period, students in PBL showed to gain slightly less knowledge, but to remember more of the acquired knowledge. Finally, the moderator analysis suggested that the mote an instrument is capable of evaluating the students" knowledge application, the larger the ascertained effect of PBL.

Chapter 5 builds on the latter result and takes the assessment as the main independent variable. The goal of this chapter was to describe the effects of PBL from the angle of the underlying focal constructs being measured with the assessment. A model on the cognitive components of problem solving (Sugrue, 1995) was used to separate variation in assessment method from variance relevant to the focal constructs being measured in the assessment. The latter was taken as a unit of analysis in this study and three research questions were formulated: What are the effects of PBL when the assessment of its main goals focuses on respectively (1) the understanding of concepts, (2) the understanding of the principles that link concepts and (3) the linking of concepts and principles to conditions and procedures for application? The results showed a difference in the reported effects of PBL, between each of the three levels in the knowledge structure. PBL had most positive effects when the focal constructs being assessed were at the level of understanding the principles that link concepts, the second level of the knowledge structure. Different from the expectation aroused in chapter 4 , that the extent to which an assessment method is capable of evaluating the students" knowledge application would be related to larger ascertained effects of PBL, the effect size for the third level of the knowledge structure was smaller and not statistically significant.

Compared to the existing reviews, both meta-analyses in this dissertation were extended by looking for studies beyond one specific domain and by analysing potential moderators of the main effects. Nevertheless, some remarks on the limitations of both reviews can be made. Although the search for literature in both reviews was broad and looked for studies beyond the medical domain, except for one study, all studies that met the criteria for inclusion were situated in the domain of medical education. In spite the clear description of criteria for inclusion and the use of a weighting technique, taking into account sample size of studies, generalisations beyond the domain of medical education should be made with caution. Notwithstanding our intention to deal with publication bias and also to 
include unpublished work, all of the studies included in the two meta-analyses turned out to be published.

The study reported in chapter 6 addressed the effects on students? knowledge and knowledge application of an in time and theme limited implementation of PBL. Data from two institutions for teacher training indicated no unequivocal conclusions with regard to the knowledge of the students, since the results of both institutions went in opposite directions. At the level of knowledge application, the results were similar for both institutions. Notwithstanding the time limited implementation, students in PBL tended to be more successful in applying their knowledge than students from conventional educational settings. In view of the specific context of the institutions in which the study was conducted and the limited range of subject matters studied, caution must be exercised where external validity is concerned. Although efforts were made to examine the comparability of the groups, statements about internal validity must be interpreted cautiously as a result of the fact that the students were not distributed at random over the experimental and control conditions.

PBL aims to educate students that are able to solve complex problems. In order to be congruent with its educational goals and resulting instructional principles and practices, the assessment of the application of knowledge when solving problems is at the heart of the matter in PBL. Therefore, one could expect students in PBL performing better at this level of the knowledge structure. From the studies reported in chapters 4,5 and 6 , it could be concluded that, with PBL, students' path towards successful problem-solvers has been accelerated. In general, students in PBL are not better at recalling specific items of information compared to students in more conventional learning environments but they do seem to posses a more structured network of concepts and principles. On the other hand, the extent to which students in PBL are better in relating their knowledge base to the goals of problem solution and conditions for action is not as high as should be expected from the aims and claims put forward by PBL. However, if PBL aims to educate better problem solvers, more attention should be paid to this, both during the learning activities that take place and students' assessment in PBL. Since the aim of educating graduates being able to solve complex problems in an efficient way is a general goal in higher education, this concern counts for all new learning environments in the context of higher education and probably beyond. It is clear that assessment has an important influence on the reported effects of PBL, but also that other moderators of PBL play a substantial role when the effects of PBL are examined. It might be expected that when the students' assessment is close to graduation, the effect measured would be bigger compared to research settings measuring at an earlier stage of the study. The expertise level of the students was, amongst other variables, one of the moderating variables in chapter 4 and indicated that the advantage of the conventional educational method in knowledge acquisition disappears more or less after the second year. The effects of PBL on the application of knowledge differentiated for the students" level of expertise and show a consistent positive effect of PBL. Other moderators such as study design and scope 
of implementation have been shown to be possible other moderating variables in the reporting of the effects of PBL.

\section{The role of students' perceptions and approaches to learning}

In order to get more insight the way students realise there learning outcomes, issues as students " perception of their learning environment and students" approaches to learning are of vital importance. Students' perception of the academic learning environment, rather than the academic environment "an sich' affect their approaches to learning, and this in turn affects their learning outcomes (Entwistle \& Tait, 1990; Fraser, Walberg, Welch \& Hattie, 1987; Brekelmans, van den Eeden, Terwel \& Wubbels, 1997).

The relationship between students' approaches to learning and students" quantitative learning outcomes, as a function of the different components of problem solving that are measured within the assessment, was addressed in chapter 3. Data were obtanined from two sources: The revised two factor study process questionnaire (R-SPQ-2F) and students" scores in their final multiple-choice exam. The model on the cognitive components of problem solving (Sugrue, 1995) presented in chapter 5 was used to categorise the different questions in the multiplechoice exam. The second year law students in the sample showed slightly higher scores for a deep approach than for a surface approach to learning. However, plotting students' approaches to learning indicated that a lot of students had low scores for both deep and surface approaches. Correlational analysis indicated no relationships between students' approaches to learning and the components of problem solving being measured within the multiple choice assessment. Consequently, the employment of deep learning approaches could not be associated with higher assessment outcomes within the multiple-choice exam. It was suggested that the wording of the questions (from what we deduced by means of Sugrue's (1995) model the components of problem solving being measured) was by itself not sufficient to influence the nature of students' responses. The method of assessment and the way students perceive and differentiate between questions within an assessment method has probably more influence on the way students study for and respond to exam questions is. In this perspective, Scouller (1998) found that success in multiple-choice examinations was related to the perception of the questions as assessing lower levels of cognitive processes and the non-employment of deep strategies. Next to the method of assessment, the content and method of teaching might also have an influence on the way students study for and respond to exam questions. Since the study was carried out within the context of a second year law course, it should be noted that law school students differ from some other disciplines in the way they approach their learning and the way it is related with study outcomes (Makinen \& Olkinuora, 2003). Further, the learning environment in the study, problem-based learning, is an example of a new learning environment that has the potential to facilitate deep approaches to learning (Biggs, 2003). Neverthelless, there is no tendency towards a strong use of deep approaches to 
learning, despite the problem-based learning environment. Seemingly, the current conditions of teaching and assessment did not make all students decide that a deep approach would give the best results, as indeed it didn't. Finally, some remarks should be made related to the model of cognitive components of problem solving (Sugrue, 1995) used in chapter 3 and 5. The model presented by Sugrue (1995) is one possible framework on the components of problem solving. The translation of the model into specifications for the assessment, including assessment by means of multiple-choice questions, made the model useful for the purpose of both chapters: The classification into the three levels of the knowledge structure can relatively easily be done in most domains, such as mathematics, science, economics and medical education. The extraction of unambiguous principles governing relationships among concepts might not be easy to use in other domains such as history and law.

Investigating the way the learning environment is perceived by the students seems to be crucial for interpreting their learning outcomes (Segers, Dochy \& Cascallar, 2003). Students' perceptions of the learning environment is subject of research in chapter 2 and partially in chapter 7 . In chapter 2, the question whether students in PBL perceive their learning environment as more constructivist compared to students in a conventional lecture-based environment is investigated. Using a questionnaire consisting of seven key factors of constructivist learning environments (Tenenbaum, Naidu, Jegede \& Austin, 2001), it resulted that students in PBL perceive the learning environment as more constructivist compared to students in a conventional lecture-based environment. The difference was statistically significant for each of the seven factors. According the effect size as measured by the $d$-index, the difference in perception between the two groups was most salient for the factors 'conceptual conflicts and dilemmas' and 'sharing ideas with others'. These two factors determine the strength of PBL in incorporating constructivist principles, tutors should be aware of the importance of facilitating these two factors to create a well functioning cooperative tutorial group that promotes meaningful knowledge construction. However, if PBL claims to be highly consistent with constructivist features, at least in the perception of the students there remain a lot of opportunities yet to take. Especially the factor "meeting students" needs" was only moderately present in PBL. On the other hand the conventional lecture-based environment succeeded to spend relatively much attention to the factors 'materials and measures targeted toward solutions' and 'making meaning, real-life examples', indicating that working with real-life contexts and authentic problems are not the restricted hallmark of PBL. Finally, it is suggested that students' perceptions of constructivist principles in the learning environment are triggered by a greater variety in learning environments.

Chapter 7 makes use of students' and teachers" perceptions in order to get more insight into the effects of integrating assessment-tasks in the learning environment. The results of chapter 7 will be summarised and discussed in the next paragraph. 


\section{Improving the effects of PBL: The role of assessment}

The question how PBL could be made more effective is addressed in chapter 7. In this respect the alignment between the learning enviromments' objectives and the assessment is crucial in achieving the goals for higher education and improving students learning (Biggs, 2003; Birenbaum, 2003; Cohen, 1987; Gibbs, 1999). The integration of assessment, learning and instruction remains a challenge for most teachers. A progressive step in the desired direction would be to integrate written assessment-tasks in the learning process in order to get more insight in the effects of written assessment-tasks integrated in the learning environment on students' performance two research questions are formulated in chapter 7. First, do students who make the assessment-tasks do better in their final exam compared to students who do not? Secondly, what are the most important concerns in students" and teachers' perceptions of the assessment-tasks? Students' final exam results were used to find out whether students who make the assessmenttasks do better than students who do not. Answers from questionnaires and semistructured interviews were used to discover the most important concerns in students' and teachers' perceptions of the assessment-tasks. The results showed that, when corrected for differences in prior academic performance, students who did submit all the assessment-tasks successfully during the course, performed better on their final exam compared to students who did not make nor succeed the assessment-tasks. This was the case for both those parts of the final exam which were related to the assessment-tasks as non-related questions, indicating that the assessment tasks seem to have influenced the general learning approach of the students. From the questionnaires and interviews it appeared that both the students and the teachers see the benelits of the assessment-tasks. Students reported to study more, more critically and more systematically as a result of the assessment tasks, moreover, a better time-management is related to higher final exam grades. Tutors perceived a time-management problem and were concerned about the feasibility of the whole project. In spite of some limitations of this study, such as the fact that students were free to participate in the assessment-tasks and the possible influence of non controlled variables such as motivation and teacher time, it is concluded that small steps in the change of the assessment system can result in relatively big improvements in students' learning and results.

\section{Suggestions for further research}

The results and limitations of the studies presented in this dissertation evoked some questions for further research. Assessment turned out to be an important mediating factor when examining the effects of PBL and a lever to improve students learning and results. Future research should probe into the way (the method of) assessment influences students' learning and results and take into account the context of assessment (for grading and/or research purposes) when 
examining the effects of PBL. Since it's a general aim of PBL to educate better problem solvers, future research on the effects of PBL should pay more attention to the extent to which students in PBL are better in relating their knowledge base to the goals of problem solution and conditions for action.

The issues of students" perceptions and approaches to learning are of vital importance for the understanding of the way students realise their learning outcomes. Future research should focus on the engineering of an optimal mix of learning environments and take into account students' perceptions in the blend of learning environments (lectures, problem-based learning, e-learning, etc.). The influence of students' perceptions of (the method of assessment on the way students approach their learning and respond to exam questions should be taken into account. Also other potential moderators such as GPA, participation in formative assessment, self-confidence, and academic self-efficacy should be subject of further research on the relationship between students' approaches to learning and students' (quantitative) learning outcomes.

Finally, future research on the effects of new learning environments in general, and PBL in particular, should also take affective and motivational effects into account and further investigate which aspects in the learning-assessment environment play a crucial role in the realisation of today's educational needs.

\section{Practical implications}

Some practical implications or suggestions for future practices can be derived from this dissertation. First, the factors 'conceptual conflicts and dilemmas' and 'sharing ideas with others' determine the strength of PBL in incorporating constructivist principles, tutors should be aware of the importance of facilitating these two factors to create a well functioning cooperative tutorial group that promotes meaningful knowledge construction. Secondly, an effective new learning environment should consist of a blend of learning environments that fosters deep approaches to learning and concentrates on problem solving, both in the learning and assessment processes. Finally, the learning and assessment environment should be more integrated. This could be done by an increasing implementation of new modes of assessment, such as self- and peer-assessment, serving both the learning of the students as the time-management feasibility of teachers.

\section{References}

Biggs, J. (2003). Teaching for quality learning at university (second edition). Buckingham: Open University Press.

Birenbaum, M. (2003). New insights into learning and teaching and their implications for assessment. In M. Segers, F. Dochy \& E. Cascallar (Eds.), Optimising new 
modes of asseswent: In search for qualities and standards (pp. 13-36). Dordrecht: Kluwer Academic Publishers:

Brekelmans, M., van den Eeden, P., Terwel, J., \& Wubbels, T. (1997). Student characteristics and learning enviromment interactions in mathematics and physics education $A$ resource perspective Intemational Joumal of Educational Research 27 (4), 283 292 .

Cohen, S.A. (1987) Instructional alignment: Searching for a magic bullet Edracational Researcher, $16(8), 16-20$.

Entwistle, N.J \& Tait, H. (1990). Approaches to learning, evaluations of teaching, and preferences for contrasting academic environments. Higher Education, 19 (2), 169194.

Praser, BJ., Walberg, H.J., Welch, W.W., Hattie, J.A. (1987). Syntheses of educational productivity research. Intemational Journal of Educational Research, 11, 145252.

Gibbs, G. (1999). Using assessment strategically to change the way students learn. In. S. Brown \& A. Glasner (Eds.), Assessment matten in higher education: Choosing and using diverse approaches (pp.41-53). Buckingham: Open University Press.

Hendry, G. D., Frommer, M. \& Walker, R.A. (1999). Constructivism and Problembased learning. Journal of Further and Higher Education, 23 (3) 359-371.

Mäkinen, J, \& Olkinuora, E. (2003, august). Personal experience of studying and study success: A three-years follow-up study of university students. Paper presented at the $10^{\text {th }}$ biannual conference of the European Association for Research on Learning and Instruction (EARLI), Padova, Italy.

Russell, A. L., Creedy, D. \& Davis, J. (1994). The use of contract learning in PBL, in: S. E. Chen, S. E. Cowdroy, A. J. Kingsland \& M. J. Ostwald (Eds.), Reflections on problem based learning, (pp. 57-72). Sydney: Australian Problem Based Network.

Savery, J. R., \& Duffy, T. M. (1995). Problem-based learning: An instructional model and its constructivist framework, Educational Technology, 35, 31-38.

Scouller, K. (1998). The influence of assessment method on students' learning approaches: Multiple choice question examination versus assignment essay. Higher Lducarion, 35, 453-472.

Segers, M., Dochy, F, \& Cascallar, E. (2003). The era of assessment engineering: Changing perspectives on teaching and learning and the role of new modes of assessment. In M. Segers, F. Dochy \& E. Cascallar (Eds.), Optimising new modes of asiessment: In search for qualities and standards (pp. 1-12). Dordrecht: Kluwer Acadenic Publishers.

Segers, M., Dochy, F., \& De Corte, E. (1999). Assessment practices and students" knowledge profiles in a problem-based curriculum. Leaming Enviromments Research, 12(2), 191-213

Simons, R.J., van der Linden, J., \& Duffy. T. (2000). New learning: Three ways to learn in a new balance. In R.J. Simons, J. van der Linden \& T. Duffy (Eds.), New learning (pp. 1-20). Dordrecht: Kluwer Academic Publishers.

Sugrue, B. (1995). A theory-based framework for assessing domain-specific problem solving ability. Educational Measurement: Issues and Practice (14) 3, 29-36.

Tenenbaum, G., Naidu, S., Jegede, O., \& Austin, J. (2001). Constructivist pedagogy in conventional on-campus and distance learning practice: An exploratory investigation. Learning and Instruction, $11,87-1 \mathbb{1 1}$ 


\section{Summary}

It is widely accepted that successful functioning in society demands more than the understancling of the basic knowledge of a domain of study. An important challenge for today's higher education remains the development and implementation of instructional practices that will foster in students the skill to solve complex problems in an efficient way. Student-centred or new learning environments, rooted in constructivism are claimed to have the potential to improve these educational outcomes for students in higher education. An example of such a new learning environment consistent with constructivist principles is problem-based learning.

The main aim in this dissertation is to investigate to what extent problembased learning (PBL) is an effective learning environment. The focus is on two broad categories of outcomes: The acquisition as well as the application of knowledge. In order to get more insight into the way students realise these learning outcomes, issues as students" perception of their learning environment and students' approaches to learning are considered to be of vital importance. Students' perception of the academic learning environment, rather than the academic environment 'an sich' affect their approaches to learning, and this in turn affects their learning outcomes

Chapter one gave an introduction to the present dissertation and described the structure and research questions.

In chapter two the question whether students in PBL perceive their learning environment as more constructivist compared to students in a conventional lecturebased environment is investigated. Using a questionnaire based on seven key factors of constructivist learning environments, it resulted that second year law students following a course on the topic of private law in PBL perceive the learning environment as more constructivist when compared to students in a conventional lecture-based environment. The difference was statistically significant for each of the seven factors. According the effect size as measured by the $d$-index, the difference in perception between the two groups was the largest for the factors "conceptual conflicts and dilemmas" and "sharing ideas with others". The factor 'meeting students" needs' was only moderately present in PBL, while the conventional lecture-based environment succeeded to pay a relatively large amount of attention to the factors 'materials and measures targeted toward solutions' and 'making meaning, real-life examples'. It is concluded that the factors 'conceptual conflicts and dilemmas' and 'sharing ideas with others' determine the strength of PBL in incorporating constructivist principles. It is suggested that students" perceptions of constructivist principles in the learning environment are triggered by a greater variety in learning environments. 
Chapter 3 addressed the relationship between students' approaches to leaming and students ${ }^{*}$ quantitative learning outcomes. Data were obtained from two sources: The revised two factor study process questionnaire (R-SPQ-2F) and students" scores on their final multiple-choice exam. A model on the cognitive components of problem solving was used to categorise the different questions in the multiple-choice exam. The second year law students in the sample followed a course on the topic of public law and showed slightly higher scores for a deep approach than for a surface approach to learning. However, plotting students' approaches to learning indicated that a lot of students had low scores for both deep and surface approaches. Correlational analyses indicated no relationships between students' approaches to learning and the components of problem solving being measured within the multiple choice assessment. Consequently, the use of deep approaches to learning could not be associated with higher assessment outcomes within the multiple-choice exam. Several explanations are discussed in the chapter.

In chapter 4 a statistical meta-analysis is reported with two general aims: To address the main effects of problem based learning on the two categories of outcomes; knowledge and knowledge application and to address potential moderators of the effect of problem-based learning. The overall conclusion was that there is a robust positive effect from PBL on the knowledge application of students. A tendency to negative results was discerned considering the effect of PBL on the knowledge of students. As possible moderators, methodological factors, the students' level of expertise; the retention period and the type of assessment method were investigated. The results from the moderator analysis showed that the negative effect of PBL on knowledge is decreasing if the quality of the research method is categorised as higher and that the negative effect of PBL on knowledge in a curriculum-wide implementation of PBL decreases within a single course. Further, both for knowledge- and knowledge application-related outcomes the student's level of expertise is associated with the variation in effect sizes. Nevertheless, the results for the application of knowledge gave a consistent positive picture. For knowledge-related outcomes the results suggested that the differences encountered in the first and the second year disappeared more or less later on. Related to the retention period, students in PBL showed to gain slightly less knowledge, but to remember more of the acquired knowledge on the long term. Finally, the moderator analysis suggested that the more an instrument is capable of evaluating the students" knowledge application, the larger the ascertained effect of PBL.

Chapter 5 builds on the results of chapter 4 and investigates the influence of assessment on the reported effects of PBL as the main independent variable. Hereto a model of cognitive components of problem solving was used. Three levels of the knowledge structure that can be targeted by assessment of problem solving were used as the main independent variables: (1) understanding of concepts, (2) understanding of the principles that link concepts, and (3) linking of concepts and principles to conditions and procedures for application. A statistical meta-analysis was conducted, supplemented by more inclusive vote counts and an associated sign test. The results showed a difference in the reported effects of PBL between each of the three levels in the knowledge structure. PBL had most positive effects when the focal constructs being assessed were at the level of understanding the principles 
that link concepts, the second level of the knowledge structure. Different from the expectation aroused in chapter 4 , that the extent to which an assessment method is capable of evaluating the students" knowledge application would be related to larger ascertained effects of PBL, the effect size for the third level of the knowledge structure was smaller and not statistically significant. It is concluded that the implications of assessment and the levels in the knowledge structure being measured must be considered when examining the effects of problem-based learning.

In chapter 6 the effects on students' knowledge and knowledge application of an in time and theme limited implementation of PBL within teacher training are investigated. Two research questions were to be answered in this chapter: First, to what degree do students studying for a limited period of time in a PBL-course acquire an accessible knowledge base of the subject studied compared to students to whom the subject was presented in a conventional way? Secondly, are students who have been subjected for a limited period of time to a PBL-course better equipped to apply the knowledge of the subject studied than students to whom the subject was presented in the conventional lecture-based way? Data from two institutions for teacher training indicated no unequivocal conclusions with regard to the knowledge of the students, since the results of both institutions went in opposite directions. At the level of knowledge application, the results were similar for both institutions. Notwithstanding the time limited implementation, students in PBL tended to be more successful in applying their knowledge compared to students from the conventional educational settings.

The purpose of chapter 7 was to get more insight in the effects of written assessment-tasks integrated in a problem-based learning environment. Both the influence on students' performances and students' perceptions were investigated. Second year law students' final exam results of a course on the topic of public law were used to find out whether students who make the assessment-tasks do better than students who do not. Answers from questionnaires and semi-structured interviews were used to discover the most important concerns in students ${ }^{*}$ and teachers' perceptions of the assessment-tasks. The results showed that, when corrected for differences in prior academic performance, students who did submit all the assessment-tasks successfully during the course, performed better on their final exam compared to students who did not make nor succeed the assessmenttasks. This was the case for both those questions in the final exam which were related to the assessment-tasks as non-related questions, indicating that the assessment tasks seem to have influenced the general learning approach of the students. From the questionnaires and interviews it appears that both the students and the teachers see the benefits of the assessment-tasks. Students reported to study more, more critically and more systematically as a result of the assessment tasks. Moreover, a better time-management was related to higher final exam grades. Tutors perceived a time-management problem and were concerned about the feasibility of the whole project. It is concluded that small steps in the change of the assessment system can result in relatively big changes in students' learning and results. 
In chapter 8 the results from the previous chapters are summarised and discussed and some suggestions for further research and future practices are formulated. In conclusion, the meta-analyses and the successive chapters in this dissertation show that as far as the knowledge of the students is concerned, no unequivocal conclusions can be drawn. However, there is a robust positive effect from PBL on the knowledge application of students. When the implications of assessment and the levels in the knowledge structure being measured are taken into account when examining the elfects of PBL, it becomes clear that students' path towards successful problem-solvers has been accelerated, but at the same time more attention for real application of knowledge is needed in both the learning activities that take place and students' assessment in PBL in order to meet the expectations in a better way. The strength of PBL in incorporating constructivist principles is to a large extent determined by the factors 'conceptual conflicts and dilemmas' and 'sharing ideas with others'. Perceptions of these and other constructivist principles seem to be triggered by a greater variety in learning environments. No relationship has been found between students' approaches to learning and the components of problem solving being measured within the multiple choice assessment; students using deep approaches to learning did not score better on any part of the multiplechoice exam. However, the making of assessment-tasks during the PBL-course had a positive influence on the general performance of the students in the final multiplechoice exam. Both the students and the teachers see the benefits of the assessmenttasks to improve the effects of PBL. 


\section{Samenvatting}

Succesvol functioneren in de huidige dynamische kemis- en informatiemaatschappij stelt meer eisen aan een afgestudeerde dan een goede basiskennis wan thet studiedomein. Het blijft vandaag een uitdaging voor het hoger onderwijs om leeromgevingen te ontwikkelen en implementeren warbinnen studenten worden opgeleid om complexe problemen aan te pakken op een efficiënte manier. Recente ontwikkelingen in het onderwijs van nieuwe, studentgecentreerde leeromgevingen zijn in grote mate gebaseerd op een constructivistische visie op leren. Zulke nieuwe leeromgevingen beweren in sterke mate tegemoet te komen aan de nieuwe eisen die gesteld worden aan het hoger onderwijs. Een voorbeeld van zo een nieuwe leeromgeving in het hoger onderwijs is het probleemgestuurd onderwijs (PGO).

De centrale vraag in dit proefschrift is de vraag in welke mate $\mathrm{PGO}$ een effectieve leeromgeving is. De klemtoon ligt daarbij op twee brede doelstellingen: het verwerven en toepassen van kennis. Om meer inzicht te krijgen in de manier waarop studenten deze doelstellingen al dan niet realiseren, is de manier waarop studenten hun leeromgeving percipiëren en de wijze waarop ze samenhangend met die perceptie hun studie aanpakken van essentieel belang. Immers, de wijze waarop studenten de leeromgeving percipiëren beïnvloedt in sterke mate de manier waarop studenten hun studie zullen aanpakken en bijgevolg ook de mate waarin de doelstellingen gerealiseerd worden.

Hoofdstuk één schetst een inleiding en beschrijft de structuur en onderzoeksvragen van het proefschrift.

In hoofdsruk twee wordt de vraag onderzocht of studenten in PGO hun leeromgeving als meer constructivistisch percipiëren dan studenten in een conventionele (hoorcollege) leeromgeving. Daarbij wordt gebruik gemaakt van een vragenlijst uitgaande van zeven kernfactoren van een constructivistische leeromgeving. De tweedejaars rechtenstudenten die een cursus op het domein van het privaatrecht in een $\mathrm{PGO}$ curriculum volgden percipieerden de leeromgeving als meer constructivistisch vergeleken met de studenten in een conventioneel curriculum. Het verschil was statistisch significant voor elk van de zeven factoren. Volgens de effectgrootte gemeten met de $d$-index was het verschil tussen de twee groepen het grootst voor de factoren "conceptuele conflicten en dilemma's" en 'ideeèn met anderen delen'. De factor 'ingaan op de wensen van studenten' was slechts middelmatig vertegenwoordigd in de PGO ongeving, terwijl in de conventionele leeromgeving de factoren 'onderwijsmateriaal gericht op oplossingen' en 'betekenisgeving, levensechte voorbeelden' relatief veel aandacht kregen. Er werd geconcludeerd dat de kracht van PGO grotendeels schuilt in de factoren 'conceptuele conflicten en dilemma's" en 'ideeën met anderen delen'. 
Verder is gesuggereerd dat percepties van constructivistische principes in de leeromgeving gestimuleerd worden door een confrontatie met een grotere variëteit aan leeromgevingen.

Hoofdsfuk 3 behandelt de relatie unssen de studieaanpak en de (kwantitatieve) resultaten van de studenten. Tweedejaars rechtenstudenten die een cursus op het domein wan het publiekrecht volgden vulden een vragenlijst in (de gereviseerde twee-factor "study process questionnaire" R-SPQ-2F) die de studieaanpak van studenten in kaart bracht. De cursus werd afgesloten met een meerkeuzetoets. De verschillende vragen in de meerkeuzetoets werden met behulp van een model van cognitieve componenten van probleemoplossen ingedeeld in drie verschillende categorieén. De studenten hadden slechts iets hogere scores voor de diepgaande studieaanpak dan voor de oppervlakkige studieaanpak. Het 'plotten' van de studieaanpak vain de studenten liet echter zien dat een grote groep studenten lage scores vertoont voor zowel de diepgaande als de oppervlakkige studieaanpak. Correlationele analyses tonen geen verband tussen de studieaanpak van studenten en de verschillende componenten van probleemoplossen zoals gemeten met een meerkeuzetoets. Een diepgaande studieaanpak kon bijgevolg niet gerelateerd worden aan hogere studieresultaten binnen de meerkeuzetoets. In het hoofdstuk worden verschillende verklaringen besproken.

In hoofdstuk 4 worden de resultaten gerapporteerd van een statistische meta-analyse met twee algemene vragen. Ten eerste, wat zijn de hoofdeffecten van PGO op de twee aangeduide brede categorieën van doelstellingen: kennis en toepassen van kennis? Ten tweede, welke zijn verschillende potentieel mediërende variabelen van de effecten van PGO? Algemeen werd geconcludeerd dat er een robuust en positief effect is van PGO op het toepassen van kennis bij studenten. Met betrekking tot de kennis van studenten laat zich echter een tendens tot negatieve resultaten zien. Als potentieel mediërende variabelen werden methodologische factoren (het design van de studies en de breedte van implementatie), het expertiseniveau van de studenten, de retentieperiode en de wijze van toetsing onderzocht. De resultaten van de analyse van deze variabelen tonen aan dat het negatieve effect van PGO op kennis afneemt als de kwaliteit van de onderzoeksmethode stijgt en dat hetzelfde negatieve effect groter is in een curriculumbrede implementatie van PGO dan in een enkele lessenreeks. Verder is het expertiseniveau van de student van invloed op zowel kennisverwerving als het toepassen van kennis. De resultaten voor het toepassen van kennis tonen een consistent positief beeld, maar voor de resultaten van de verwerving van kennis suggereren de resultaten dat de vastgestelde negatieve effecten op kennis in het eerste en tweede jaar van de opleiding daama nagenoeg verdwijnen. Met betrekking tot de retentieperiode wordt duidelijk dat studenten in PGO op korte termijn iets minder kennis verwerven maar er op لange termijn meer van onthouden dan studenten uit het conventioneel onderwijs. Tot slot suggereerde de analyse van de mediërende variabelen dat cle mate waarin een toetsinstrument in staat is de toepassing van kennis te meten, gerelateerd is aan de vastgestelde positieve effecten van PGO.

Hoofdstuk 5 bouwt verder op deze laatste suggestie en onderzoekt de invloed van toetsing op de gerapporteerde effecten van PGO. Hiertoe wordt een 
model van cognitieve componenten van probleemoplossen gebruikt. Drie niveaus die kunnen worden onderscheiden in de kennisstructuur en die elk voorwerp kunnen zijn van een probleemoplossende toets, worden gebruikt als onafhankelijke variabelen: (1) het begrijpen van concepten, (2) het begrijpen van de principes die concepten met elkaar verbinden, en (3) het verbinden van concepten en principes naar condities en procedures voor toepassing. De resultaten van de statistische meta-analyse tonen aan dat er een verschil is in de gerapporteerde effecten van PGO tussen elk van de drie niveaus in de kennisstructuur. De effecten van PGO zijn het grootst wanneer "het begrijpen van de principes die concepten met elkaar verbinden' -het tweede nivean in de kennisstructuur- voorwerp van toetsing is. Anders dan gesuggereerd op basis van de resultaten in hoofdstuk 4 (namelijk dat de mate waarin een toetsinstrument in staat is de toepassing van kennis te meten zou gerelateerd zijn aan de vastgestelde positieve effecten van PGO) is de effectgrootte voor het derde niveau in de kennisstructuur kleiner en niet statistisch significant. Er wordt geconcludeerd dat de implicaties van de toetsing en de getoetste niveaus in rekening moeten worden gebracht wanneer de effecten van PGO worden onderzocht.

In hoofdstuk 6 wordt het effect van een vier weken durende implementatie van PGO op de kemnis en het toepassen van kennis bij studenten nagegaan in twee instituten voor lerarenopleiding. De volgende probleemstelling staat centraal: in welke mate zijn studenten uit een PGO-setting in vergelijking met studenten uit een conventionele setting in staat om over een bepaald onderwerp enerzijds kennis te verwerven en anderzijds kennis over dat onderwerp toe te passen? De resultaten van het quasi-experimenteel vergelijkend onderzoek laten wat de kennis van de studenten betreft geen eenduidige conclusies toe, aangezien de resultaten in beide instituten niet in dezelfde lijn liggen. Op het niveau van het toepassen van kennis zijn de resultaten wel gelijklopend voor beide instituten: niettegenstaande de in tijj beperkte implementatie, lijken studenten uit PGO meer succesvol te zijn in het toepassen van kennis dan studenten uit het conventioneel onderwijs.

De centrale vraag in hoofdstuk 7 was of het integreren van 'assessmenttaken" in de probleemgestuurde leeromgeving resulteert in betere studieresultaten. De toetsresultaten van tweedejaars rechtenstudenten in een cursus in het domein van het publiekrecht werden gebruikt om te onderzoeken of studenten die assessment-taken maken beter scoren dan studenten die geen assessment-taken maken. Vragenlijsten en semi-gestructureerde interviews werden afgenomen om meer inzicht te krijgen in het effect van de assessment-taken. De resultaten van de studie tonen aan dat het maken van de assessment-taken een positieve invloed heeft op de algemene prestatie van de studenten op de afsluitende toets. Studenten die de assessment-taken maken en voldoen aan de daaraan gestelde eisen scoren niet alleen beter op de onderwerpen in de toets die betrekking hebben op de assessmenttaken maar ook op de onderwerpen die niet gerelateerd zijn aan één van de assessment-taken. De resultaten van de vragenlijsten en interviews maken duidelijk dat zowel de studenten als de docenten voordelen zien in het werken met assessment-taken. Studenten rapporteerden meer, kritischer en systematischer te studeren als gevolg van de assessment-taken, daarbij sterk aangemoedigd door het 
te yerdienen bonuspunt. De docenten zijn enthousiast maar ook terughoudend over de halbaarheid: het geven van feedback op de assessment-taken vraagt meer (nakijk)tijd. Er werd geconcludeerd dat kleine aanpassingen in de manier waarop onderwijs en toetsing op elkaar worden afgestemd, kunnen leiden tot relatief grote veranderingen in de kwaliteit van het leren van de student.

In hoofdstuk 8 worden de resultaten van de vorige hoofdstukken samengevat en worden implicaties voor de praktijk en suggesties voor verder onderzoek gegeven. Concluderend tonen de meta-analyses en de opeenvolgende onderzoeken in dit proefschrift aan dat wat het verwerven van kennis betreft geen eenduidige conclusies kunnen worden getrokken. Er is wel een robuust positief effect van PGO op het toepassen van kennis bij studenten. Wanneer de implicaties wan de toetsing en de getoetste niveaus in rekening worden gebracht bij het onderzoeken van de effecten van PGO, wordt duidelijk dat PGO de weg naar succesvol probleemoplossen voor studenten bespoedigd, maar dat meer aandacht voor echte toepassing van kennis in nieuwe situaties zowel tijdens het onderwijs als bij de toetsing nodig is om beter aan de verwachtingen te kunnen voldoen. De kracht van PGO schuilt grotendeels in de factoren "conceptuele conflicten en dilemma's' en 'ideeën met anderen delen'. Percepties van deze en andere constructivistische principes lijken gestimuleerd te worden bij studenten door een confrontatie met een grotere variëteit aan leeromgevingen. $\mathrm{Er}$ is geen verband gevonden tussen de studieaanpak van studenten in PGO en de verschillende componenten van probleemoplossen zoals gemeten met een meerkeuzetoets; studenten met een diepgaande studieaanpak scoren niet beter en dit op geen enke] onderdeel van de meerkeuzetoets. Het maken van assessment-taken tijdens het onderwijs had wel een positieve invloed op de algemene prestatie van de studenten op de afsluitende meerkeuzetoets. Zowel de studenten als de docenten zien het voordeel van het werken met assessment-taken om het effect van PGO te vergroten. 


\section{Appendices}

\section{Appendix A: Studies measuring knowledge}

\begin{tabular}{|c|c|c|c|c|c|c|c|c|c|}
\hline \multirow[t]{2}{*}{ Shudy } & \multirow{2}{*}{$\begin{array}{l}\text { Pbs- } \\
\text { instatute }\end{array}$} & \multirow{2}{*}{$\begin{array}{l}\text { Leve } \\
1\end{array}$} & \multirow[t]{2}{*}{ Scope } & \multirow[t]{2}{*}{ Designii } & \multirow{2}{*}{$\begin{array}{l}\text { Subj. } \\
\text { pblicony }\end{array}$} & \multirow[t]{2}{*}{ Ret $_{*}$} & \multirow[t]{2}{*}{ Operats. DV } & \multicolumn{2}{|c|}{ Resull } \\
\hline & & & & & & & & $\mathbb{E S}$ & p-watur \\
\hline $\begin{array}{l}\text { Eisenstaedt, } \\
1990\end{array}$ & Temole: & $\begin{array}{l}2 \\
4\end{array}$ & 5 & $\mathbb{R}$ & $32 / 58$ & $\begin{array}{l}N \\
Y\end{array}$ & $\begin{array}{l}\mathrm{MCQ}(\text { arad ex. } \\
\mathrm{MCQ}\end{array}$ & $\begin{array}{r}8.291 \\
+2.211\end{array}$ & $\begin{array}{l}p<001 \\
x<001\end{array}$ \\
\hline Menuin 199 & $\begin{array}{l}\text { New } \\
\text { Mexico }\end{array}$ & 2 & $C$ & $\mathrm{~K}$ & 1671508 & $\bar{N}$ & $\mathrm{NMBE} 1$ & -7.908 & pret.0001 \\
\hline Butch, 1990 & $\begin{array}{l}\text { New } \\
\text { Mexico } \\
\end{array}$ & $A$ & $\mathrm{C}$ & $\mathrm{K}$ & $3 7 \longdiv { 4 1 }$ & $N$ & NBME I & -10.9199 & $p<<0001$ \\
\hline $\begin{array}{l}\text { Verwijinen, } \\
1990\end{array}$ & Maststricht & A & $\mathrm{C}$ & $\overline{1}$ & $\begin{array}{l}26611254 \\
471 / 894 \\
565 / 1234 \\
565 / 167\end{array}$ & $\mathrm{~N}$ & $\begin{array}{l}\text { MCQ }(64) \\
\text { questoms } \\
\mathrm{MCQ}(70) \\
\mathrm{MCQ}(64) \\
\mathrm{MCQ}(264)\end{array}$ & $i$ & \\
\hline Sxtanders, 1900 & NewCuatle & $\begin{array}{l}\text { L } \\
69\end{array}$ & $\bar{C}$ & 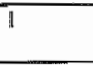 & $\begin{array}{l}45 / 243 \\
47 / 242 \\
\end{array}$ & $\mathrm{~N}$ & $\begin{array}{l}\mathrm{MCO}(40, \text { contr }) \\
\mathrm{MCQ}(40, \text { Pb) }\end{array}$ & $\begin{array}{r}0.716 \\
-10.476\end{array}$ & $\begin{array}{l}p<001 \\
p<01\end{array}$ \\
\hline Morgan: 1977 & Rochester & 2 & $\begin{array}{l}\text { C in } \\
\text { 2nd } \\
\text { year }\end{array}$ & $\mathrm{R}, \mathrm{K}$ & $\begin{array}{l}15 / 82 \\
15 / 76 \\
16 / 81 \\
\end{array}$ & $\mathrm{~N}$ & $\begin{array}{l}\text { Subjests } 2 \text { nd ywa } \\
\text { NBME I } \\
\text { NBME I } \\
\text { NBME I }\end{array}$ & $\begin{array}{l}4 \\
+ \\
+ \\
\end{array}$ & \\
\hline Farquinar, 1986 & Michigata & 2 & $\mathrm{C}$ & $\bar{k}$ & $40 / 40$ & $N$ & 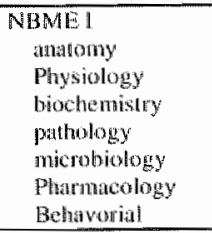 & $\begin{array}{l}+ \\
+ \\
+ \\
+ \\
+ \\
+\end{array}$ & 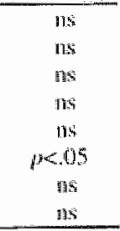 \\
\hline Katuffruan, 1989 & $\begin{array}{l}\text { New } \\
\text { Mitexico }\end{array}$ & 2 & $C$ & $\mathrm{~K}$ & & $N$ & $\begin{array}{l}\text { NBME I } \\
\text { Chass onf } \\
1083 \\
1084 \\
1085 \\
1980 \\
1087 \\
1988 \\
1980 \\
19090 \\
\end{array}$ & $\begin{array}{l}- \\
- \\
. \\
- \\
- \\
. \\
- \\
- \\
\end{array}$ & 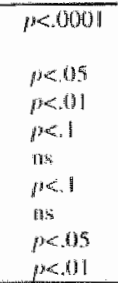 \\
\hline $\begin{array}{l}\text { Santow-Gornez } \\
1990\end{array}$ & $\begin{array}{l}\text { Miew } \\
\text { Mexico }\end{array}$ & AI & $\mathrm{C}$ & $\overline{\mathrm{K}}$ & $\begin{array}{l}41 / 78 \\
39 / 71 \\
43 / 70 \\
\end{array}$ & $Y$ & 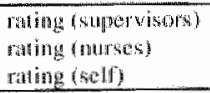 & $\begin{array}{r}+10,257 \\
-19.446 \\
+0.525 \\
\end{array}$ & $\begin{array}{l}p=.21 \\
p=04 \\
p=05\end{array}$ \\
\hline $\begin{array}{l}\text { Manticnsola } \\
1985\end{array}$ & $\begin{array}{l}\text { Katolingki } \\
\text { fostivluet }\end{array}$ & $\begin{array}{l}\text { Al: } \\
2\end{array}$ & 5 & $H$ & $1651 / 418$ & $\begin{array}{l}\mathrm{Y} \\
\mathbb{N}\end{array}$ & $\begin{array}{l}\text { Shor answer } \\
\text { Shart abswer }\end{array}$ & -9.15 & $p<0,040$ \\
\hline Sehwarte, 1997 & Kendulactey & 3 & $C$ & $\mathrm{~K}$ & & $N$ & $\begin{array}{l}\text { MCQ iest } 1 \\
\text { MCQ test } 2 \\
\text { MCQ lest } 3 \\
\text { MCQ limal exilfs }\end{array}$ & $\begin{array}{l}5 \\
1 \\
1 \\
1\end{array}$ & \\
\hline $\begin{array}{l}\text { Goodman. } \\
1991\end{array}$ & Rush & 2 & $\mathrm{C}$ & $\mathrm{K}$ & $\begin{array}{l}72 / 501 \\
12 / 12 \\
15 / 13\end{array}$ & $N$ & 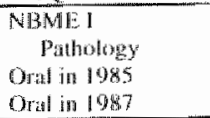 & $\begin{array}{l}0,(1444 \\
-0.242 \\
0.69 \\
+10.667\end{array}$ & $\begin{array}{l}p=0,40 \\
p=0.911 \\
p=0,07 \\
p=0.96\end{array}$ \\
\hline
\end{tabular}




\begin{tabular}{|c|c|c|c|c|c|c|c|c|c|}
\hline 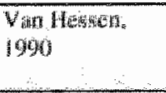 & Wastotroht & 6 & $C$ & N & 1179 & Y & $\begin{array}{l}\text { MCQ } 247 \\
\text { guestions: progrest } \\
\text { dest }\end{array}$ & $\cdots$ & $p<05$ \\
\hline findley, $10 \mathrm{gh}$ & Merces & 2 & $C$ & W & $\begin{array}{l}2 \mathrm{y} \\
24 \\
2 \mathrm{H} \\
24 \\
2 \mathrm{H} /\end{array}$ & $\mathrm{M}$ & $\begin{array}{l}\text { NBME I } \\
\text { Pahology }\end{array}$ & $\begin{array}{l}3 \\
+ \\
+ \\
- \\
4\end{array}$ & \\
\hline Anthepol 10999 & Köln & 3 & 5 & 㥒, C & $55 / 57$ & $\mathrm{NW}$ & $\begin{array}{l}\text { MCO } \\
\text {-Short answer } \\
\text { ghestons } \\
\text { - Tolvil }\end{array}$ & $\begin{array}{l}-0.125 \\
0.424 \\
0.167 \\
\end{array}$ & $\begin{array}{l}p=.4 \\
p=.07 \\
p=.43\end{array}$ \\
\hline $\begin{array}{l}\text { Ventiouren; } \\
\text { logis }\end{array}$ & Mistsarticht & $\begin{array}{l}1 \\
2 \\
3 \\
4 \\
5 \\
6\end{array}$ & $c$ & 1 & $\begin{array}{l}1901124 \\
146 / 104 \\
135 / 87 \\
188 / 151 \\
1444140 \\
1351122\end{array}$ & N & $\begin{array}{l}\text { Progress teste } \\
\text { (242 items) }\end{array}$ & $\begin{array}{l}0.203 \\
0.211 \\
0.288 \\
0.1193 \\
0.037 \\
0.385\end{array}$ & 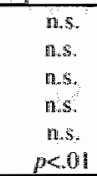 \\
\hline Letwis, 1987 & $\begin{array}{l}\text { New } \\
\text { Brtunswisk }\end{array}$ & 2 & 5 & $\mathrm{~K}, \mathrm{C}$ & $22 / 20$ & $\mathrm{~N}$ & MCQ (100 items) & 0,024 & $p=479$ \\
\hline Angepolit 1907 & Kon & 3 & 5 & $\mathrm{~K}, \mathrm{M}$ & 110110 & N & Short answer: & $\begin{array}{l}0.603 \\
p=0013\end{array}$ & \\
\hline Tamiss. 1988 & $\begin{array}{l}\text { Institute } \\
\text { for hägliger } \\
\text { vacationut } \\
\text { equcation }\end{array}$ & 1 & 5 & $\vec{R}$ & $77 / 45$ & $\mathrm{~N}$ & $\begin{array}{l}\text { MCO (60 item } \\
\text { Free-secall tesil }\end{array}$ & $\begin{array}{l}-2.583 \\
2.171\end{array}$ & $\begin{array}{l}p=001: 3 \\
p<005\end{array}$ \\
\hline Finch 1999 & $\begin{array}{l}\text { Michener } \\
\text { Institute }\end{array}$ & 3 & $C$ & $\mathrm{H}$ & $21 / 26$ & N & MCQ (60 iternas) & & $p>05$ \\
\hline $\begin{array}{l}\text { Sorl \& Valn } \\
\text { Sickle, } 2000\end{array}$ & $\begin{array}{l}2 \text { colleges } \\
\text { econonitics }\end{array}$ & $?$ & 5 & $\begin{array}{l}\text { Non- } \\
\text { equival } \\
\text { ont } \\
\text { com- } \\
\text { parison } \\
\text { group } \\
\text { design }\end{array}$ & $72 / 80$ & $\bar{N}$ & $\begin{array}{l}\text { Instrument: } \\
16 \mathrm{MCQ} \\
8 \text { correctincorr } \\
1 \text { short answer } \\
\text { idem }\end{array}$ & 0.381 & $\begin{array}{l}p=0.05 \\
p=0.05\end{array}$ \\
\hline A.nton, 1998 & Alberta & 2 & $\$$ & $\mathrm{H}$ & $\begin{array}{l}\| 13 / 12 \mid \\
17 / 12 \\
\end{array}$ & $\mathrm{~N}$ & $\mathrm{MCQ}$ & $\begin{array}{r}-0.440 \\
-0.769 \\
\end{array}$ & $p<05$ \\
\hline Block, 1994 & $\begin{array}{l}\text { Harvard } \\
\text { Medical } \\
\text { Sohool }\end{array}$ & 2 & $\mathrm{C}$ & $\mathrm{R}$ & $62 / 63$ & $\bar{M}$ & $\begin{array}{l}\text { NBME part I } \\
\text { "behuvorial } \\
\text { science subtest }\end{array}$ & $\begin{array}{l}= \\
+\end{array}$ & $\begin{array}{l}\text { n.s. } \\
\text { sign. }\end{array}$ \\
\hline Richardis, 1996 & $\begin{array}{l}\text { Watko } \\
\text { Fores }\end{array}$ & 3 & $\mathrm{C}$ & $\mathbf{K}$ & $82 / 364$ & $y^{\prime}$ & 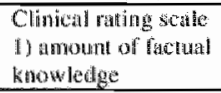 & 0.5 & $p=000$ \\
\hline Doncet, 1998 & $\begin{array}{l}\text { Drthoulsis } \\
\text { University. } \\
\text { Hullifux }\end{array}$ & $\begin{array}{l}\text { CNA } \\
\text { li: }\end{array}$ & 5 & $\mathrm{~K}, \mathrm{C}$ & $34 / 29$ & $\mathrm{~N}$ & MCO (4le itemas) & 0.434 & $p=05$ \\
\hline $\begin{array}{l}\text { Disthehoris. } \\
\text { logs }\end{array}$ & $\begin{array}{l}\text { Souther: } \\
\text { lllindis: }\end{array}$ & 2 & C & $\mathrm{k}, \mathrm{C}$ & $47 / 154$ & $M$ & NBME part 1 & 0.18 & $p=6528$ \\
\hline Inthos, : 1984 & Marusinghi & $\mathrm{A}$ & $c$ & I & & $N$ & $\begin{array}{l}\text { Antanny (progrest } \\
\text { test) }\end{array}$ & $\begin{array}{l}\text { From you } \\
\text { yent } 5 \text { en }\end{array}$ & $\begin{array}{l}1-4:= \\
+\end{array}$ \\
\hline Jones: 1984 & $\begin{array}{l}\text { Michigall } \\
\text { State }\end{array}$ & 2 & $\mathrm{C}$ & $\mathrm{k}$ & $63 / 138$ & $M$ & $\begin{array}{l}\text { PBME pary I } \\
\text { Overitl } \\
\text { anatomy } \\
\text { physiology } \\
\text { biochemistry } \\
\text { pathology } \\
\text { microbiology } \\
\text { phimmacology } \\
\text { behtin woral }\end{array}$ & $\begin{array}{l}+ \\
- \\
+ \\
+ \\
- \\
+ \\
+\end{array}$ & 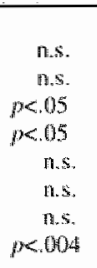 \\
\hline & & & & & 170031 & $\mathrm{~N}$ & $\begin{array}{l}\text { Subject matter parl } \\
\text { "clerckships exams" } \\
\text { (pretest) } \\
\text { OB/Gyn }\end{array}$ & . & n.s. \\
\hline
\end{tabular}




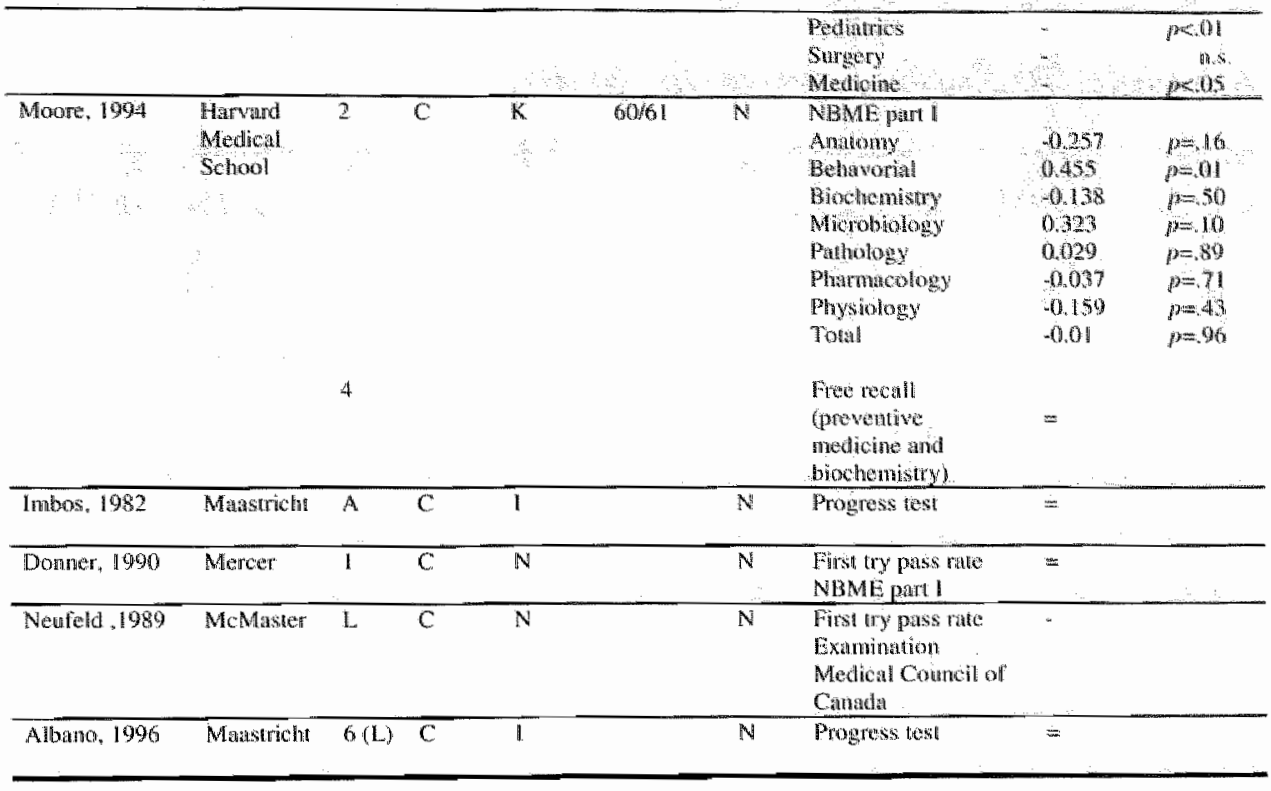




\section{Appendix B. Studies measuring skills}

\begin{tabular}{|c|c|c|c|c|c|c|c|c|c|}
\hline Stuty & Pla & Leve & Serape & Destugn & Sulbj- & Ret: & Operat. AV & Resa & \\
\hline & & & & & & & & $\mathbf{E S}$ & p-yalue \\
\hline Mermin. 1993 & New & 3 & 6 & $K$ & $144 / 447$ & 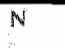 & NBME II & 40.046 & $p=.29$ \\
\hline Schind de $\| 900$ & Mialstrictio & $\mathrm{A}$ & $\mathrm{Co}$ & 1 & $t 01=612$ & N & 30 cases & +0.310 & $\gamma$ \\
\hline Bats, 1996 & $\begin{array}{l}\text { Now } \\
\text { Methor }\end{array}$ & 3 & $\mathrm{C}$ & $1, M$ & $367^{4} 36$ & $\mathbb{N}$ & NBME II & 1 & $i$ \\
\hline Patel, $199 \mathrm{ll}$ & Mckater & $\begin{array}{l}1 \\
3 \\
1\end{array}$ & $\mathrm{C}$ & 1 & $\begin{array}{l}12 / 12 \\
12 / 12 \\
12 / 12\end{array}$ & 3 & 1 cathe & $\begin{array}{l}- \\
-\end{array}$ & 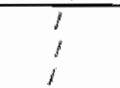 \\
\hline Hine:10, 1999 & l & 1 & $\mathrm{CS}$ & K & 39137 & $N$ & $\begin{array}{l}6 \text { cases } \\
\text {-accunacy } \\
\text { - lengh rensoning } \\
\text {-H findings } \\
\text { use scientific } \\
\text { concepts }\end{array}$ & $\begin{array}{r}+0.768 \\
+0.521 \\
+0.762 \\
+0.547 \\
+1.241\end{array}$ & $\begin{array}{l}p<5 \\
p<005 \\
p<05 \\
p<001\end{array}$ \\
\hline Saunderth, 1990 & NewCistle & L. & $\mathrm{C}$ & 1 & $\begin{array}{l}45 / 240 \\
44 / 243\end{array}$ & $\mathbb{N}$ & $\begin{array}{l}M E Q 1 \\
M E Q 2\end{array}$ & $\begin{array}{l}-0.066 \\
+1017 \\
+0.4755\end{array}$ & $p<001$ \\
\hline Hunclo. 1997 & 1 & 1,2 & $\mathrm{~S}$ & $K$ & $20 / 20$ & $\mathbb{N}$ & $\begin{array}{l}\text { 1. cake } \\
\text {-length reglsoning } \\
\text { - ase scientific } \\
\text { concepts }\end{array}$ & $\begin{array}{l}+0.7305 \\
+0.883 \\
+0.578\end{array}$ & $\begin{array}{l}p<01 \\
p<1\end{array}$ \\
\hline Barrows 1976 & McGill & 2 & $\$$ & $K$ & $10 / 10$ & $\mathbb{N}$ & $\begin{array}{l}\text { Standardized Patient } \\
\text { Simulathon }\end{array}$ & +1.409 & $p<005$ \\
\hline Kaltulman. 1989 & $\begin{array}{l}\text { New } \\
\text { Mexich }\end{array}$ & 3 & $\mathrm{C}$ & $\mathrm{K}$ & $\begin{array}{l}\text { Total: } \\
120438\end{array}$ & $\mathbf{N}$ & $\begin{array}{c}\text { NBME II } \\
\text { id } 1983 \\
1984 \\
1985 \\
1986 \\
1987 \\
1988 \\
\text { clinical rotations } \\
\text { in } 1983 \\
1984 \\
1985 \\
1986 \\
1987 \\
1988 \\
1989 \\
\text { clinical sulbscores } \\
\text { of collin. rot. } \\
\text { lin } 1983 \\
1984 \\
1985 \\
1986 \\
1087 \\
1988 \\
1989 \\
\end{array}$ & $\begin{array}{l}40.22 .4 \\
- \\
4 \\
4 \\
4 \\
4 \\
1 \\
- \\
- \\
4 \\
+ \\
4 \\
4 \\
4 \\
4 \\
+ \\
4 \\
4 \\
4\end{array}$ & 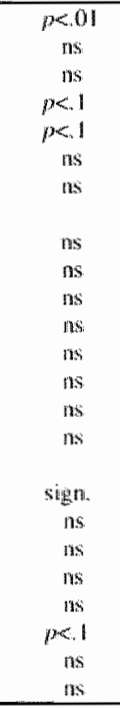 \\
\hline Selhwate 1907 & Kentwelk & 3 & $\mathrm{C}$ & 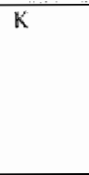 & & 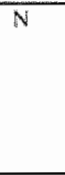 & $\begin{array}{l}\text { Standardized Patien } \\
\text { shmulistion } \\
\text { MEQ } \\
\text { NBME II } \\
\text { surgery } \\
\text { subsection }\end{array}$ & $\begin{array}{l}+ \\
4 \\
7 \\
4\end{array}$ & $\begin{array}{l}/ \\
1 \\
\text { nes } \\
\operatorname{sign} .\end{array}$ \\
\hline $\begin{array}{l}\text { Gowdinats. } \\
1991\end{array}$ & Rush & $\begin{array}{l}3 \\
3\end{array}$ & $\mathrm{C}$ & $K$ & $\begin{array}{l}12 / 12 \\
15 / 13\end{array}$ & $N$ & $\begin{array}{l}\text { NBME II } \\
\text { Orul (problem } \\
\text { solving } \\
\text { in } 1985 \\
\text { in } 1987\end{array}$ & $\begin{array}{l}-0.071 \\
+0.769\end{array}$ & $\begin{array}{l}p=.89 \\
p=04\end{array}$ \\
\hline
\end{tabular}




\begin{tabular}{|c|c|c|c|c|c|c|c|c|c|}
\hline $\begin{array}{l}\text { Sowuwith, } \\
19 \text { gr }\end{array}$ & Masistrich: & $\begin{array}{l}1 \\
2 \\
3 \\
4 \\
5 \\
4 \\
67 \\
6\end{array}$ & a & 1 & $\begin{array}{l}30 / 32 \\
30 / 30 \\
30 / 30 \\
29 / 30 \\
27 / 30 \\
32 / 25\end{array}$ & $\mathrm{~N}$ & 60 dharl anes & $\begin{array}{l}+0.06 \\
+0.25 \\
-6.114 \\
40.238 \\
+0.72 \\
+1.254\end{array}$ & $\begin{array}{l}p<01 \\
p<0,0101\end{array}$ \\
\hline $\begin{array}{l}\text { Wairfenson } \\
1985\end{array}$ & $\begin{array}{l}\text { Karolínsolia } \\
\text { Innstitulet } \\
\end{array}$ & 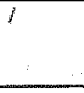 & 5 & $\mathrm{H}$ & $818 / 1651$ & N & 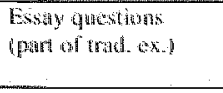 & $\begin{array}{l}+0.15 \\
p<00003\end{array}$ & \\
\hline Lewis, 1987 & $\begin{array}{l}\text { New } \\
\text { Bronswick }\end{array}$ & 2 & $s$ & $k^{*}$ & $22 / 20$ & $M$ & $\begin{array}{l}\text { Clintoal } \\
\text { pertormance }\end{array}$ & 40.234 & $p=0.2256$ \\
\hline Fincth, 1999 & $\begin{array}{l}\text { Mothener } \\
\text { Inst stute }\end{array}$ & $3(\mathrm{~L})$ & $\mathrm{C}$ & $H$ & 2126 & $\mathrm{~N}$ & Essay dutations & +1.944 & $p<, 0005$ \\
\hline Astrom, 1998 & Aberta & 2 & $S$ & $H$ & 1719 & $\mathrm{~N}$ & Eosay chesuions & 0.0 & 1095 \\
\hline Black. 1994 & $\begin{array}{l}\text { Hirwand } \\
\text { Medical } \\
\text { Sohool }\end{array}$ & 3 & $C$ & $\mathrm{~K}, \mathrm{R}$ & $62 / 63$ & $N$ & $\begin{array}{l}\text { NBME part II } \\
\text { Public fledilth }\end{array}$ & i & $\begin{array}{l}\text { nes. } \\
\text { signg. }\end{array}$ \\
\hline $\begin{array}{l}\text { Bloshuizen. } \\
1993\end{array}$ & Matsistricht & $3+4$ & $C$ & 1 & $4 / 4$ & $\mathbf{N}$ & I conse & +2.268 & $j=024$ \\
\hline Rishards, 1996 & $\begin{array}{l}\text { Wake } \\
\text { Forest }\end{array}$ & 3 & $\mathrm{C}$ & $\mathrm{K}, \mathrm{C}$ & $88 / 364$ & $Y$ & 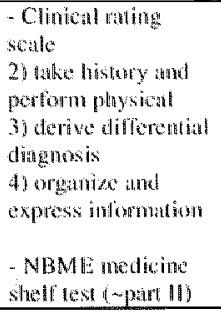 & $\begin{array}{r}+0.426 \\
+0.425 \\
+0.462 \\
+0.390 \\
+0.073\end{array}$ & $\begin{array}{l}f=002 \\
f=0005 \\
p=0(0)=4 \\
j=80\end{array}$ \\
\hline Dotucet, 1998 & $\begin{array}{l}\text { Continuing } \\
\text { Medical } \\
\text { Education }\end{array}$ & $\begin{array}{l}\mathrm{CM} \\
\mathrm{E}\end{array}$ & $S$ & K & $21 / 26$ & $Y$ & $\begin{array}{l}\text { Key Foature } \\
\text { Problem } \\
\text { cximumation } 28 \\
\text { cilses) }\end{array}$ & +1.293 & $\mu=9001$ \\
\hline $\begin{array}{l}\text { Distlehors. } \\
1998\end{array}$ & $\begin{array}{l}\text { Sounhern } \\
\text { Illinoss }\end{array}$ & 3 & $\begin{array}{l}\text { C } \\
(\text { hiss } 2 \\
\text { yeatas) }\end{array}$ & $\mathrm{K}, \mathrm{C}$ & $47 / 154$ & $Y$ & 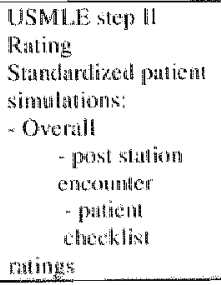 & $\begin{array}{l}+0.3 \\
+0.33 \\
+0.14\end{array}$ & $\begin{array}{l}p=0.1596 \\
p=0.19742 \\
p=1609\end{array}$ \\
\hline Jonits. 1984 & $\begin{array}{l}\text { Michigan } \\
\text { State }\end{array}$ & 4 & $\begin{array}{l}\mathrm{C} \\
\text { (finst } 2 \\
\text { years) }\end{array}$ & K & $60 / 142$ & $Y$ & 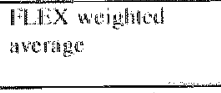 & + & 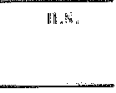 \\
\hline Moorn. 19994 & $\begin{array}{l}\text { Horvand } \\
\text { Medical } \\
\text { Senool }\end{array}$ & 2 & $C$ & $\mathbb{K K}, \mathbb{R}$ & $60 / 61$ & $N$ & 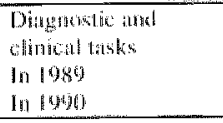 & No difit & toinst \\
\hline Neuteld, 1989 & McMinsier & $L$ & $\mathrm{C}$ & $N$ & & $\mathbb{N}$ & 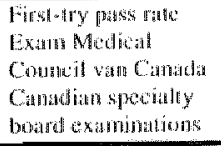 & * & \\
\hline
\end{tabular}




\section{Appendix C: Legend for the tables of Appendix A and B.}

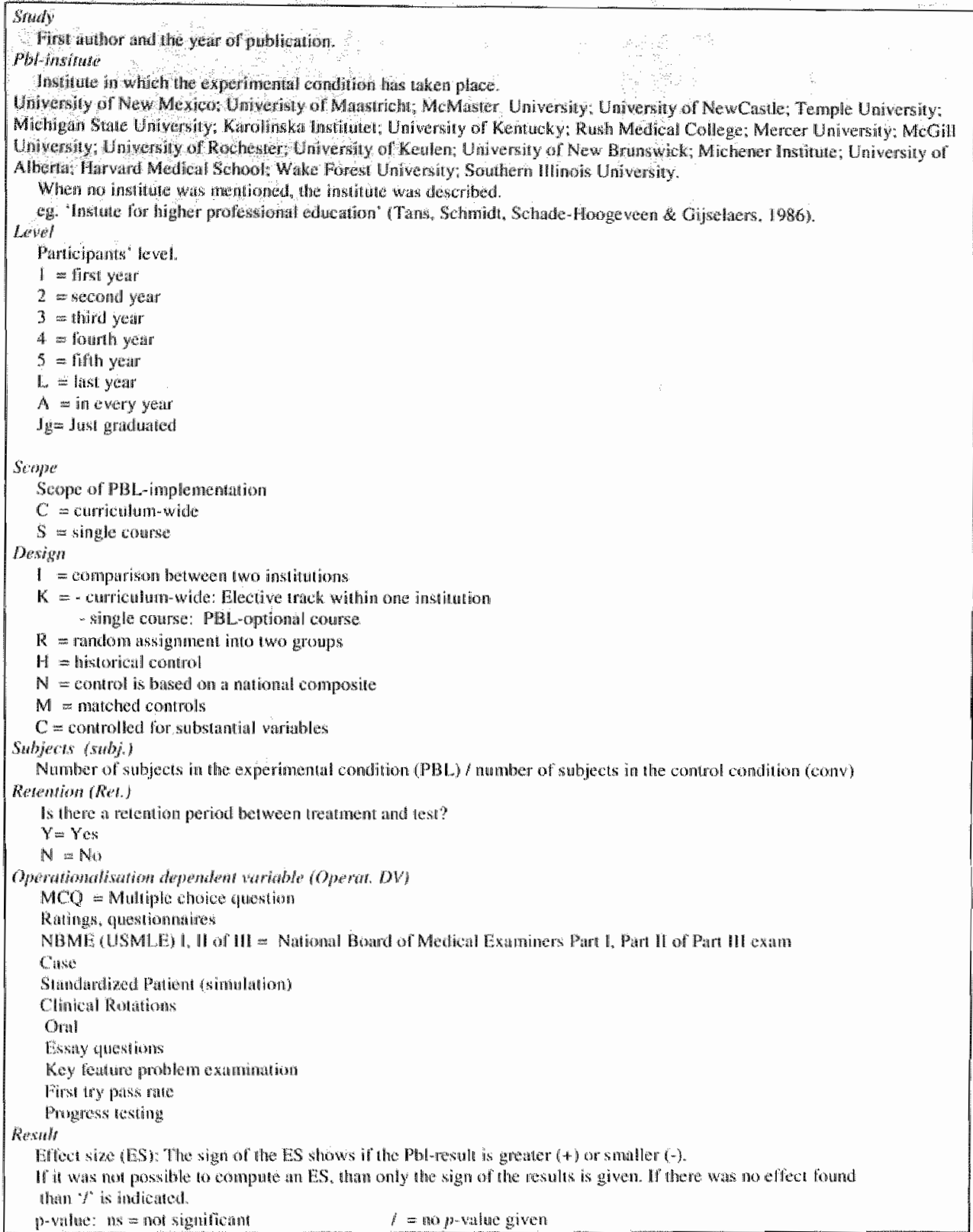




\section{Appendix D. Studies measuring the knowledge structure}

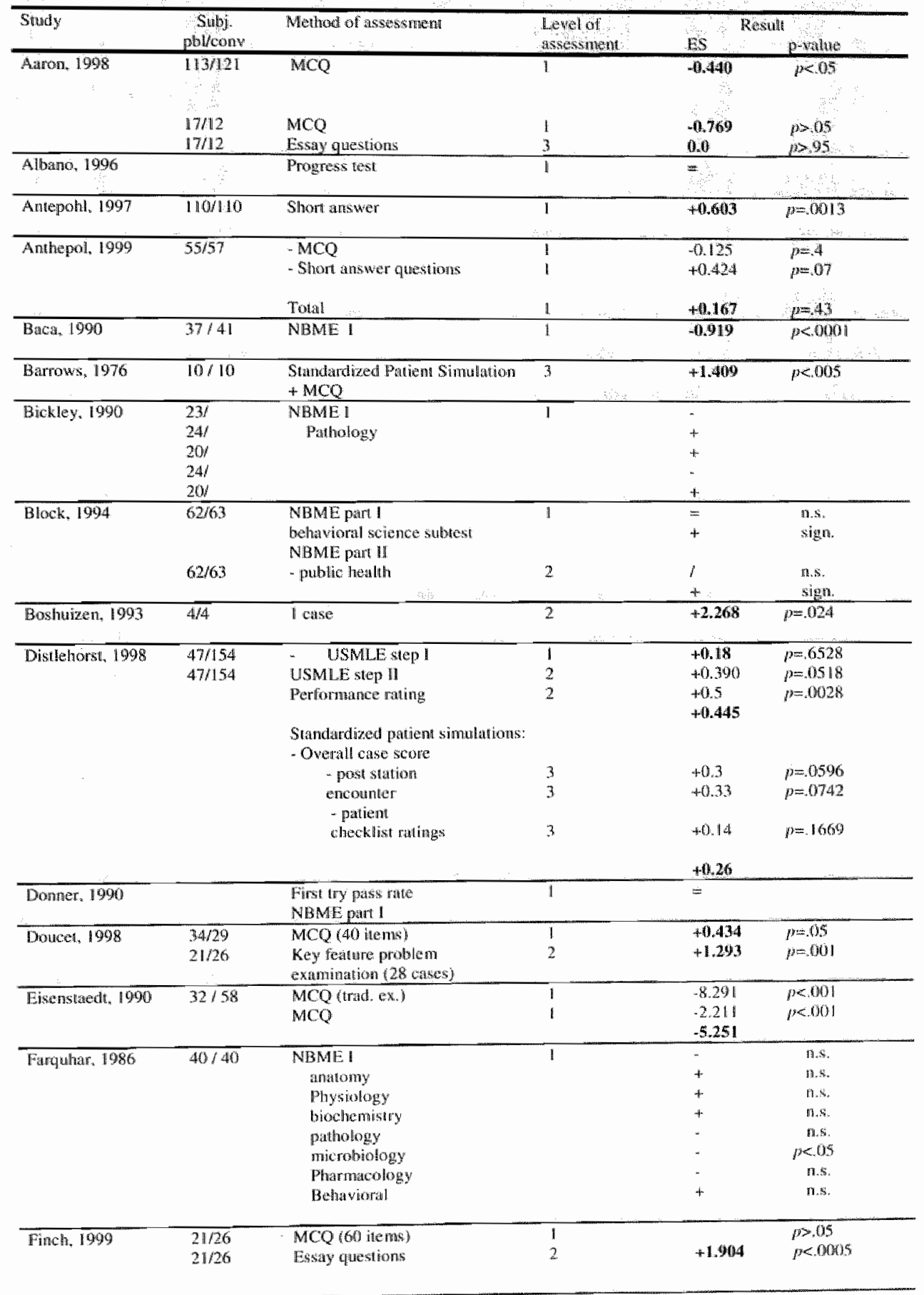




\begin{tabular}{|c|c|c|c|c|c|}
\hline \multirow[t]{2}{*}{ Goodman, 1991} & 72504 & NGHLL & $1:=$ & (10.044 & $j x=0,40$ \\
\hline & & Pratfology & 1 & -9.242 & $p=0.01$ \\
\hline \multirow{6}{*}{ : } & $12 / 12$ & Orallin 198 & i & 0.0 & $p=0.97$ \\
\hline & 15,13 & Oral In $198 \%$ & 1 & -0.667 & $p=0,06$ \\
\hline & 36297 & NBNAE part II & 2 & -0.133 & $p=73$ \\
\hline & & Orall (problem sulung) & 2 & & \\
\hline & $12 / 12$ & In 1985 & 2 & -0.071 & $p=89$ \\
\hline & $15 / 13$ & $\ln ] 1887$ & 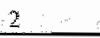 & +0.769 & $\mathrm{p}=\mathrm{O}=\mathrm{OH}$ \\
\hline \multirow[t]{3}{*}{ Whelo, 1997} & $20 / 20$ & latie & 2 & +0.7305 & \\
\hline & $\vdots$ & - Jesugth reasoninge & 8 & +1988 & $p<0.01$ \\
\hline & & - Gse serentilic concepts. & 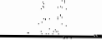 & $+0.57 \mathrm{~B}$ & $p<1$ \\
\hline \multirow[t]{5}{*}{ Howe $10_{i} 1998$} & 39137 & 6 easises & 2 & +0.768 & \\
\hline & & -ncotracy. & & +0.521 & $p<05$ \\
\hline & & - Jength ressosing & & +0.762 & $p<005$ \\
\hline & & At findings & & 40.547 & $p<05$ \\
\hline & & - use scientific concepts & & +1.241 & $p<001$ \\
\hline Imbers, 1982 & & Progress test & 1 & $=$ & \\
\hline \multicolumn{2}{|l|}{ InTibo: 1984 } & Antilomy (progress lest) & 1 & \multicolumn{2}{|c|}{$\begin{array}{l}\text { frorer year } 1 \times 4:= \\
\text { year } 5 \text { and } 6:+\end{array}$} \\
\hline \multirow[t]{15}{*}{ Jones. 1984} & $63 / 138$ & NBME pairt I & 1 & & \\
\hline & & Onerall & & +* & ก... \\
\hline & & anstomy & & - & enc.s. \\
\hline & & physioglogy & & + & $p<05$ \\
\hline & & biochetuistry & & + & $p \times 0.05$ \\
\hline & & pxithology & & - & n.s. \\
\hline & & microbiology & & - & n..5. \\
\hline & & pharmacology & & $*^{n}$ & n.s. \\
\hline & & bethatioris & & + & $p<004$ \\
\hline & $170 / 33$ & $\begin{array}{l}\text { Subject matter pall "derckships } \\
\text { exams' (pretest) }\end{array}$ & 1 & & \\
\hline & & OB/Oyn & & n & m.S. \\
\hline & & Pediaticics & & - & $p<01$ \\
\hline & & Surgery & & - & If. 5. \\
\hline & & Medicine & & - & $p<005$ \\
\hline & 60142 & PLEX weighted average & 1 & + & n.s. \\
\hline \multirow[t]{28}{*}{ Kaufman, 1989} & & NBME I & 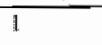 & - & $p<0,0001$ \\
\hline & & Class of & & & \\
\hline & & 1083 & & - & $p<05$ \\
\hline & & 1984 & & . & $p<01$ \\
\hline & & 1.985 & & - & perd \\
\hline & & 1986 & & - & 跳. \\
\hline & & 1987 & & 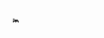 & $p \times 1$ \\
\hline & & 1988 & & - & n.s. \\
\hline & & 1989 & & - & $p<05$ \\
\hline & & 1900 & & - & $p \times a l$ \\
\hline & & NBME: II & 2 & * & $p<n$ \\
\hline & & in 198 & & - & n.: $s_{4}$ \\
\hline & & 1984 & & - & nt.s. \\
\hline & & 1085 & & + & $p<1$ \\
\hline & & 1986 & & 4 & pes 1 \\
\hline & & 1987 & & + & mis.s. \\
\hline & & 1988 & & + & H... \\
\hline & & ovetst : 3th yetr clerkship & 3 & 1 & 政, s. \\
\hline & & in 1983 & & . & n.s. \\
\hline & & 1984 & & - & mas. \\
\hline & & 1985 & & - & $n, s$ \\
\hline & & 1386 & & + & n.s. \\
\hline & & 1987 & & + & M.s. \\
\hline & & 1988 & & 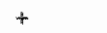 & n.s. \\
\hline & & 1989 & & 4 & $\mathrm{a}, \mathrm{s}$ \\
\hline & & clinbcal subseones & & & \\
\hline & & of clin. tot. & & + & sijgm. \\
\hline & & ini 1983 & & - & H. 3 \\
\hline
\end{tabular}




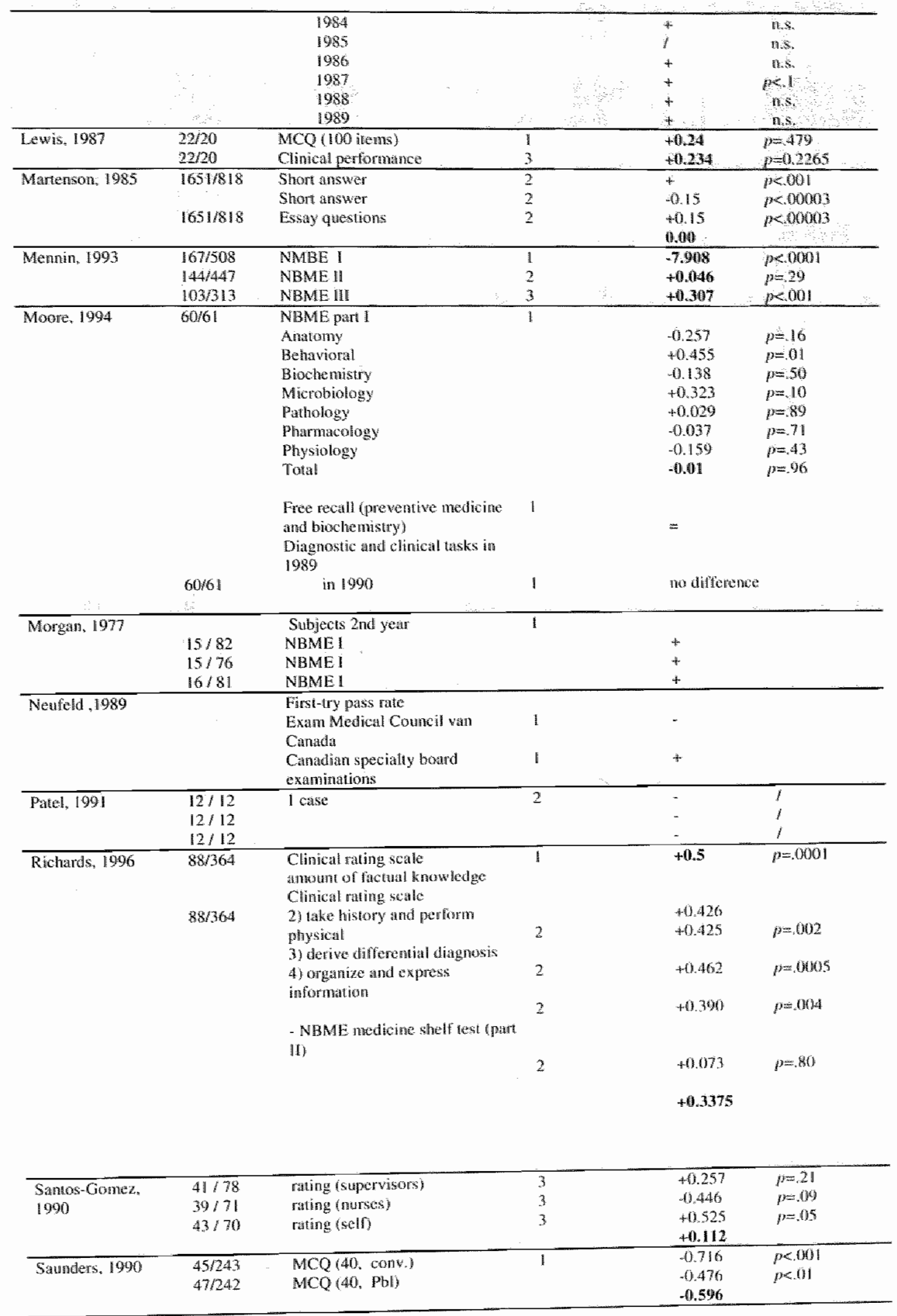




\begin{tabular}{|c|c|c|c|c|c|}
\hline & $\begin{array}{l}45 / 240 \\
44 / 443 \\
\end{array}$ & $\begin{array}{l}\text { MEOI } \\
\text { MeO2 }\end{array}$ & 3 & $\begin{array}{l}-0.066 \\
+1.017 \\
+0.4755\end{array}$ & prosis \\
\hline Sebmide 1996 & $1091=612$ & 34 casses & 2 & +0.310 & 1 \\
\hline $\begin{array}{c}\text { Schumithti, } 1999 \\
0 \\
\end{array}$ & $\begin{array}{l}30 / 32 \\
30 / 30 \\
30 / 30 \\
20 / 30 \\
27 / 30 \\
32 / 25\end{array}$ & 60 short ceats & $\begin{array}{l}3 \\
\cdots \\
\vdots \\
\vdots \\
\end{array}$ & $\begin{array}{l}+0.06 \\
+0.25 \\
-0.114 \\
+0.238 \\
+0.732 \\
+1.25 \\
\end{array}$ & $\begin{array}{l}p<01 \\
p<001\end{array}$ \\
\hline Schwartion 1997 & & $\begin{array}{l}\text { MCQ Lest I } \\
\text { MCQ tert } 2 \\
\text { MCQ Lest } 3 \\
\text { MCQ find enam }\end{array}$ & 1 & $\begin{array}{l}i \\
i \\
i\end{array}$ & \\
\hline & & 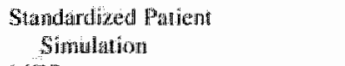 & 3 & + & 1 \\
\hline & & MEQ : & 3 & + & 1 \\
\hline & & $\begin{array}{l}\text { WBME II } \\
\text { surgery subsect hon }\end{array}$ & 2 & $\begin{array}{l}1 \\
+ \\
\end{array}$ & $\begin{array}{l}\text { n.s. } \\
\text { siger. }\end{array}$ \\
\hline $\operatorname{son}, 2000$ & $72 / 69$ & 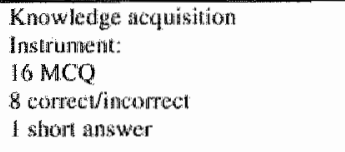 & 1 & +9.381 & $y=0,05$ \\
\hline & 72,80 & 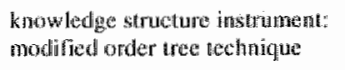 & 2. & +0.384 & $y=05$ \\
\hline Tans; 1986 & $-7 / 4 / 45$ & MCQ (60 items) & I & .2 .583 & $p=0 \mathrm{con}$ \\
\hline & 615 & Firee-fectall test & 2 & +2.171 & $p<005$ \\
\hline Van Hessen. 1990 & $? / 179$ & $\begin{array}{l}\text { MCQ (247 guestions; progress } \\
\text { lesst) }\end{array}$ & 1 & - & $p<05$ \\
\hline Varlinewen, 1998 & $\begin{array}{l}190 / 124 \\
146 / 104 \\
135 / 87 \\
18 / 8 / 151 \\
14 / 1 / 140 \\
135 / 122 \\
\end{array}$ & $\begin{array}{l}\text { Progess tests } \\
\text { (242 items) }\end{array}$ & 1 & $\begin{array}{l}-0.203 \\
+0.211 \\
+0.288 \\
+0.193 \\
-0.037 \\
-0.385 \\
\end{array}$ & $\begin{array}{l}n . s . \\
n . s . \\
n . s . \\
n . s . \\
n . s . \\
p<01 \\
\end{array}$ \\
\hline Verwijnen, 1990 & $\begin{array}{l}266 / 1253 \\
471 / 894 \\
565 / 1234 \\
565 / 167 \\
\end{array}$ & $\begin{array}{l}\text { MCQ (64 questions) } \\
\text { MCQ }(70) \\
\text { MCQ }(64) \\
\text { MCQ }(264)\end{array}$ & 1 & $\begin{array}{l}- \\
i \\
1\end{array}$ & \\
\hline
\end{tabular}




\section{Curriculum Vitae}

David Gijbels was born on the 1st of April 1977, in Turnllout, Belgium. After completing his pre-university secondary education at the 'Sint-Pietersinstituut Turnhout' in 1995, he started his graduation in Educational Sciences at the Catholic University of Leuven. After his graduation in 2000, he started as assistant professor at the department of Educational Innovation and Information Technology (EDIT) at the faculty of law at the University of Maastricht, The Netherlands. As from the $1^{\text {si }}$ of July 2004 he works as a researcher at the Centre of Excellence in Higher Education (ECHO) at the University of Antwerp, Belgium.

\section{Publications}

Dochy, F., Gijbels, D., Van de Watering, G. (2004, June). Assessment engineering: Aligning assessment, learning and instruction. Paper presented at the EARLi-Northumbria Assessment Conference, Bergen, Norway.

Dochy, F., Segers, M., Gijbels, D., \& Van den Bossche, P. (2002). Studentgerich onderwijs \& probleengestuurd onderwijs. Betekenis, achtergronden en effecten. [Student-centred education \& problem-based learning. Meaning, backgrounds and effects]. Utrecht: Lemma.

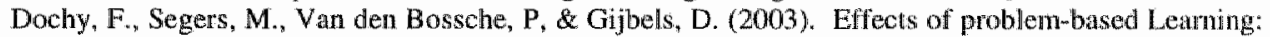
A meta-analysis. Learning and Instruction, 5 (13), 533-568.

Gijbels, D., Claes, K., Dochy, F. (2000). Op weg naar nieuwe assessmentwomen: nieuwe noden, nieuwe uitdagingen [On the move towards new modes of assessment: New needs, new challenges]. Onderzoek van Onderwijs, 29 (4), 57-59.

Gijbels, D., Van den Bossche. P., Dochy. F., \& Segers, M. (2002). Effecten van probleemgestuurd onderwigs in de lerarenopleiding [Effects of problem-based learning in teacher training]. Tijdschriff woor Hoger Onderwigs 20 (1), 60-72.

Gijbels, D., Dochy, F., Segers, M., \& Van den Bossche, P. (2000, okrober) Effecten wan studengenichn onderwijs in de levarenopleiding [Effects of student-centred education in teacher trainingl. Paper gepresenteerd op het vijfde VFO congnes, Letwen.

Gijbels, D., Dochy, F., Segers, M., \& Van den Bossche, P. (2001. Augusit). Effects of problem-bored learning in teacher education. A comparison between a PBL and a conventional educational approach. Paper presented at the 9th Biennial conference of the European Association for Research on Learning and Instruction (EARLI), Fribourg, Switserdand,

Gijbels, D., Dochy, F., Van den Bossche, P., \&e Segers, M. (2003). Effects of short term implementations of problem-based learning within teacher trainimg. Intemational tounal of Educational Policy, Research \& Preartice, 3 (4), 55-72.

Gijbels, D., Dochy. F. Van den Bossche, P., \& Segers. M. (2003, August). The relarion befween assessment practices and outcomes of studies: The case of problem-based leaming. Paper presented at the 10th Biennial conference of the European Association for Reseatch on Leatrining and Instruction (EARLI), Padova, Italy.

Gijbels, D., Dochy, F., Van den Bossche, P., \& Segers, M. (2004). Effects of problem-based learning: A meta analysis from the angle of assessment. Accepted for publication in Review of Edwcational Research. 
Gijbels, D., Vau de Watering, C., Dochy, F. 2004, november). Het Hegreven wan assessmentaken in de leenongewing: widdel om de kwaliteit val het leerproces le verbeteren [integrating atssessment lasks in the learning environment: Improving the quality of learningl. Paper gepresenteerd op het negende VFO congres, Brussel.

Gijbels, D., Van de Watering. G., \& Dochy, F. (2005). Integrating assessment tasks in a problem-based leaming enwiromment. Assessment and Evaluation in Higher Education, 30 (1), 73 m86.

Gijbels, D. Van den Bossche, P., Dochy, F. \& Segers, M. (2001. April). Effects of problem-based learning in teacher-training-programs. Paper presented at the American Educational Research Association (AERA) annuall conference, Seatte, USA.

Gijbels, D. wan der Rijt, J, Van de Watering; $G$. (2004). Het bindend studieadvies in het hoger wetenschappelijk onderwijs worden de juiste studenten geselecteerd? lCompulsory study advice at the university: Are the right students selected?]. Tijdschrift woor Hoger Orderwijs, $22(2), 62-72$.

Newmen, M., Van den Bossche, P., Gijbels, D., McKendree, J., Roberts, T., Rolfe, I., Smucny, J., \& De Virgilio, G. (2004). Responses to the pilot systematic review of problem-based learning. Medical Education, 38, 921-923.

Newman, M. De Virgilio, G. Engel, C., Gijbels, D., McKendmee, J., Roberts, A., Rolfie, II, Smucny, I., \&Van den Bossche, P. (2003). A pillot systematic review and meta-analysis on the effectiveness of problem based leaming. Newcaste: Learning and Teaching Subject Network. Centre for Medicine, Dentistry and Veterinary Medicine. Lavailable on line: hutp://whw.ltsn01 ac.uk/docs/pbl_report.pdf

Newman, M., McKendree, J., Roberts, T., Rolle, I., Smucny, J., De Virgilio, G., Van den Bossche, P., Gijbels, D., E Engels, Ch. (2002, december). The effectiveness of problem based tearning: Results of a pilot Campbell collaboration systematic review. Paper presented at the amnual conference of the Society for Research into Higher Education (SRHE), Glasgow, UK.

Newman, M., McKendree, J., Robents, T., Rolfe, I., Sinucny, J., De Virgilio, G., Van den Bossche, P., \& Gijbels, D. , Engels, Ch. (2003, August). The effectiveness of problen based learning. Results of a pilot Campbell Collaboration systematic review. Paper presented at the 10th Biennial conference of the European Association for Research on Learning and Instruction (EARLI), Padova, ltally.

Newman, M. McKendree, J., Roberts, T., Smucny, J., Rolfe, I., De Virgilio, G., Gijbels, D., Van den Bossche, P., \& Engel, C. (2003. April). A systematic review of the effectiveness of PBL results of a pilot situdy. Paper presented at the annual conference of the American Educational Research Association. Chicago, USA.

Newman, M., McKendree, J., Roberts, T., Smucny, J., Rolfe, I., De Virgilio, G., Gijbels, D., Van den Bossche, P., \& Engel, C. (2003, Februari). Pilot of a systematic review protocol: pracrical

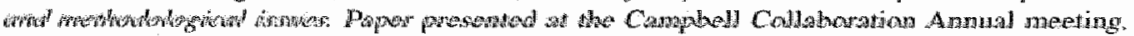
Stockholm, Sweden.

Van den Bossche, P., Gijbels, D., \& Dochy, F. (2000, June). Does problem-based learning edurate problem-solvers? A meta-andysis an the effects of problem-based Leaming. Paper presented at the $7^{\text {th }}$ international conference of Educational Innowation in Economics and Business (EDINEB), Newport Beach, CA, USA.

Vian den Bossche, P., Gijbels, D., Dochy, F., Segers, M. (2001, August). Effects of problens-based learning on students" leaning outcomes: A meka-amalysis. Paper presented at the 9th Biemial conference of the European Association for Research on Learning and Instruction (EARLI). Varibourg, Switserland.

Van den Bossche, P., Segers, M., Gijbels, D... Dochy, F. (2001). Effecten van een probleemgestuurd economisch curriculum [Effects of an economics problem-based curriculum]. Tijdschrift vor Hoger Onderwijs, $19(4), 242 \times 253$.

Van den Bossche, P.., Segers, M. Gijbels, D., \& Dochy, F. (2001., June). Effects of problem-based leaming in business education: A comparison between a pbl and a conventional approach. Papper presented at the 8th international conference of Educational Innovation in Economics. and Business (EDINEB), Nice, France.

Van den Bossche, P.. Segers, M., Gijbels, D., \& Dochy. F. (2004). Effects of problem-based learning in business education: A comparison between a PBL and a conventional educational approach. In R. Ottewill \& L. Borredon \& L. Falque \& B. Macfarlane \& A. Wall (Eds.), Edwcational inmoyation in economics and business VIIL: Pedagogy, technology and innovation (pp. 205228). Dordrecht: Kluwer Acadenic Publishers. 